Aus der Abteilung Kieferorthopädie

(Prof. Dr. med. dent. D. Kubein-Meesenburg)

im Zentrum Zahn-, Mund- und Kieferheilkunde

der Medizinischen Fakultät der Universität Göttingen

\title{
Kraft- und Drehmomentabgabe thermoplastisch geformter Schienen bei Frontzahnderotation vor und nach Alterungssimulation
}

\author{
Inaugural-Dissertation \\ zur Erlangung des Doktorgrades für Zahnheilkunde \\ der Medizinischen Fakultät \\ der Georg-August-Universität zu Göttingen \\ vorgelegt von \\ Benjamin Engelke \\ aus \\ Göttingen
}

Göttingen 2010 
Dekan:

I. Berichterstatter:

II. Berichterstatter/in:

III. Berichterstatter/in:

Tag der mündlichen Prüfung:

07.12 .2010 
Abkürzungsverzeichnis.............................................................................................................. 1

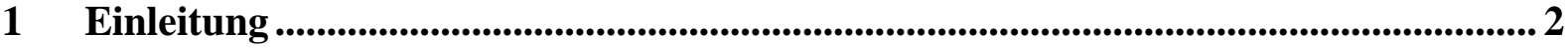

1.1 Historischer Überblick und aktuelle Erkenntnisse der orthodontischen

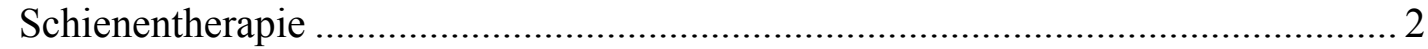

1.2 Biomechanische Grundlagen der Zahnbewegung .................................................... 4

1.3 Biologisch-mechanische Grundlagen der Zahnbewegung ...................................... 5

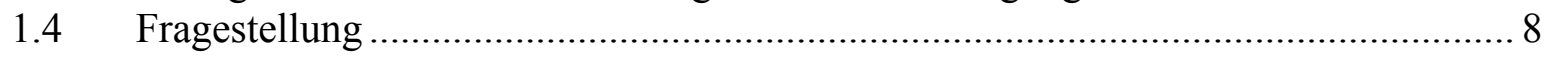

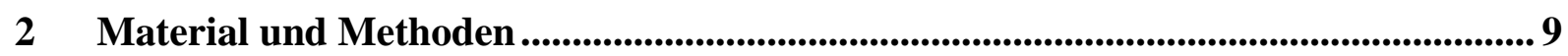

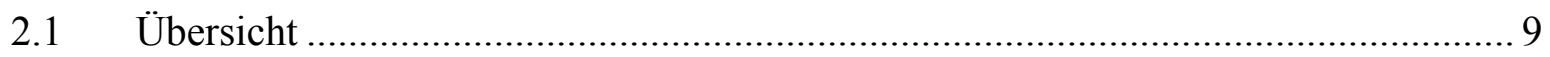

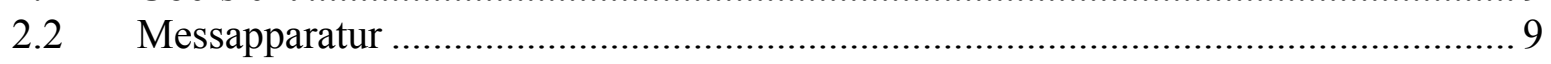

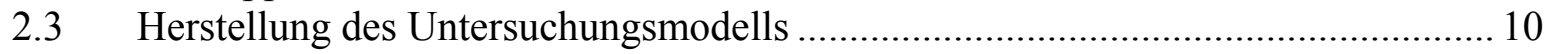

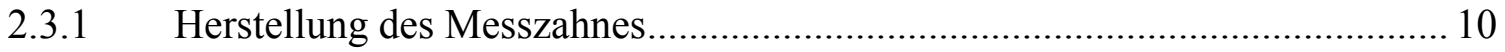

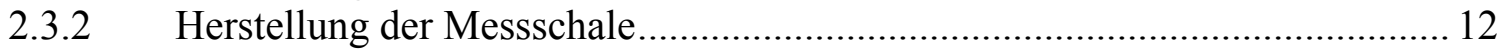

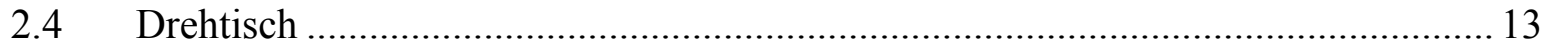

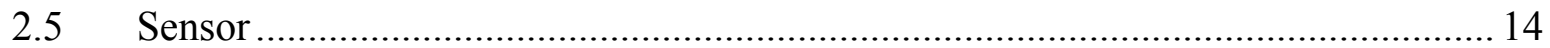

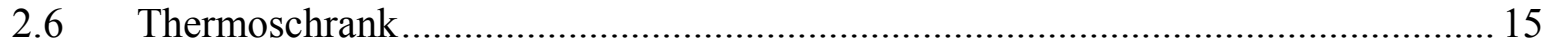

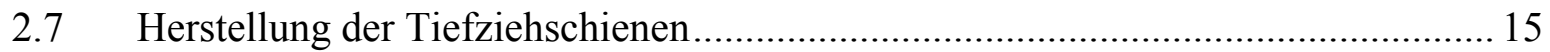

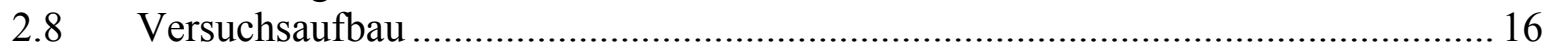

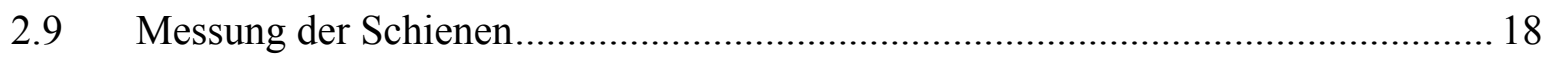

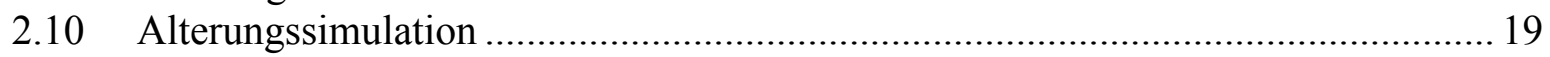

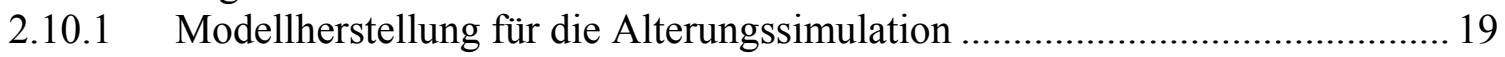

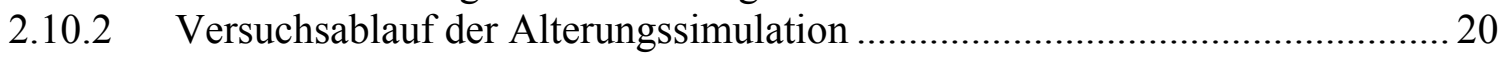

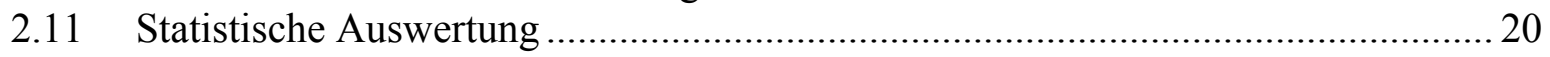

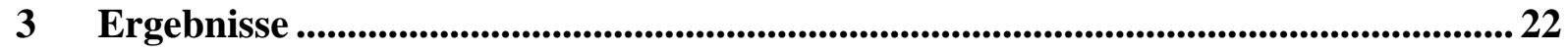

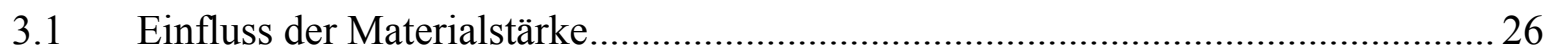

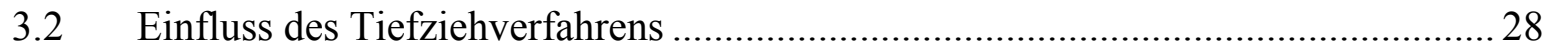

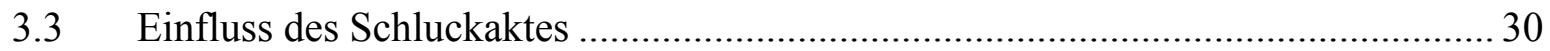

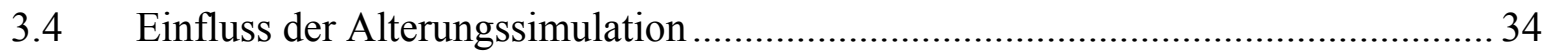

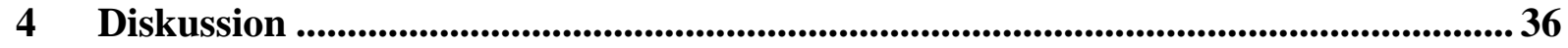

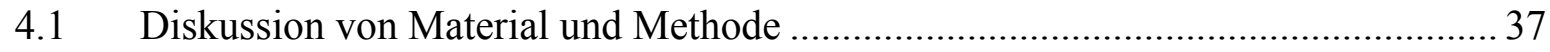

4.2 Drehmomente und intrusive Kräfte bei der Derotation eines zentralen

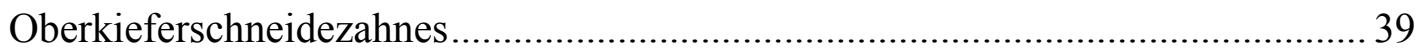

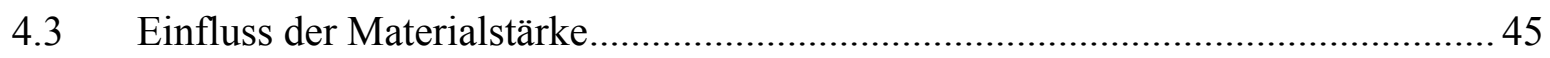

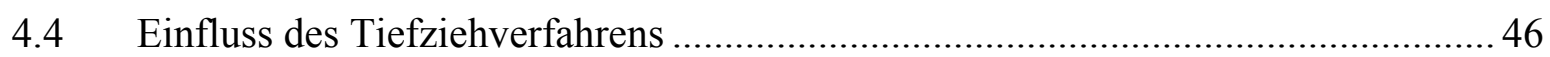

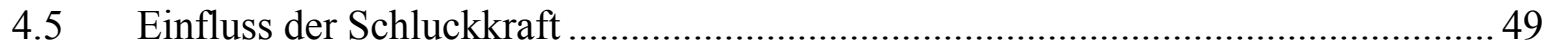

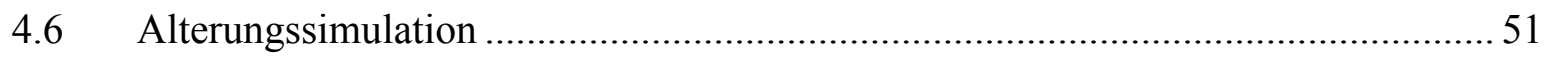

4.6.1 Wasserlagerung unter mechanischer Vorbelastung ................................... 52

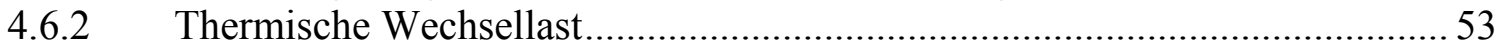

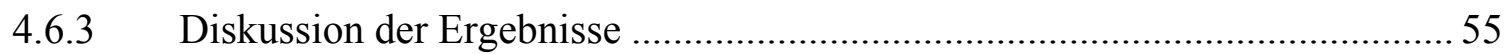

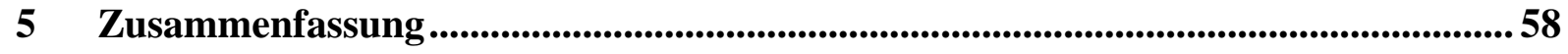

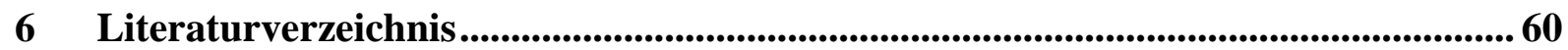




\section{Abkürzungsverzeichnis}

\begin{tabular}{|c|c|}
\hline Abb. & Abbildung \\
\hline Anova & Analysis of variance (Varianzanalyse) \\
\hline Bar & Gesetzliche Einheit für Druck \\
\hline bzw. & Beziehungsweise \\
\hline${ }^{\circ} \mathrm{C}$ & Grad Celsius \\
\hline ca. & Zirka \\
\hline CAD & Computer Aided Design (Computergestütztes Konstruieren) \\
\hline CAM & Computer Aided Manufacturing (Computerunterstütze Fertigung) \\
\hline DMS & Dehnmessstreifen \\
\hline ect. & et cetera \\
\hline $\mathrm{F}$ & Force (Symbol für die Kraft) \\
\hline $\mathrm{g} / \mathrm{cm}^{3}$ & Gramm pro Kubikzentimeter (Maßeinheit für die Dichte) \\
\hline $\mathrm{kg}$ & Kilogramm \\
\hline Min & Minute \\
\hline$\mu \mathrm{m}$ & Mikrometer \\
\hline $\mathrm{mm}$ & Millimeter \\
\hline $\mathrm{mm}^{2}$ & Quadratmillimeter \\
\hline $\mathrm{mm}^{3}$ & Kubikmillimeter \\
\hline $\mathrm{N}$ & Newton (Maßeinheit für die Kraft) \\
\hline $\mathrm{Nm}$ & Newtonmeter (Maßeinheit für das Drehmoment) \\
\hline $\mathrm{Nmm}$ & Newtonmillimeter (Maßeinheit für das Drehmoment) \\
\hline $\mathrm{N} / \mathrm{m}^{2}$ & Newton pro Quadratmeter (Maßeinheit für die Spannung) \\
\hline PDL & Parodontales Ligament \\
\hline PET & Polyethylenterephthalat \\
\hline $\mathrm{s}$ & Sekunde \\
\hline SD & Standardabweichung \\
\hline s.o. & siehe oben \\
\hline $\mathrm{T}$ & Torque (Symbol für das Drehmoment) \\
\hline Tab. & Tabelle \\
\hline Var. & Variabel \\
\hline vs. & versus \\
\hline $\mathrm{v} / \mathrm{v}$ & Volumenanteil \\
\hline z.B. & zum Beispiel \\
\hline
\end{tabular}




\section{$1 \quad$ Einleitung}

\subsection{Historischer Überblick und aktuelle Erkenntnisse der orthodontischen Schienentherapie}

Das Konzept von Zahnbewegungen mit Hilfe einer auf Setup-Modellen individuell gefertigten Serie elastischer Apparaturen wurde zuerst von Kesling im Jahre 1945 beschrieben.

Während Kesling anfänglich nur die Feineinstellung bzw. Retention der Zähne nach Bandentfernung durchführte, wurden mit der Entwicklung neuer Materialien (Hinz 1991, Warunek et al. 1989) die möglichen Zahnbewegungen immer umfangreicher. Andere Autoren wie Ponitz (1971), McNamara et al.(1985), Sheridan et al. (1993) Rinchuse \& Rinchuse (1997) stellten ähnliche auf Setup-Modellen basierende Ansätze vor, wobei vor allem der Herstellungsprozess und die Materialauswahl modifiziert wurden.

Das Prinzip der Zahnbewegung mittels thermoplastisch geformter Schienensysteme beruht auf dem am Patientenmodell neu erstellten und auf die Schiene übertragenen Setup. Nach Anfertigung eines Modells der Ist-Position des Patienten werden die zu bewegenden Zähne in Teilschritten in Richtung der Idealposition verstellt. Für jeden Teilschritt wird ein Modell erstellt, welches der Herstellung einer Schiene dient. Bei Applikation wirken die durch das abweichende Setup bedingten Rückstellkräfte des Aligners auf die zu therapierenden Zähne. Über eine aufeinander folgende Serie individuell hergestellter Schienen wird somit die kieferorthopädisch gewünschte Zahnstellung erzielt.

Der konventionelle Weg über die vom Zahntechniker erstellten Setupmodelle wird nach wie vor vom kommerziellen Clear Smile ${ }^{\circledR}$ System angewandt (Barbagallo 2008 a). Ein anderes Verfahren wurde von Raintree Essix (New Orleans, La) entwickelt (Sheridan et al. 1994), wobei zur Korrektur milder orthodontischer Diskrepanzen Fenster und Kompressionsnoppen in die Tiefziehschiene eingearbeitet werden.

Ein weiterer Ansatz findet sich in der Invisalign ${ }^{\circledR}$-Therapie wieder. Die Setup-Modelle zur Herstellung der Aligner werden hierbei berechen- und reproduzierbar durch ein CAD/CAMVerfahren hergestellt (Joffe 2003, Vlaskalic et al. 2001).

Die hauptsächlich aus Polyethylen oder Polypropylen bestehenden Schienen haben eine Dicke zwischen 0,7 mm und 1,016 mm (Boyd und Vlaskalic 2001, Faltin et al. 2003, Kwon et al. 2008, Sheridan et al. 2003). Für den Prozess des Thermoformings zur Schienenherstellung stehen zwei verschiedene Verfahren auf dem Markt zu Verfügung: Systeme mit Vakuum und solche mit Druckluft. Die in das Setup einprogrammierte Auslenkungsstrecke liegt zwischen 0,15 mm und $50 \mathrm{~mm}$ (Barbagallo et al. 2008 b, Boyd et al. 2000, Faltin et al. 2003, Joffe 
2003, Melkos 2005, Owen 2001, Vlaskalic et al. 2001). Als tägliche Tragedauer werden 22 Stunden vorgegeben. Nach jeweils 10 bis 14 Tagen wird ein neuer Aligner eingegliedert (Joffe 2003), was nach einer Studie von Bollen et al. (2003) einen besseren Behandlungserfolg gegenüber einem wöchentlichen Alignerwechsel erzielt.

Die Haupteinsatzgebiete von Tiefziehschienen erstrecken sich auf erwachsene oder jugendliche Patienten mit vollständig entwickelter zweiter Dentition bei moderaten Zahnfehlstellungen und Platzproblemen von 1-5 mm, Korrektur eines tiefen Bisses durch Intrusion der Front und leichter Zahnbogenexpansion durch Kippung (Chenin et al. 2003, Christensen 2002, Joffe 2003, Lagravère und Flores-Mir 2005).

Mit eingeschränkten Behandlungserfolgen ist bei stärkeren Zahnfehlstellungen, skelettalen anterior-posterioren Diskrepanzen größer als $2 \mathrm{~mm}$, zentrischen Relations- und Okklusionsdiskrepanzen, offenem Biss, Extrusion, Distalisierung von Molaren, Zähnen mit kurzen klinischen Kronen und stark rotierten Zähnen über $20^{\circ} \mathrm{zu}$ rechnen (Djeu et al. 2005, Joffe 2003, Vlaskalic und Boyd 2002). Die Probleme in Bezug auf die Derotation von Zähnen untermauert vor allem die Studie von Kravitz et al., in der bei Derotation von Eckzähnen mittels Invisalignschienen ohne zusätzliche Attachements lediglich in 30,8\% das angestrebte Ergebnis erzielt wurde. Auch durch interproximale Reduktion oder zusätzliche Attachements konnte kein signifikant besseres Ergebnis erzielt werden (Kravitz et al. 2008).

Die Vorteile der Schienentherapie gegenüber konventionellen orthodontischen Apparaturen sind neben der Ästhetik auch die einfache Handhabung, der Tragekomfort, keine Beeinträchtigung der Mundhygiene und die verkürzte Stuhlzeit (Joffe 2003, Vlaskalic et al. 2001). Demgegenüber stehen die oben bereits erwähnten Einschränkungen in der Behandlung und das Auftreten eines posterior offenen Bisses, posttherapeutisch unerwünschte Intrusionen, sowie die Abhängigkeit des Erfolges von der Patientencompliance (Brezniak 2008, Joffe 2003, Melkos 2005, Vlaskalic und Boyd 2002). Unerwünschte externe Wurzelresorptionen sind nach einer Studie von Barbagallo et al. (2008 a) in etwa vergleichbar mit dem Einsatz von leichten orthodontischen Kräften in der Multibandtherapie.

Trotz zahlreicher veröffentlichter Behandlungserfolge mit thermoplastischen Apparaturen (Bollen et al. 2003, Clements et al. 2003, Djeu et al. 2005, Wong 2002) wurden die komplexen Kraftübertragungsmechanismen bei der orthodontischen Schienentherapie bis dato nicht systematisch untersucht. Lediglich ein paar Studien $\mathrm{zu}$ dieser Thematik sind veröffentlicht (Rost et al. 1995, Warunek et al. 1989). 
Rost et al. untersuchten 1995 die entstehenden Kräfte bei der Schneidezahnprotrusion mittels Positioner. Die Ergebnisse suggerieren eine positive Interdependenz zwischen der gemessenen Kraft und der Auslenkungsstrecke bzw. dem Material.

Warunek et al. untersuchten 1989 die physikalischen und mechanischen Eigenschaften verschiedener Elastomere, die für die Herstellung kieferorthopädischer Positioner Verwendung finden. In ihrer Studie ermittelten sie unter anderem in vitro die bei labiopalatinaler Auslenkung eines Oberkieferschneidezahns entstehenden Kräfte. Die Auslenkungsstrecken lagen hierbei zwischen 0,5 $\mathrm{mm}$ und 2,5 $\mathrm{mm}$.

In einer kürzlich publizierten Studie wurden die durch eine Tiefziehschiene generierten orthodontischen Kräfte mittels druckempfindlicher Sensorfolien gemessen (Barbagallo et al. 2008 b). Die Ergebnisse suggerieren eine hohe Kraft auf die zu bewegenden Zähne in der Initialphase, gefolgt von einem schnellen Kräfteabfall während der Tragezeit.

Kwon et al. untersuchten die Eigenschaften der Kraftübertragung bei thermoplastischen orthodontischen Materialien. Neben der Kraftgröße befassten sie sich auch mit dem Verhalten des Schienenmaterials bei wiederholten Belastungen und künstlicher Alterung (Kwon et al. 2008). Sie kamen zu dem Schluss, dass die optimale Auslenkungsstrecke für Zahnbewegungen materialabhängig im Bereich von 0,2 bis $0,5 \mathrm{~mm}$ liegt. Thermocycling verringerte die Kraftgröße zwar, jedoch war dies im optimalen Auslenkungsbereich nicht statistisch signifikant. Wiederholte Belastungen führten jedoch $\mathrm{zu}$ einer signifikanten Abnahme der gemessenen Kräfte (Kwon et al. 2008).

Während Kwon et al. (2008) die Kraftübertragung der Aligner durch einen Dreipunktbiegeversuch untersuchten, ermittelten Barbagallo et al. $(2008$ b) die orthodontischen Kräfte in der Schienentherapie bei Kippbewegungen eines Oberkieferprämolaren.

\subsection{Biomechanische Grundlagen der Zahnbewegung}

Grundsätzlich können in der Kieferorthopädie drei Bewegungsarten voneinander unterschieden werden: 1. Translation, 2. reine Rotation oder 3. Kombination von Rotation und Translation (Smith und Burstone 1984). Translation bezeichnet eine körperliche Bewegung, bei der der Kraftangriff durch das Widerstandszentrum geführt und somit jeder beliebige Punkt des Zahnes um den gleichen Betrag in die gleiche Richtung bewegt wird.

Geht der Kraftangriff nicht durch das Widerstandszentrum des Zahnes, so führt dies zu einer Rotation. Das Potential der Rotation wird als Drehmoment, dem Vektorprodukt aus Kraftarm und Kraft, gemessen und in der SI-Einheit Nm angegeben. Somit hat sowohl die Änderung 
der Kraftgröße als auch die Änderung des Abstandes zum Widerstandszentrum einen Einfluss auf den Betrag des daraus resultierenden Drehmomentes.

Wirkt nun eine Einzelkraft auf den Zahn, welche nicht durch das Widerstandszentrum geht, so resultiert daraus eine Kombination aus Translation und Rotation, wobei sich die translative Komponente so verhält, als ob der Kraftangriff durch das Widerstandszentrum gehen würde. Eine Einzelkraft kann somit keine reine Rotation erzeugen. Hierfür bedarf es immer eines Kräftepaares bestehend aus zwei Kräften gleicher Größe mit parallelem, jedoch gegenläufigem Kraftangriff.

Betrachten wir nun diesen Aspekt vereinfacht anhand der Rotation des Oberkieferschneidezahnes durch eine Tiefziehschiene. Zunächst wird am Setupmodell eine Rotation des Zahnes in entsprechender Richtung vorgenommen. Diese Information wird durch den Tiefziehvorgang auf die Schiene übertragen. Bei Insertion des Aligners wirkt nun ein Kräftepaar auf den zu rotierenden Zahn. Die Schiene übt an der mesialen Schneidekante eine Kraft Richtung vestibulär und an der Distalen eine Kraft Richtung palatinal aus. In Abbildung 1 ist ein beispielhaft wirkendes Kräftepaar von $1 \mathrm{~N}$ dargestellt. Die Kräfte sind gleichgroß und verlaufen parallel zueinander, zeigen jedoch einen gegenläufigen Kraftangriff. Diese adversativen translationalen Kräfte löschen sich gegenseitig aus. Das Drehmoment jeder Einzelkraft beträgt $1 \mathrm{~N}$ multipliziert mit dem Abstand zum Widerstandszentrum, welches in diesem Fall 3,9 mm beträgt. Beide Kräfte wirken im Uhrzeigersinn und haben ein Drehmoment von je 3,9 Nmm. Somit ergibt sich ein daraus resultierendes rotatives Moment von 7,8 Nmm, was theoretisch zu einer reinen Rotation des Messzahnes führen würde.

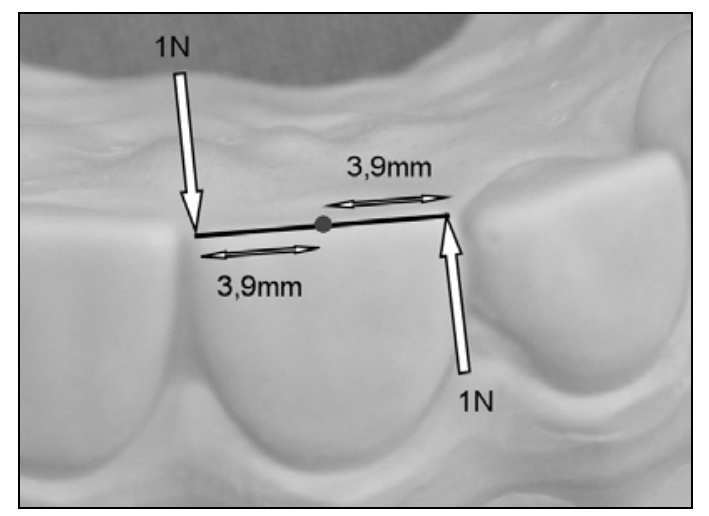

Abbildung 1 Zwei gleichgroße, parallele und gegenläufige Kräfte bilden ein Kräftepaar

\subsection{Biologisch-mechanische Grundlagen der Zahnbewegung}

Andersen et al. konnten 1991 mit Hilfe der Finite-Element-Methode nachweisen, dass die Kraftverteilung im Desmodont mit den kieferorthopädisch wirkenden Kräften korreliert. 
Diese biophysikalischen Veränderungen im Zahnhalteapparat leiten durch Transduktion, d.h. über die Umwandlung von mechanischer Energie in biologische Signale, die zellulären Reaktionen und damit die morphologischen Umbauprozesse des Zahnhalteapparats ein (Roberts et al. 1981).

Die kraftinduzierte Deformation des parodontalen Ligaments modifiziert dessen Vaskularität und Durchblutung, was eine lokale Synthese und Freisetzung diverser Schlüsselmolekühle wie Neurotransmitter, Zytokine, Wachstumsfaktoren, Kolonie-stimulierende Faktoren und Arachidonsäuremetaboliten bewirkt. Diese Molekühle können viele zelluläre Antworten verschiedener Zelltypen evozieren welche ein günstiges Mikromilieu für die Resorption oder Ablagerung von Gewebe schaffen (Krishnan und Davidovitch 2006).

Von Böhl und Kuijpers-Jagtman (2009) beschreiben in ihrem Review-Artikel die hauptsächlich auf histologischen Studien basierende Druck- und Zugzonentheorie, welche trotz neuerer Erkenntnisse immer noch $\mathrm{zu}$ deskriptiven Zwecken Anwendung findet. Demnach kommt es, induziert durch die orthodontische Kraft, zur Umwandlung von Progenitorzellen des PDL in kompressionsassoziierte Osteoklasten und zugassoziierte Osteoblasten, welche Knochenabbau bzw. Knochenanbau evozieren (Masella und Meister 2006).

Wird jedoch bei einer orthodontischen Zahnbewegung auf der Druckseite die Blutzirkulation im komprimierten parodontalen Ligament gestört, kann dies zu einem Zelltod (Hyalinisation) in diesem Bereich führen. Die Resorption des hyalinisierten Gewebes durch Makrophagen, sowie unterminierende Knochenresorptionen des angrenzenden Gewebes durch Osteoklasten sind die Folge (von Böhl und Kuijpers-Jagtman 2009).

Bleibt die Durchblutungsstörung länger als zwei Stunden bestehen, kommt es zu einer irreversiblen Schädigung und Nekrose des Gewebes im Versorgungsgebiet der betroffenen Gefäße. Die dadurch gesteigerte Aktivität der Osteoklasten führt zu tiefen Resorptionen, die sich bis ins Dentin erstrecken können (Murell et al. 1996). Auch Studien von Brudvik und Rygh bestätigen, dass die apikale Wurzelresorption Teil des Eliminationsprozesses der hyalinisierten Bereiche ist (Brudvik und Rygh 1993, 1994 a, 1994 b 1994 c, 1995 a, 1995 b). Vor allem bei der Kombination aus kontinuierlicher Krafteinwirkung und hoher Kraftgröße kommt es vermehrt zu externen Wurzelresorptionen (Weiland 2003). Dabei sind Extrusion, Intrusion, Zahnbewegungen über intermaxilläre Gummizüge, Jigglingbelastung von Zähnen und eine lange Behandlungsdauer weitere negative Einflussfaktoren (Baumrind et al. 1996, Göz und Rakosi 1989, Harry und Sims 1982, Mirabella und Artun 1995, Proffit und Fields 1999). 
Es wird daher nach wie vor empfohlen, die Zähne nicht mit zu hohen Kraftgrößen zu überlasten, da diese zu größeren hyalinisierten Arealen im parodontalen Ligament führen, was eine stärkere apikale Wurzelresorption zur Folge haben könnte (Brudvik und Rygh 1993, 1994b).

In der Literatur lassen sich verschiedene Meinungen über die Kraftgröße finden, welche in einer optimalen biologischen Gewebereaktion für die orthodontische Zahnbewegung mündet. Es wird angenommen, dass ein optimales Kräftesystem wichtig für eine adäquate biologische Antwort im parodontalen Ligament sei (Burstone 1989). Hierbei sollte dem Maximum der Zahnbewegung eine minimal irreversible Schädigung der Wurzel, des parodontalen Ligaments und des alveolaren Knochens gegenüberstehen.

Das derzeitige Konzept für die optimale Kraft basiert auf der Hypothese, dass eine Kraft bestimmter Größe und zeitlicher Charakteristiken wie kontinuierlich oder intermittierend, konstant oder abnehmend ect. geeignet ist, eine maximale Zahnbewegung ohne Gewebeschädigung und mit maximalem Patientenkomfort zu erzielen. Diese optimale Kraft könnte sich bei verschiedenen Zähnen und Individuen unterscheiden (Proffit 1999).

Ren et al. kamen in ihrem 2003 veröffentlichten Review-Artikel über die optimale Kraft in der orthodontischen Zahnbewegung zu dem Schluss, dass kein evidenz-basiertes Kraftlevel für eine optimale Effizienz in der kieferorthopädischen Zahnbewegung empfohlen werden kann. Die generell bestehende Annahme, dass eine geringe Kraft effizienter und „biologischer“, und deshalb auch weniger schmerzhaft sei, klingt laut Ren et al. zwar attraktiv, jedoch ist der Terminus der geringen Kraft frei und willkürlich gewählt. Es existieren weder universeller Konsensus noch einwandfreie wissenschaftliche Aussagen hinsichtlich der Kraftgröße (Ren et al. 2003). Des Weiteren ist das Konzept der geringen Kraft anwendungsabhängig. Eine Kraft, die bei einer bestimmten Applikation als zu hoch erachtet wird, könnte bei einer anderen ideal sein (Proffit 1999).

So findet man in der Literatur lediglich Empfehlungen bezüglich der anzuwendenden Kräfte und Drehmomente. Proffit gibt als idealen Kraftbereich für Kippung 0,35-0,6 N, für Intrusion 0,1-0,2 $\mathrm{N}$ und bei körperlicher Bewegung 0,7-1,2 $\mathrm{N}$ an. Bei der Rotation wird anstelle eines Drehmomentes auch eine Kraft von 0,35-0,6 N angegeben. Diese wird dadurch begründet, dass nicht alle Wurzelbereiche bei der Rotation gleich belastet werden, dadurch ähnlich wie bei der Kippung Spitzenbelastungen im parodontalen Ligament entstehen und deswegen auch gleiche Kraftbereiche anzustreben sind (Proffit 1999). 


\section{$1.4 \quad$ Fragestellung}

Zusammenfassend kann festgestellt werden, dass zwar zahlreiche Veröffentlichungen in der Literatur $\mathrm{zu}$ finden sind, diese jedoch vornehmlich anhand von Patientenfällen die Einsatzmöglichkeit und Effizienz einer orthodontischen Schienenbehandlung untersuchen. Von diversen Autoren wird daher die Forderung laut, mehr klinische und werkstoffkundlichphysikalische Studien zu diesem Thema zu veröffentlichen, da viele Fragen bis dato noch ungeklärt sind (Brezniak 2008, Kwon et al. 2008, Lagravère und Flores-Mir 2005, Turpin 2005).

Ziel der vorliegenden Studie war es, das Ausmaß der rotativen Drehmomente bei der Schienentherapie in Abhängigkeit von der Bewegungsstrecke zu erfassen. Die Messung wurde dazu exemplarisch an einem mittleren Oberkieferfrontzahn durchgeführt, da dieser aus ästhetischen Gründen ein häufig zu bewegender Zahn ist (Meier et al. 2003). Außerdem ist von Interesse, ob bei Rotationsbewegungen intrusive Kräfte gemessen werden können, welche den therapeutisch unerwünschten Nebeneffekt der Intrusion bei einer Schienentherapie erklären könnten. Durch die Verwendung verschiedener Folienmaterialien und Tiefziehgeräte konnten des Weiteren die Einflüsse der Materialstärke sowie des Tiefziehverfahrens auf die generierten Kräfte und Drehmomente ermittelt werden. Auch wurde der Fragestellung nachgegangen, inwieweit der Schluckakt bzw. eine künstliche Alterung zu einer Modulation der orthodontischen Kräfte und Drehmomente führen. 


\section{Material und Methoden}

\section{1 Übersicht}

Um die Fragestellungen beantworten zu können, wurde eine in-vitro-Konstellation zur dreidimensionalen Erfassung von Kräften und Drehmomenten in der Schienentherapie entwickelt. Bei dieser modularen Messapparatur konnte der Zahn 11 eines Oberkieferzahnbogenmodells um eine Achse durch das Zentrum der Inzisalkante und die horizontale Wurzelmitte rotiert und die dabei initial wirkenden Kräfte und Drehmomente nach Eingliederung verschiedener Tiefziehschienen in vitro gemessen werden. Der Einfluss des Schluckaktes auf die generierten Kräfte und Drehmomente wurde durch erneute Messung aller Schienen unter Belastung mit einem definierten Gewicht ermittelt. Nach Abschluss dieser Versuchsreihen erfolgte eine künstliche Alterung der Aligner mit erneuter Messung der Kräfte und Drehmomente. Abbildung 2 gibt eine grobe Übersicht des Versuchsablaufes wieder. Darauf folgend werden Herstellung der Messapparatur sowie Durchführung der Versuchsreihen detailliert beschrieben.

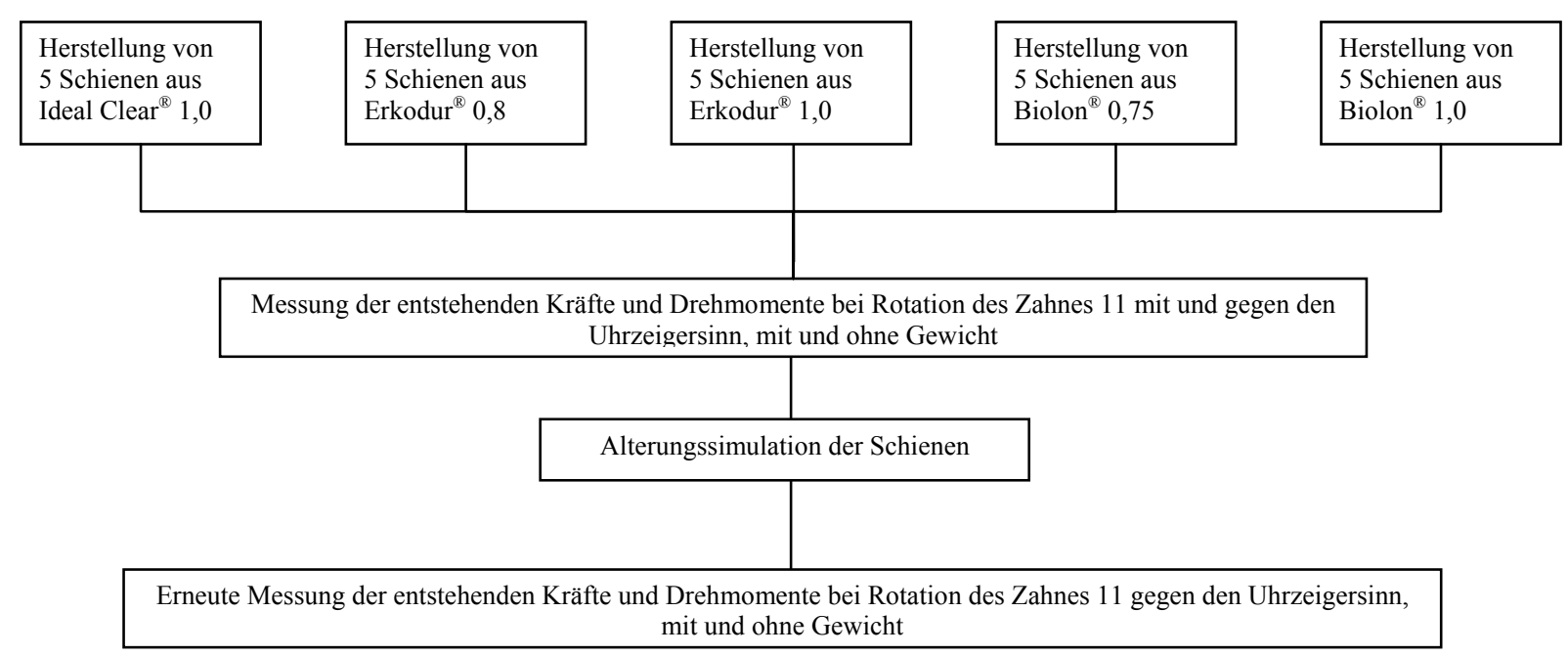

Abbildung 2 Schematische Darstellung des Versuchsablaufes

\subsection{Messapparatur}

Bei dem für die Studie entwickelten Messapparat handelt es sich um eine modulare Messapparatur. Sie besteht aus einem Metallrahmen aus Hartaluminium, welcher über vier Rundstäbe mit einer Bodenplatte verbunden ist. Der Metallrahmen dient der reversiblen Aufnahme einer Kunststoffschale, in welcher sich das zu untersuchende Modell befindet. Bei dem Untersuchungsmodell handelt es sich um einen idealisierten Oberkieferzahnkranz eines männlichen 15 bis 20 jährigen (Frasaco GmbH, Tettnang, Deutschland). Die Kunststoffschale kann durch eine Klemmschraube an exakt gleicher Position starr arretiert werden. 
Um verschiedene Zahnbewegungen simulieren zu können, kann auf der Bodenplatte des Metallrahmens durch Verzapfung und Verschraubung ein Grundgestell mit dem für die jeweilige Zahnbewegung verwendeten manuellen Positionierungstisch befestigt werden. In der vorliegenden Arbeit wurde der Drehtisch DT 130 (OWIS GmbH, Staufen, Germany) verwendet. Dieser wiederum kann mit dem für die Messung verwendeten Sensor (Nano 17 Sensor, ATI Industrial Automation, Apex, USA) verbunden werden. Eine auf der Oberseite des Nano 17 angebrachte Klemmvorrichtung dient der Aufnahme des Messzahnes. In Abbildung 3 ist die zuvor beschriebene modulare, reversibel zusammensetzbare Messapparatur schematisch dargestellt. Zur besseren Ansicht wurden die vorderen Hälften des Metallrahmens und der Kunststoffschale wegretuschiert. In der Klemmvorrichtung des Sensors befindet sich hier ein Metallstift ohne Messzahn.

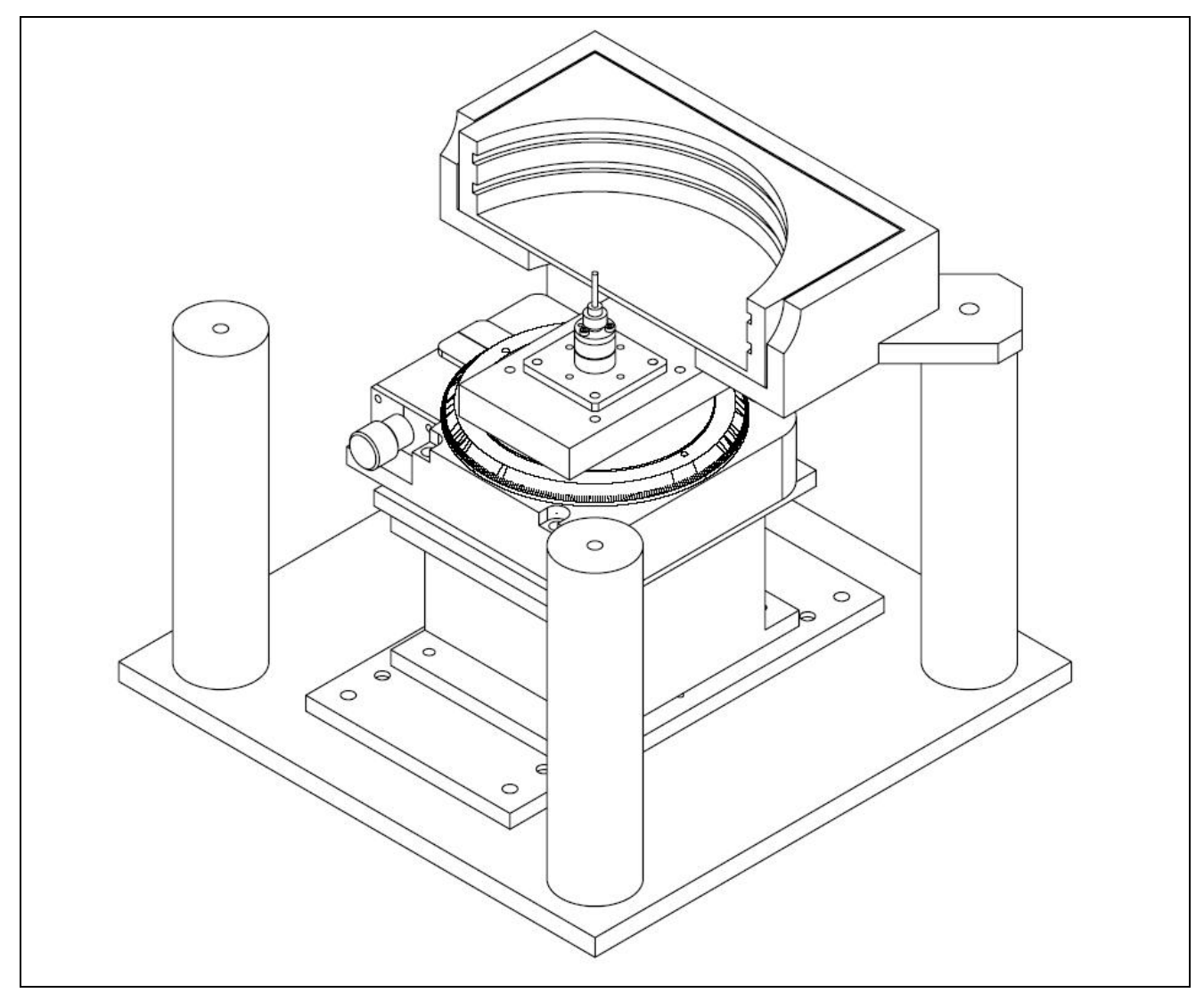

Abbildung 3 Schematische Darstellung der modularen Messapparatur

\subsection{Herstellung des Untersuchungsmodells}

\subsubsection{Herstellung des Messzahnes}

Vor Entfernung des Messzahnes wurde $\mathrm{zu}$ dessen eindeutigen Repositionierung ein Repositionierungsschlüssel aus Dentalgips der Klasse IV (GC Fujirock ${ }^{\circledR}$ EP, GC Deutschland 
GmbH, München, Deutschland) an dem verwendeten Zahnbogenmodell hergestellt. Anschließend wurde der Zahn 11 aus der Modellbasis entnommen und dieser Bereich des Sockels herausgefräst, um eine absolute Bewegungsfreiheit des Zahnes während des Versuchsablaufes zu gewährleisten.

Um eine Verbindung des Messzahnes mit dem Sensor $\mathrm{zu}$ ermöglichen, wurde der Wurzelanteil des Kunststoffzahnes durch einen Metallstift ersetzt. Dabei erfolgte zunächst die Kürzung der Wurzel des Frasacozahnes bis auf $1 \mathrm{~mm}$ unterhalb der vestibulären Schmelzzementgrenze. Nachfolgend wurden sowohl Inzisalkante als auch gekürzte Wurzel optisch vermessen (Peak $^{\text {TM }}$ Zoomlupe 816, YAM POK (H.K.) Technology Limited, Hongkong, China) und die Mittelpunkte mit einem feinen Diamantbohrer (Diamant H 001 005, Dr. Hopf GmbH, Langenhagen, Deutschland) zur späteren Zentrierung angekörnt. Darauf erfolgte die Justierung des Zahnes in dem eigens dafür hergestellten Zentrierungsapparat. Dieser besteht aus zwei Halbschalen, welche miteinander verschraubt eine zylindrische Hohlform ergeben. An der einen Hälfte der Form sind sowohl an der Oberals auch an der Unterseite verstellbare Zentrierungsspitzen angebracht, über welche der Zahn im Zentrum der Hohlform positioniert werden kann. Die Zentrierungsspitzen wurden dabei soweit vorgeschraubt, bis diese die angekörnten Markierungen des Messzahnes erreichten um so den Zahn in seiner Rotationsachse reproduzierbar zu fixieren (Abb. 4).

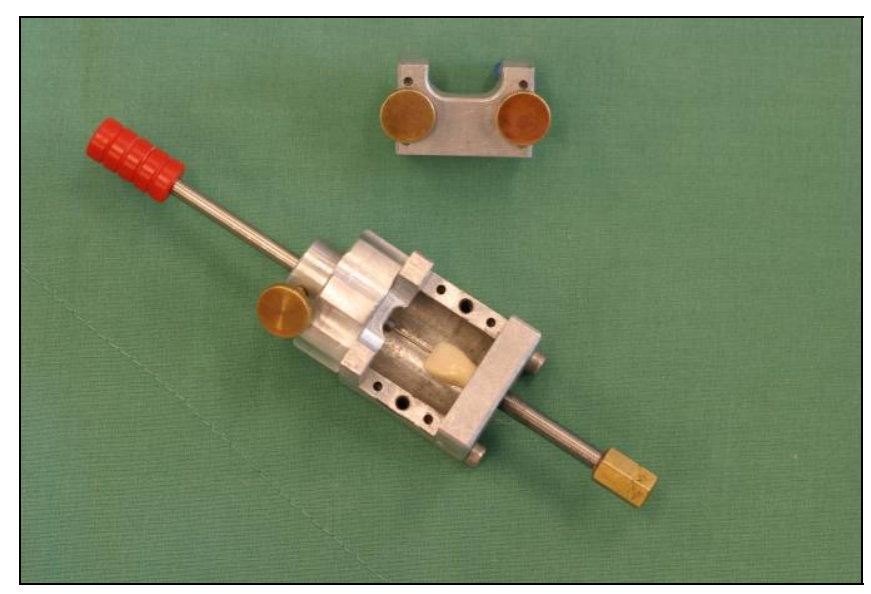

Abbildung 4 Zentrierungsapparatur mit eingespanntem Messzahn

Anschließend wurden die zwei Halbschalen miteinander verschraubt und der sich in der entstandenen Hohlform befindliche Zahn mit Gips (GC Fujirock ${ }^{\circledR}$ EP, GC Deutschland GmbH, München, Deutschland) eingegossen. Nach Aushärtung des Gipses wurde die Verschraubung der Hohlform gelöst und die Gipsform entnommen. Dieser Gipszylinder wurde nun achsenzentriert durch ein Dreibackenfutter in eine Präzisionsdrehbank (Condor, 
Weiler Werkzeugmaschinen, Emskirchen, Deutschland) eingeschraubt und eine Normbohrung mit einem HSS-Spiralbohrer (Ø 2,5 mm) an der Unterseite des Zahnes angelegt (Abb. 5).

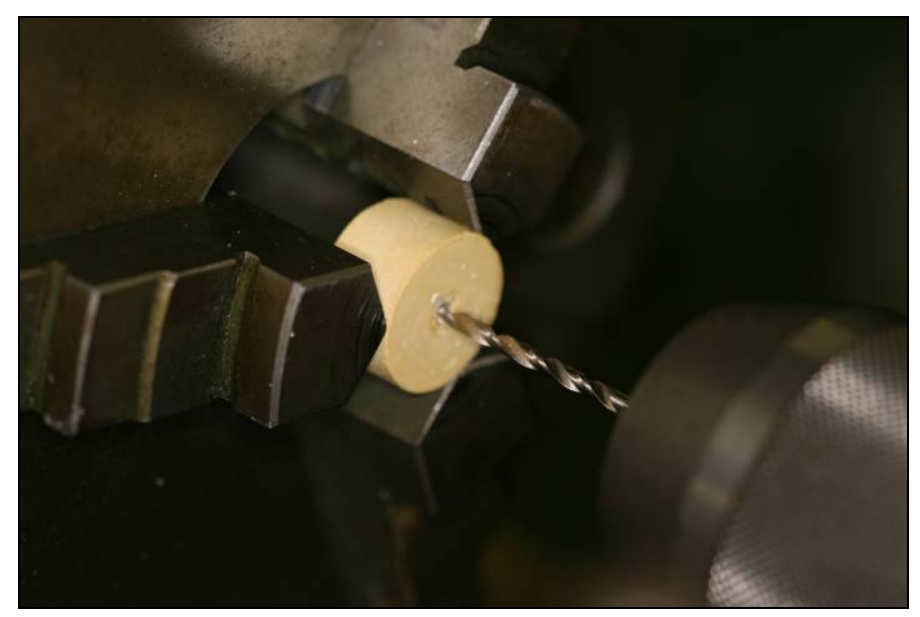

Abbildung 5 Anlegen der Normbohrung an der Unterseite des im Gips fixierten Messzahnes

In diese Normbohrung wurde der Schaft des verwendeten Spiralbohrers verdrehsicher mit einem Spezialkunststoff (Weitur ${ }^{\circledR}$ Press, Johannes Weithas Dental-Kunststoffe, Lütjenburg, Deutschland) einpolymerisiert. Zum Überlastschutz des Sensors wurde der Schaft des Bohrers anschließend soweit gekürzt, dass der mit ihm verbundene Zahn die Klemmvorrichtung des Sensors nicht berührt und ein möglichst kurzer Hebelarm in Bezug auf die Sensoroberfläche entstand. Der Abstand zwischen Sensor und Zahn betrug somit lediglich $1 \mathrm{~mm}$. Die Gesamtlänge von Zahn und Metallstift betrug 24,4 mm.

\subsubsection{Herstellung der Messschale}

Zunächst wurde ein Loch in den Boden der Kunststoffschale gefräst, um eine Verbindung des Sensors mit dem Modell zu ermöglichen. Nach Positionierung und Arretierung der so vorbereiteten Schale in der Haltevorrichtung der Messapparatur erfolgte die Fixierung des Messzahnes 11 über den anfangs hergestellten Gipsschlüssel und Hartklebewachs (Deiberit 502, Siladent Dr. Böhme \& Schöps GmbH, Goslar, Deutschland) in seiner Ausgangsposition am Zahnkranzmodell. Das Modell mit dem fixierten Zahn wurde nun innerhalb der Schale ausgerichtet (Abb. 9). Während der Ausrichtung in der Schale war die Einheit aus Modell und Zahn mit Hilfe des in der Längsachse des Messzahnes fixierten Stahlstiftes über die Klemmvorrichtung mit dem Nano 17 FT Sensor zunächst locker verbunden und konnte so um die Längsachse des Stahlstiftes rotiert werden. 


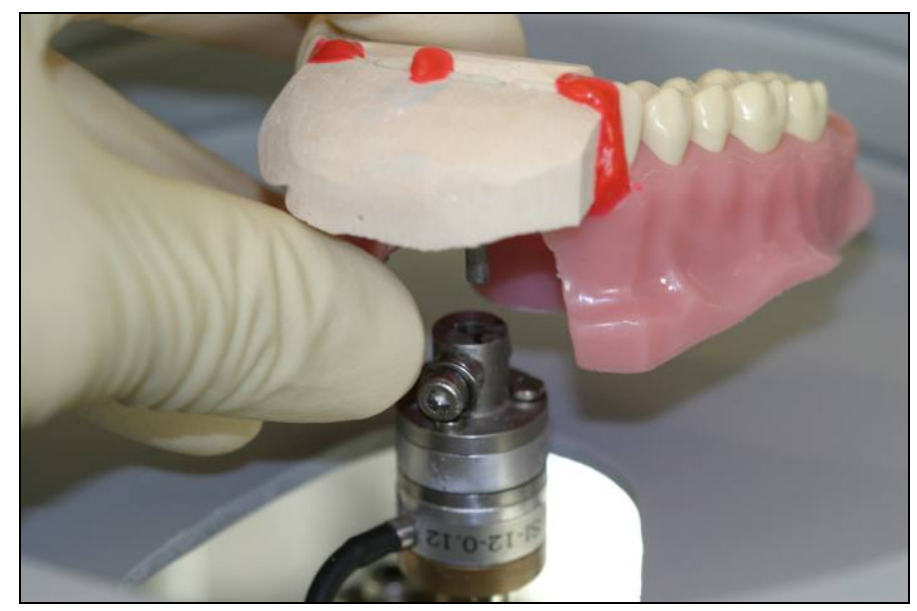

Abbildung 6 Der Stahlstift des fixierten Messzahnes wird in die Klemmvorrichtung eingeführt

Die Ausrichtung des Modells erfolgte so, dass die Inzisalkante des Messzahnes parallel zur Rückfläche der Kunststoffschale lag. In dieser Position wurde die Klemmvorrichtung geschlossen und somit die Einheit aus Modell und Zahn mit dem Sensor starr verbunden. Anschließend erfolgte das Eingipsen des Modells mit Superhartgips (GC Fujirock ${ }^{\circledR}$ EP, GC Deutschland GmbH, München, Deutschland) in der jetzt festgelegten Position innerhalb der Kunststoffschale. In Abbildung 10 ist das auf der Schale fixierte Modell mit dem Messzahn und den Repositionierungsschlüsseln abgebildet.

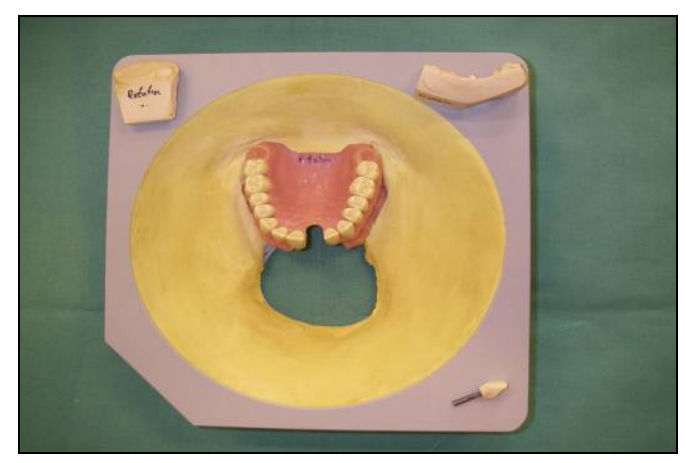

Abbildung 7 Messteller mit Messzahn und Repositionierungsschlüssel

\subsection{Drehtisch}

Für die Messung der vorliegenden Studie wurde der Drehtisch DT 130 (OWIS GmbH, Staufen, Deutschland) verwendet. Er besitzt einen vorgespannten Schneckenantrieb mit einer Übersetzung von 180:1 und einer Einstellempfindlichkeit von $<30$ Bogensekunden bei einem Verstellbereich von $360^{\circ}$. 
Auf dem Drehteller wurde eine Metallplatte befestigt, welche eine Verschraubung und Verzapfung des DT 130 mit dem Nano 17 Sensor (ATI Industrial Automation, Apex, USA) ermöglicht.

\subsection{Sensor}

Das Kernstück der Messeinheit ist der Nano 17 Sensor (ATI Industrial Automation, Apex, USA). Der Kraft- und Moment-Sensor ist in der Lage, Kräfte und Drehmomente zu erfassen und diese getrennt für alle Ebenen des Raumes aufzuschlüsseln (Abb. 8).

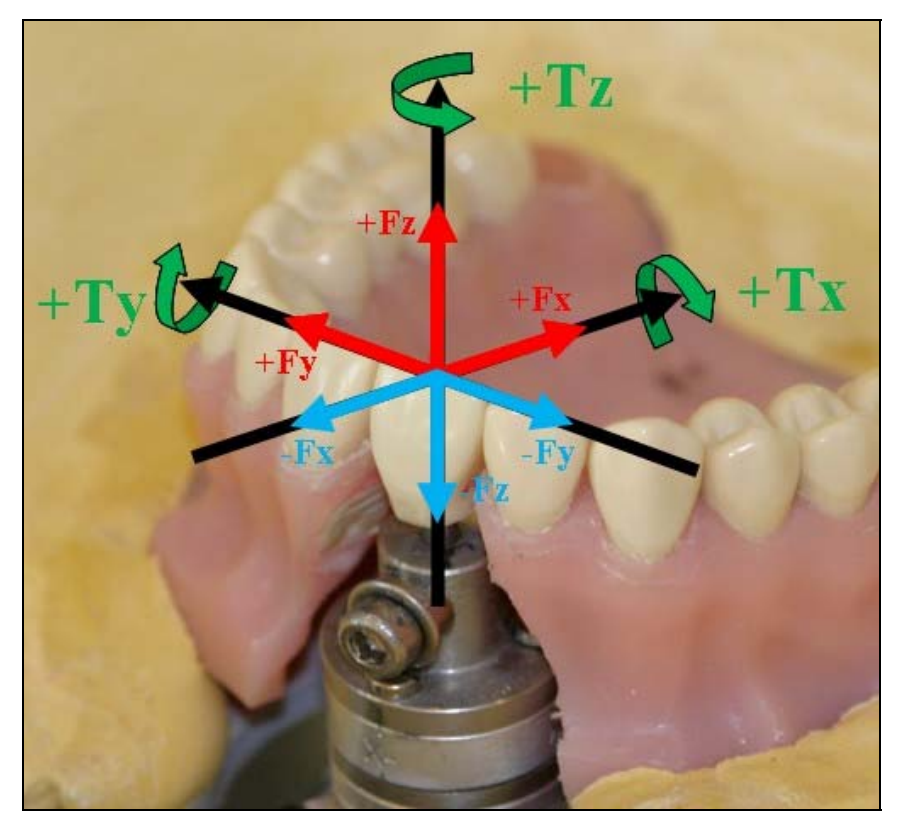

Abbildung 8 Koordinatensystem für die gemessenen Kräfte und Drehmomente. Die negativen Drehmomente laufen gegenläufig zu den eingezeichneten positiven Drehmomenten (grüne Pfeile).

Das Wirkungsprinzip ist ein monolithischer Messkörper mit 3 Messsträngen im Winkel von $120^{\circ}$. Jeder Strang ist mit 2 Halbleiter-Dehnungsmessbrücken bestückt, welche die Verformung im Mikrometerbereich erfassen. Bei dem vom Sensor ausgegebenen analogen Messwert handelt es sich um verstärkte Spannungen der Dehnmessstreifen (DMS) und nicht um Kräfte und Momente. Der Signalverstärker und ein Multiplexer für die Signalübertragung zur Auswerteeinheit befinden sich in einer separaten Verstärkerbox, die zwischen Sensor und Verbindungskabel eingebaut ist. In der Auswerteeinheit werden die DMS-Signale über die Kalibrationsmatrix (ATI DAQ F/T Demo Software, Version 1.2.4) in die drei Kraftkomponenten Fx, Fy und Fz und die drei Momentkomponenten Tx, Ty und Tz umgerechnet. Der Sensor verfügt über eine Hardware-Temperaturkompensation und ist für eine Umgebungstemperatur von 0 bis $43^{\circ} \mathrm{C}$ geeignet. Er zeigt laut Herstellerangaben eine 
Messgenauigkeit unter 1\% vom Messbereichsendwert bei einer Umgebungstemperatur von $22^{\circ} \mathrm{C}$. Der optimale Messbereich in der gewählten Kalibration des Herstellers „SI-12-0.12“ liegt bei $\pm 12 \mathrm{~N}$ für $\mathrm{Fx}$ und Fy, $\pm 17 \mathrm{~N}$ für $\mathrm{Fz}$ und $\pm 120 \mathrm{Nmm}$ für Tx, Ty and Tz. Die Auflösung beträgt hierbei $\pm 1 / 1280 \mathrm{~N}$ für Fx, Fy and Fz und $\pm 1 / 256 \mathrm{Nmm}$ für Tx, Ty und Tz. Der Sensor ist auf seiner Unterseite durch Verschraubung und Verbolzung reversibel mit einer Haltevorrichtung verbunden, welche ihrerseits mit dem jeweiligen Positionierungstisch verbunden werden konnte. Auf der Oberseite des Sensors ist die Klemmvorrichtung zur Aufnahme des Messzahnes angebracht.

\subsection{Thermoschrank}

Die Messung der Kräfte und Drehmomente erfolgte in einem der Mundtemperatur (ca. $37^{\circ} \mathrm{C}$ ) entsprechend temperierten Raum. Hierfür wurde der Temperaturschrank Typ HTD 50 (Flohr Instruments, Utrecht, Holland) verwendet. Der Thermoschrank ist für einen Temperaturbereich bis $+45^{\circ} \mathrm{C}$ geeignet und verfügt zusätzlich über die Möglichkeit der Luftfeuchtigkeitsanpassung bis maximal 96\% relative Luftfeuchte. Im Boden des Temperaturschrankes befindet sich eine Öffnung, an welche die modulare Messapparatur über einen Hubtisch herangefahren werden kann.

\subsection{Herstellung der Tiefziehschienen}

Um gleiche Ausgangsbedingungen für die Herstellung der $\mathrm{zu}$ messenden Schienen zu schaffen, wurde zunächst ein Modell erstellt, welches als Kopiervorlage für alle weiteren Modelle zur Herstellung aller thermoplastisch geformten Schienen diente und der Stellung des Zahnes in Nullposition (ohne Rotation) entspracht. Zur Herstellung dieses Uhrmodells erfolgte zunächst der Aufbau der modularen Messapparatur und die Positionierung und Arretierung des Messzahnes. Anschließend wurde ein Alginatabdruck (Tetrachrom, Kaniedenta, Herford, Deutschland) des Rotationsmodells mit einem Rim-Lock-Löffel genommen. Um unter sich gehende Bereiche bei der Abformung zu vermeiden und eine fortlaufende Referenzlinie bei der Schienenherstellung zu erhalten, wurde der Gingivaverlauf im Bereich des Messzahnes mit Modellierwachs rekonstruiert.

Der entstandene Abdruck des Frasacomodells wurde anschließend mit einem Dentalgips der Klasse IV (GC Fujirock ${ }^{\circledR}$ EP, GC Deutschland GmbH, München, Deutschland) nach Herstellerangaben ausgegossen, auf eine Höhe von $2 \mathrm{~cm}$ parallel zur Okklusionsebene getrimmt (Sheridan 2003) und zirkulär zu einem Zahnkranz ohne unter sich gehende Stellen beschliffen. 
Von dem fertig gestellten Urmodell wurde mit Adisil ${ }^{\circledR}$ blau 9:1 (Siladent Dr. Böhme \& Schöps GmbH, Goslar, Deutschland) eine Dublierform gemäß den Herstellerangaben erstellt. Diese wurde $25 \mathrm{mal}$ mit Dentalgips der Klasse IV (GC Fujirock ${ }^{\circledR}$ EP, GC Deutschland GmbH, München, Deutschland) ausgegossen, wobei zur besseren Benetzbarkeit der Dublierform Waxit $^{\circledR}$ (DeguDent GmbH, Hanau-Wolfgang, Deutschland) zur Anwendung kam. Nach Aushärtung der Modelle wurden lediglich mit einem Trimmer leichte Unebenheiten plan getrimmt, ohne die durch die Dublierform vorgegebene Höhe von $2 \mathrm{~cm}$ zu verändern.

Die über die Dublierform entstandenen Modelle wurden für die Herstellung der Schienen verwendet. Als Schienenmaterial wurden Ideal Clear ${ }^{\circledR}$ der Stärke 1,0 mm (Dentsply GAC, Gräfelfing, Deutschland), Erkodur ${ }^{\circledR}$ in den Stärken 0,8 mm und 1,0 mm (Erkodent ${ }^{\circledR}$ Erich Kopp GmbH, Pfalzgreifenweiler, Deutschland) sowie Biolon ${ }^{\circledR}$ 0,75 mm und 1,0 mm (Dreve Dentamid GmbH, Unna, Deutschland) verwendet. Die Schienen bestehen hauptsächlich aus modifiziertem Polyethylenterephthalat (PET). Bei PET handelt es sich um einen durch Polykondensation hergestellten thermoplastischen Kunststoff aus der Familie der Polyester. Aus jedem Material wurden jeweils 5 Schienen für die Studie produziert.

Für den Tiefziehvorgang der Ideal Clear ${ }^{\circledR}$-Schienen wurde die „Vacuum Forming Machine“ Modelnr.202 (Dentsply GAC, Gräfelfing, Deutschland), für die Erkodur ${ }^{\circledR}$ Schienen der Erkoform RVE (Erkodent ${ }^{\circledR}$ Erich Kopp GmbH, Pfalzgreifenweiler, Deutschland) und für die aus Biolon ${ }^{\circledR}$ der Drufomat-TE (Dreve Dentamid GmbH, Unna, Deutschland) verwendet, wobei die Herstellung nach den jeweiligen Herstellerangaben erfolgte. Bei den beiden erstgenannten Tiefziehgeräten handelt es sich um Vakuum-Geräte, wohingegen der Drufomat-TE ein Druck-Tiefziehgerät ist. Für die Ausarbeitung der Schienen kamen der HSS Spiralbohrer und Lisko-S Polierscheiben (Erkodent ${ }^{\circledR}$ Erich Kopp GmbH, Pfalzgreifenweiler, Deutschland) zur Anwendung, wobei der Schienenrand dem Verlauf der marginalen Gingiva folgte.

Für alle in dieser Studie durchgeführten Messreihen kamen nur die zuvor beschriebenen 25 Tiefziehschienen zum Einsatz.

\subsection{Versuchsaufbau}

Zunächst wurden die Einzelteile des modularen Messapparates über Verschraubung und Verbolzung an ihrer exakten Position miteinander verbunden. Anschließend wurde die Kunststoffschale mit dem Versuchsmodell in dem Metallrahmen über die Klemmvorrichtung fixiert. Nun wurde der Messzahn 11 mit dem Stahlstift in die Klemmvorrichtung des Sensors 
eingeführt und reproduzierbar mittels Gipsschlüssel mit dem Nano 17 verschraubt (Abb. 9 und 10).

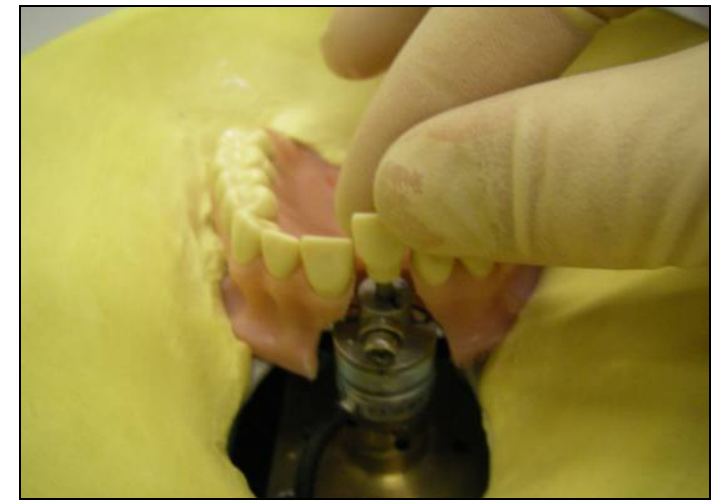

Abbildung 9 Positionierung des Messzahnes

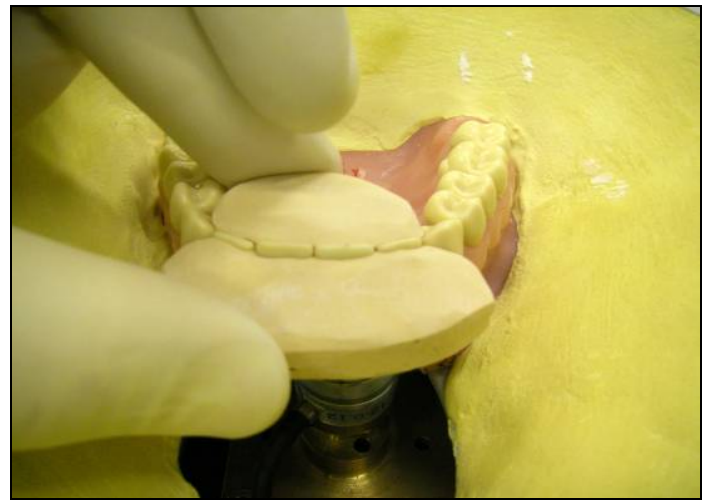

Abbildung 10 Reproduzierbare Fixierung des Messzahnes mittels Gipsschlüssel

Hinterher wurde die Messeinheit über den Stelltisch unter den Thermoschrank gehoben und der Thermoschrank auf $37^{\circ} \mathrm{C}$ vorgeheizt. In Abbildung 11 ist der komplette Versuchsaufbau dargestellt.

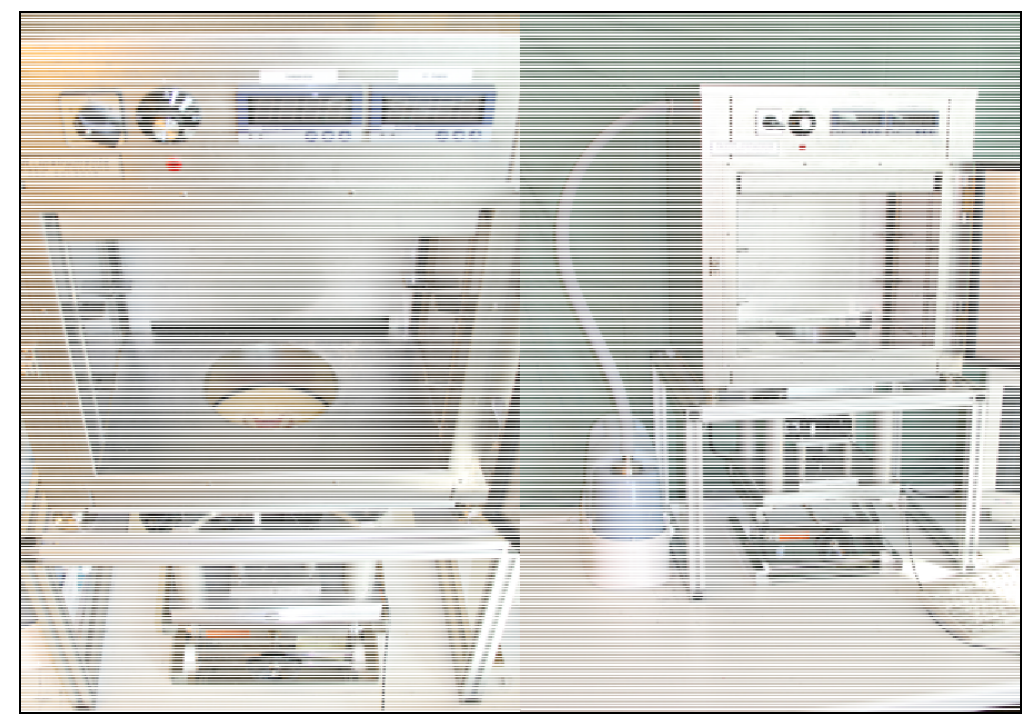

Abbildung 11 Kompletter Versuchsaufbau. In der linken Bildhälfte erkennt man das Modell in der Aussparung der Bodenplatte des Thermoschrankes. In der rechten Bildhälfte ist der komplette Versuchsaufbau in der Frontansicht dargestellt. Das Messsystem wurde über einen Hubtisch unter den Thermoschrank gefahren.

Die Verarbeitung der Daten erfolgte mittels DAQ F/T-Software (ATI Industrial Automation, Apex, NC; USA), welche eine numerische und graphische Darstellung der auftretenden Kräfte und Momente ermöglichte. 


\subsection{Messung der Schienen}

Im Einzelnen wurde, wie im Folgenden beispielhaft für eine Ideal Clear ${ }^{\circledR} 1,0 \mathrm{~mm}$ Schiene aufgeführt, vorgegangen:

Die Schiene wurde leicht (2 Sprühstöße) mit künstlichem Speichel (Universitätsklinikumsapotheke der UMG, Deutschland) eingesprüht und auf das Zahnkranzmodell mit dem in Nullposition befindlichen Messzahn 11 gesetzt. Kräfte und Drehmomente wurden vor Beginn des Messdurchlaufes über die DAQ F/T-Software genullt. Die Schiene unterlag zunächst zwei zeitlich getrennt voneinander ablaufenden Messreihen:

1. Rotation des Messzahnes im Uhrzeigersinn von $0^{\circ}$ auf $10^{\circ}$ auf $0^{\circ}$ in $0,5^{\circ}$-Schritten

2. Rotation gegen den Uhrzeigersinn von $0^{\circ}$ auf $10^{\circ}$ auf $0^{\circ}$ in $0,5^{\circ}-$ Schritten

Dabei wurden die Kräfte und Drehmomente jedes Messschrittes 5mal mittels DAQ F/TSoftware gespeichert. Zwischen den einzelnen Messschritten lag jeweils ein konstantes Zeitintervall von 30 Sekunden. Erst nachdem der erste Messdurchlauf mit allen zu messenden Schienen eines Materials beendet war, wurde der zweite Durchlauf gestartet. Gleiches galt für die anderen Materialien.

Zum Vergleich der drei Materialien wurden die klinisch relevanten Messwerte für die intrusive Kraft Fz und das rotative Drehmoment $\mathrm{Tz}$ bei einer Aktivierung von $\pm 2,5^{\circ}, \pm 5^{\circ}$ und $\pm 7,5^{\circ}$ herangezogen. Zum besseren Vergleich mit anderen Messwerten wurden diese in Bewegungsstrecken in Millimeter der äußersten mesialen und distalen Endpunkte der Inzisalkante des Messzahnes umgerechnet $( \pm 0,17 \mathrm{~mm}, \pm 0,34 \mathrm{~mm}$ und $\pm 0,51 \mathrm{~mm})$. Die beiden ersten Werte entsprechen hierbei annähernd der in der Literatur angegebenen Unter- bzw. Obergrenze von $0,15 \mathrm{~mm}$ bzw. $0,33 \mathrm{~mm}$ für die Auslenkungsstrecke bei einer Invisalignbehandlung (Boyd et al. 2000, Faltin et al. 2003, Joffe 2003, Melkos 2005, Owen 2001, Vlaskalic et al. 2001), wohingegen der dritte Wert von $\pm 0,51 \mathrm{~mm}$ in etwa der in das Setup einprogrammierte Zahnbewegung von $0,5 \mathrm{~mm}$ des Clear Smile ${ }^{\circledR}$ Systems entspricht (Barbagallo et al. 2008 b).

Um die Auswirkung der durchschnittlichen vertikalen Kraft beim Schlucken auf die Kraftabgabe der Schienen zu untersuchen, wurden alle Schienen erneut unter vertikaler Belastung mit einem Gewichtsäquivalent gemessen. Das für die Versuchsreihe verwendete Gewicht von $3 \mathrm{~kg}$ zur Simulation der Schluckkraft wurde hierfür in den wissenschaftlichen Werkstätten des Universitätsklinikums eigens hergestellt und entspricht dem in der Literatur angegebenen Mittelwert der Schluckkraft (Eichner 1963, Proffit et al. 1983). Zur korrekten 
Positionierung der Gewichte auf der zu messenden Schiene wurde ein Silikonschlüssel aus dem Material Picodent ${ }^{\circledR}$ twinduo (Picodent ${ }^{\circledR}$ Dental-Produktions- und Vertriebs- GmbH, Wipperfürth, Deutschland) hergestellt.

Nach Positionierung der Schiene auf dem Zahnbogenmodell, Aufbringen des Simulationsgewichtes und Nullung über die DAQ F/T-Software wurden die zwei zuvor beschriebenen Messdurchläufe wiederholt. Abbildung 12 zeigt die auf der Messschiene positionierten Gewichte.

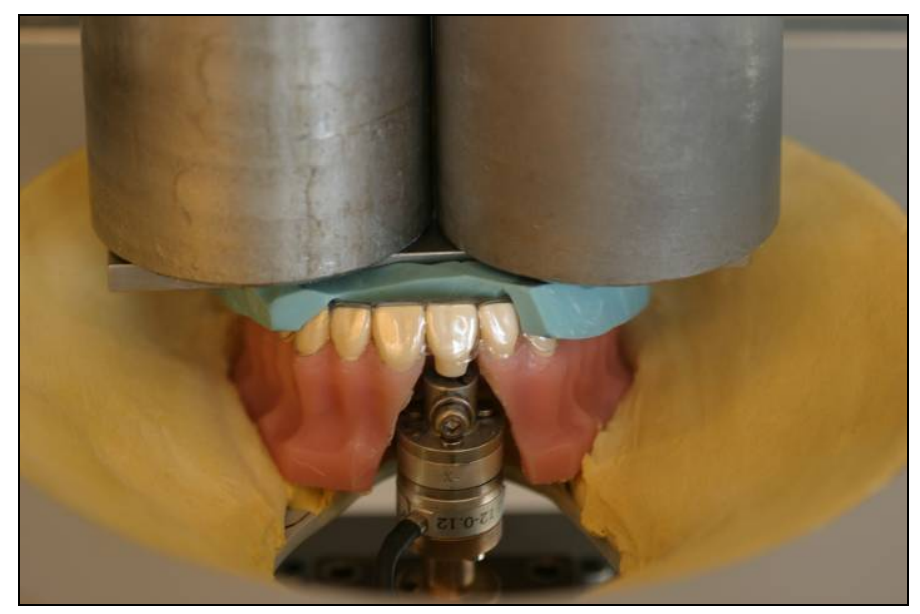

Abbildung 12 Messschiene und positioniertes Gewicht zur Simulation der Schluckkraft

\subsection{Alterungssimulation}

Im Anschluss an die Rotationsmessungen wurden die Schienen einer 14tägigen künstlichen Alterung unterzogen. Dies entspricht in etwa der durch die Literatur empfohlenen Tragezeit der Aligner (Barbagallo et al 2008 b, Joffe 2003). Vornehmlich von Interesse war hierbei, welche Auswirkung Temperaturschwankungen, Wasserlagerung und länger anhaltende Belastungen auf die Schienen haben.

\subsubsection{Modellherstellung für die Alterungssimulation}

Für die Alterungssimulation der Schienen, bei welcher diese im Bereich des Messzahnes eine Vorbelastung erfahren sollten, wurden spezielle Modelle hergestellt. Es erfolgte zunächst eine Alginat-Abdrucknahme des Versuchmodells, wobei hierfür der Messzahn 11 um $3^{\circ}$ gegen den Uhrzeigersinn rotiert wurde. Der Abdruck wurde anschließend mit einem Gips der Klasse IV (GC Fujirock ${ }^{\circledR}$ EP, GC Deutschland GmbH, München, Deutschland) ausgegossen und von dem entstandenen Gipsmodell mit Adisil ${ }^{\circledR}$ blau 9:1 (Siladent Dr. Böhme \& Schöps GmbH, Goslar, Deutschland) gemäß Herstellerangaben eine Dublierform erstellt. In diese Form wurden nun die zum Zahnkranzmodell passenden Kunststoffzähne (Frasaco GmbH, Tettnang, 
Deutschland) an ihrer jeweiligen Position eingesetzt und die Dublierform mit Prothesenkunststoff (Palapress rosa, Heraeus Kulzer, Hanau, Deutschland) aufgefüllt. Für einen besseren Verbund mit dem Prothesenkunststoff wurde die Wurzeloberfläche der Modellzähne vorher angeraut und mit Retentionsrillen versehen. Nach Aushärtung erfolgte die Ausarbeitung des Modells. Hierbei wurden die Wurzeln der Frasacozähne weitestgehend gekürzt und die Oberfläche des Prothesenkunststoffes mit Handinstrumenten (Acrylic Polierer, Edenta AG, Au, Schweiz) poliert.

\subsubsection{Versuchsablauf der Alterungssimulation}

Zur Alterungssimulation wurden die bereits beschriebenen Tiefziehschienen auf das für die Vorbelastung konzipierte Kunststoffmodell gesetzt, mit drei Gummiringen fixiert und in einem Wasserbad bei $37^{\circ} \mathrm{C}$ für 7 Tage gelagert. Im Anschluss an die Wasserlagerung erfolgte eine thermische Wechselbelastung der Schienen mit dem Willytec Thermocycler V 2.9 (Ekton AG, Gräfeling Deutschland). Insgesamt wurden 70 Zyklen durchgeführt, wobei sich die Schienen für jeweils $30 \mathrm{~s}$ in einem $+5{ }^{\circ} \mathrm{C}$, bzw. $+55^{\circ} \mathrm{C}$ temperierten Wasserbad befanden. Der Wechsel zwischen den beiden Bädern erfolgte automatisiert. Hierbei waren die Schienen $10 \mathrm{~s}$ der Umgebungsluft ausgesetzt. Nach Beendigung der thermischen Wechsellast erfolgte eine erneute 7tägige Lagerung der Aligner in dem $37{ }^{\circ} \mathrm{C}$ warmen Wasserbad.

Nach Abschluss der 14tägigen Alterung wurden alle Schienen erneut gemessen. Das Messprotokoll entsprach weitestgehend dem vor der Alterungssimulation. Lediglich der Messablauf der Schienen mit und ohne Gewicht im Uhrzeigersinn wurde weggelassen:

1. Rotation gegen den Uhrzeigersinn von $0^{\circ}$ auf $10^{\circ}$ auf $0^{\circ}$ in $0,5^{\circ}$-Schritten ohne Gewicht

2. Rotation gegen den Uhrzeigersinn von $0^{\circ}$ auf $10^{\circ}$ auf $0^{\circ}$ in $0,5^{\circ}$-Schritten mit Gewicht

\subsection{Statistische Auswertung}

Die tabellarische Erfassung der Messergebnisse wurde mit dem Kalkulationsprogramm Excel (Office-Paket, Version 2000, Microsoft Corporation, Deutschland) vorgenommen.

Die einzelnen Einflussgrößen auf das Drehmoment (Tz) bzw. die Rotationskraft (Fz) wurden mittels univariaten Varianzanalysen für Wiederholungsmessungen untersucht. Das Signifikanzniveau wurde bei allen Tests auf $\alpha=5 \%$ festgelegt. Da für das Drehmoment annähernd eine Normalverteilung vorausgesetzt werden kann, wurde hierfür eine normale parametrische Varianzanalyse angewandt. Die Rotationskraft hingegen zeigt eine stark 
linksschiefe Verteilung. Daher wurde für deren Analyse eine nichtparametrische Varianzanalyse verwendet.

Entsprechend diesen Verteilungseigenschaften wurde das Drehmoment in den einzelnen Stufen der Variablen durch den Mittelwert ( \pm Standardfehler) näher charakterisiert. Für die Rotationskraft wurde hingegen der Median (sowie das 25\%- und 75\%-Quantil) angegeben.

Die Varianzanalysen wurden mit der Software SAS (Version 9.1, SAS Institute GmbH, Heidelberg, Deutschland) vorgenommen.

Für die Errechnung der Mittelwerte und Standardabweichung bzw. Median sowie 25\%- und 75\%-Quantile der jeweiligen Drehmomente bzw. Kräfte wurde lediglich der Hinweg einer Messreihe betrachtet, also von $0^{\circ}$ auf $10^{\circ}$. Der Rückweg sowie die Messwerte nach Alterungssimulation wurden hierbei nicht berücksichtigt. Von Interesse waren die initialen Kräfte und Drehmomente für die Winkel $\pm 2,5^{\circ}, \pm 5^{\circ}$ und $\pm 7,5^{\circ}$. Umgerechnet entsprechen diese einer Auslenkungsstrecke von $\pm 0,17 \mathrm{~mm}, \pm 0,34 \mathrm{~mm}$ und $\pm 0,51 \mathrm{~mm}$.

Die Varianzanalysen wurden auf verschiedene Teildatensätze angewandt (Tabelle 1). Die zugehörigen Graphen wurden mit den Programmen R (Version 2.6, www.r-project.org) und Excel erstellt.

\begin{tabular}{|c|c|}
\hline Untersuchte Einflussgröße & Komponenten des Subdatensatzes \\
\hline Schienenstärke & $\begin{array}{l}\text { Zielgrößen: } \\
\text { Fz; Tz } \\
\text { Stufen der sonstigen Einflussgrößen: } \\
\text { Alterung }=\text { vor } \\
\text { Richtung }=\text { Hinweg } \\
\text { Gegenüberstellung von: } \\
\text { Biolon }^{\circledR} 1,0 \mathrm{~mm} \text { vs. Biolon } \\
\text { Erkodur }^{\circledR} 1,0 \mathrm{~mm} \text { vs. Erkodur }{ }^{\circledR} 0,8 \mathrm{~mm} \\
\end{array}$ \\
\hline Tiefziehverfahren & $\begin{array}{l}\text { Zielgrößen: } \\
\text { Fz;Tz } \\
\text { Stufen der sonstigen Einflussgrößen: } \\
\text { Alterung }=\text { vor } \\
\text { Richtung }=\text { Hinweg } \\
\text { Gegenüberstellung von: } \\
\text { Biolon }^{\circledR}, \text { Erkodur }{ }^{\mathbb{Q}}, \text { Ideal Clear }{ }^{\circledR} \text { in } 1,0 \mathrm{~mm}\end{array}$ \\
\hline Gewicht & $\begin{array}{l}\text { Zielgrößen: } \\
\text { Fz; } T z \\
\text { Stufen der sonstigen Einflussgrößen: } \\
\pm 2,5^{\circ}, \pm 5^{\circ} \text { und } \pm 7,5^{\circ} \\
\text { Alterung }=\text { vor } \\
\text { Richtung }=\text { Hinweg }\end{array}$ \\
\hline Alterung & $\begin{array}{l}\text { Zielgrößen: } \\
F z ; T z \\
\text { Stufen der sonstigen Einflussgrößen: } \\
-2,5^{\circ},-5^{\circ} \text { und }-7,5^{\circ} \\
\text { Richtung = Hinweg }\end{array}$ \\
\hline
\end{tabular}

Tabelle 1 Untersuchte Einflussgröße und der dafür konzipierte Subdatensatz Alterung = vor bedeutet, dass lediglich die Messwerte vor Alterungssimulation verwendet wurden. Richtung = Hinweg bedeutet, dass lediglich der Messbereich von $0^{\circ}$ auf $10^{\circ}$ verwendet wurde 


\section{Ergebnisse}

Im Folgenden werden zunächst exemplarisch an einer Biolon ${ }^{\circledR}$ 1,0 $\mathrm{mm}$ Schiene die gemessenen Kräfte und Drehmomente in Bezug zur Auslenkungsstrecke für den Hin- und Rückweg der Messreihen graphisch dargestellt (Abb. 13). Der negative Bereich der Auslenkungsstrecke steht in diesem Fall für die Rotation des Messzahnes gegen den Uhrzeigersinn, der Positive für die Rotation im Uhrzeigersinn. Bei Betrachtung der drei Kraftkomponenten Fx, Fy und Fz zeigt sich, dass die intrusiven Kräfte (Fz) wesentlich stärker sind, als die Kräfte in Fx und Fy. In gleicher Weise verhält sich das rotative Drehmoment (Tz) gegenüber Tx und Ty. Anhand der Graphik wird des Weiteren deutlich, dass die Fehler des Erfassungsgerätes im Messsystem zu vernachlässigen sind, da jede Auslenkungsstrecke fünfmal gemessen wurde und sich diese Werte in der Graphik deutlich überlagern.

Bei allen Messungen konnten mehr oder weniger stark ausgeprägte Hysteresephänomene beobachtet werden (Abb. 13).

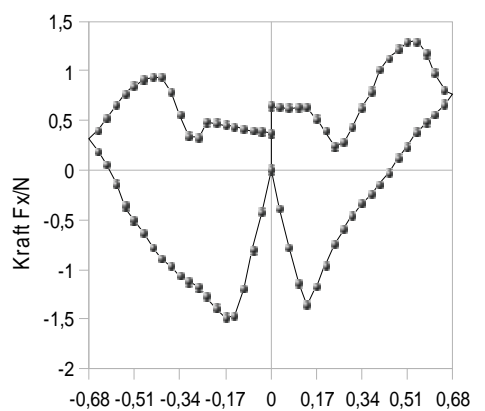

Rotation/mm

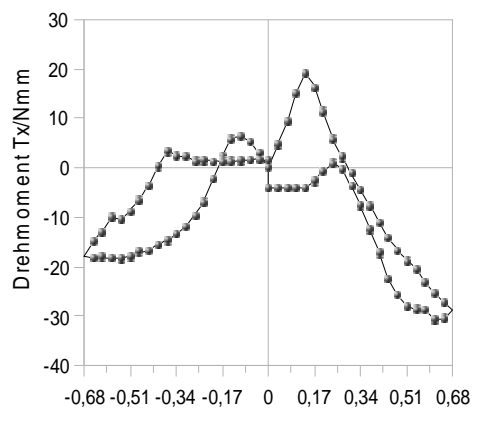

Rotation/mm

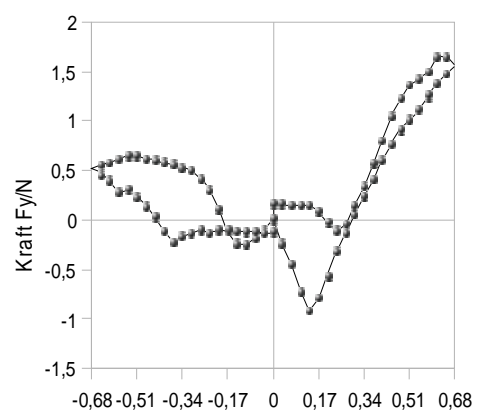

Rotation/mm

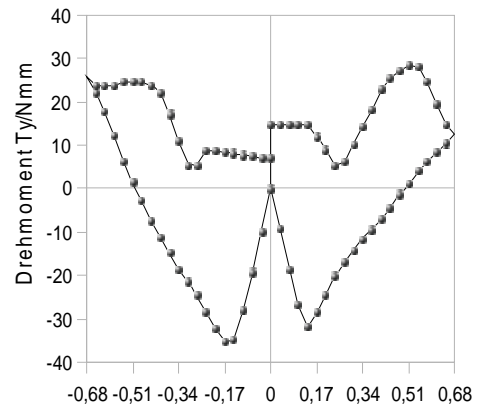

Rotation/mm

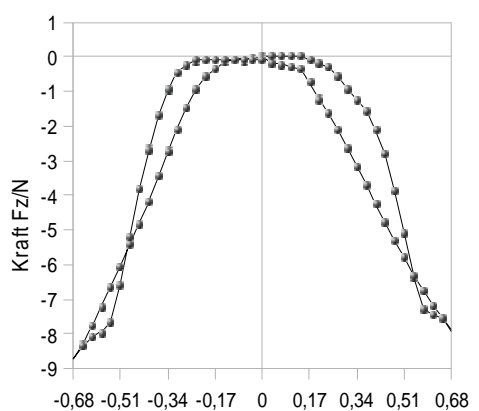

Rotation/mm

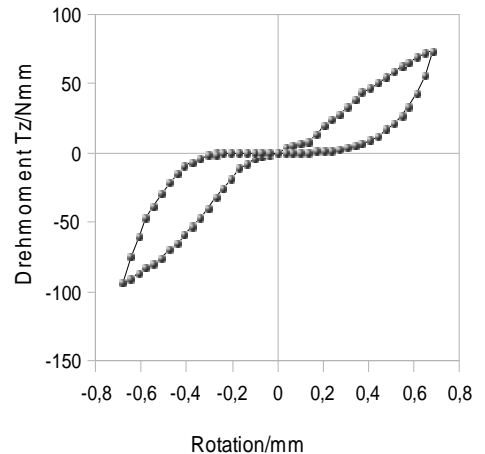

Abbildung 13 Typische Kräfte (Fx, Fy, Fz obere Reihe) und Drehmomente (Tx, Ty, Tz untere Reihe) wie sie in dieser Studie in Abhängigkeit zur Auslenkungsstrecke bei dem Material Biolon ${ }^{\circledR}$ in der Stärke 1,0 mm gemessen wurden

Zur weiteren Auswertung wurden die Werte Fz und Tz, die für die Rotation und den in der Literatur beschriebenen Nebeneffekt der Intrusion bei Schienentherapie relevant sind, herangezogen. In Tabelle 2 sind für Tz bei den einzelnen Materialien die Mittelwerte und Standardabweichungen der Auslenkungsstrecken $\pm 0,17 \mathrm{~mm}, \pm 0,34 \mathrm{~mm}$ und $\pm 0,51 \mathrm{~mm}$ 
angegeben. Das höchste rotative Drehmoment wurde hierbei durch die Schienen aus Biolon ${ }^{\circledR}$ $1,0 \mathrm{~mm}$ bei einer Auslenkung von $\pm 0,51 \mathrm{~mm}$ hervorgerufen. Es betrug bei einer Rotation mit dem Uhrzeigersinn mittelwertig 56,7 $\mathrm{Nmm}(\mathrm{SD} \pm 2,0 \mathrm{Nmm})$ und gegen den Uhrzeigersinn $-71,8 \mathrm{Nmm}$ (SD $\pm 2,5 \mathrm{Nmm}$ ). Demgegenüber steht als Schienenmaterial mit dem niedrigsten rotativen Drehmoment bei einer Auslenkung von $\pm 0,51 \mathrm{~mm}$ das Material Erkodur ${ }^{\circledR}$ in der Stärke 0,8 mm. Hier betrugen die Momente 30,5 Nmm (SD $\pm 1,3 \mathrm{Nmm}$ ) bzw. -40,6 Nmm (SD $\pm 1,1 \mathrm{Nmm})$. Bei einer Auslenkung von $\pm 0,34 \mathrm{~mm}$ variierten die Drehmomente material- und richtungsabhängig zwischen $-44,5 \mathrm{Nmm}\left(\mathrm{SD} \pm 1,7 \mathrm{Nmm}\right.$ ) bei Biolon ${ }^{\circledR} 1,0 \mathrm{~mm}$ und 18,2 $\mathrm{Nmm}$ (SD $\pm 0,9 \mathrm{Nmm}$ ) bei Erkodur ${ }^{\circledR} 0,8 \mathrm{~mm}$. Für die Auslenkungsstrecke $\pm 0,17 \mathrm{~mm}$ wurden Drehmomente zwischen 20,2 Nmm (SD $\pm 1,3 \mathrm{Nmm}$ ) bei Ideal Clear ${ }^{\circledR} 1,0 \mathrm{~mm}$ und 4,3 $\mathrm{Nmm}$ (SD $\pm 0,5 \mathrm{Nmm}$ ) bei Erkodur ${ }^{\circledR} 0,8 \mathrm{~mm}$ gemessen. Der dazugehörige Boxplot ist in Abbildung 14 dargestellt.

\begin{tabular}{|c|c|c|c|c|c|}
\hline $\begin{array}{l}\text { Auslenkungs- } \\
\text { Strecke (mm) }\end{array}$ & Var. & Material & $\begin{array}{l}\text { Material- } \\
\text { Stärke } \\
(\mathrm{mm})\end{array}$ & $\mathbf{N}$ & $\begin{array}{l}\text { Mittelwert } \\
\pm \\
\text { Standartfehler } \\
(\mathrm{Nmm})\end{array}$ \\
\hline$-0,51$ & $\mathrm{Tz}$ & $\begin{array}{l}\text { Biolon }^{\circledR} \\
\text { Erkodur }^{(} \\
\left.\text {Ideal Clear }^{(}\right) \\
\text {Biolon }^{\circledR} \\
\text { Erkodur }^{(}\end{array}$ & $\begin{array}{l}1,0 \\
1,0 \\
1,0 \\
0,75 \\
0,8\end{array}$ & $\begin{array}{l}25 \\
25 \\
25 \\
25 \\
25\end{array}$ & $\begin{array}{l}-71.8 \pm 2,5 \\
-53.3 \pm 2.1 \\
-60.6 \pm 2.2 \\
-49.9 \pm 0.7 \\
-40.6 \pm 1.1\end{array}$ \\
\hline$-0,34$ & $\mathrm{Tz}$ & $\begin{array}{l}\text { Biolon }^{(\otimes)} \\
\text { Erkodur }^{(} \\
\left.\text {Ideal Clear }^{(}\right) \\
\text {Biolon }^{(} \\
\text {Erkodur }^{(}\end{array}$ & $\begin{array}{l}1,0 \\
1,0 \\
1,0 \\
0,75 \\
0,8\end{array}$ & $\begin{array}{l}25 \\
25 \\
25 \\
25 \\
25 \\
\end{array}$ & $\begin{array}{l}-44.5 \pm 1.7 \\
-30.1 \pm 1.3 \\
-41.8 \pm 1.7 \\
-28.8 \pm 0.3 \\
-24.2 \pm 0.7\end{array}$ \\
\hline$-0,17$ & $\mathrm{Tz}$ & $\begin{array}{l}\text { Biolon }^{(8)} \\
\text { Erkodur }^{(} \\
\text {Ideal Clear }^{(\mathbb{B}} \\
\left.\text { Biolon }^{(}\right) \\
\text {Erkodur }^{(}\end{array}$ & $\begin{array}{l}1,0 \\
1,0 \\
1,0 \\
0,75 \\
0,8 \\
\end{array}$ & $\begin{array}{l}25 \\
25 \\
25 \\
25 \\
25 \\
\end{array}$ & $\begin{array}{l}-9.8 \pm 0.7 \\
-7.3 \pm 0.8 \\
-18.3 \pm 1.2 \\
-7.3 \pm 0.2 \\
-6.1 \pm 0.7\end{array}$ \\
\hline 0,17 & $\mathrm{Tz}$ & $\begin{array}{l}\text { Biolon }^{(B)} \\
\text { Erkodur }^{(} \\
\text {Ideal Clear }^{(\mathbb{B}} \\
\text { Biolon }^{\circledR} \\
\text { Erkodur }^{(}\end{array}$ & $\begin{array}{l}1,0 \\
1,0 \\
1,0 \\
0,75 \\
0,8 \\
\end{array}$ & $\begin{array}{l}25 \\
25 \\
25 \\
25 \\
25\end{array}$ & $\begin{array}{l}12.8 \pm 1.0 \\
8.2 \pm 1.0 \\
20.2 \pm 1.3 \\
4.9 \pm 0.6 \\
4.3 \pm 0.5\end{array}$ \\
\hline 0,34 & $\mathrm{Tz}$ & $\begin{array}{l}\text { Biolon }^{(\circledR)} \\
\text { Erkodur }^{(} \\
\left.\text {Ideal Clear }^{(}\right) \\
\text {Biolon }^{\circledR} \\
\text { Erkodur }^{(}\end{array}$ & $\begin{array}{l}1,0 \\
1,0 \\
1,0 \\
0,75 \\
0,8\end{array}$ & $\begin{array}{l}25 \\
25 \\
25 \\
25 \\
25\end{array}$ & $\begin{array}{l}35.3 \pm 2.3 \\
26.7 \pm 1.3 \\
39.4 \pm 1.6 \\
25.3 \pm 1.6 \\
18.2 \pm 0.9\end{array}$ \\
\hline 0,51 & $\mathrm{Tz}$ & $\begin{array}{l}\text { Biolon }^{(\circledR)} \\
\text { Erkodur }^{(} \\
\left.\text {Ideal Clear }^{(}\right) \\
\text {Biolon }^{\circledR} \\
\text { Erkodur }^{(}\end{array}$ & $\begin{array}{l}1,0 \\
1,0 \\
1,0 \\
0,75 \\
0,8\end{array}$ & $\begin{array}{l}25 \\
25 \\
25 \\
25 \\
25 \\
\end{array}$ & $\begin{array}{l}56.7 \pm 2.0 \\
42.3 \pm 1.7 \\
54.1 \pm 1.8 \\
42.3 \pm 1.9 \\
30.5 \pm 1.3\end{array}$ \\
\hline
\end{tabular}

Tabelle 2 Mittelwerte und Standartabweichungen der gemessenen Materialien bei den Auslenkungsstrecken $\pm 0,17 \mathrm{~mm}, \pm 0,34 \mathrm{~mm}$ und $\pm 0,51 \mathrm{~mm}$ für die Variable $T z$ 


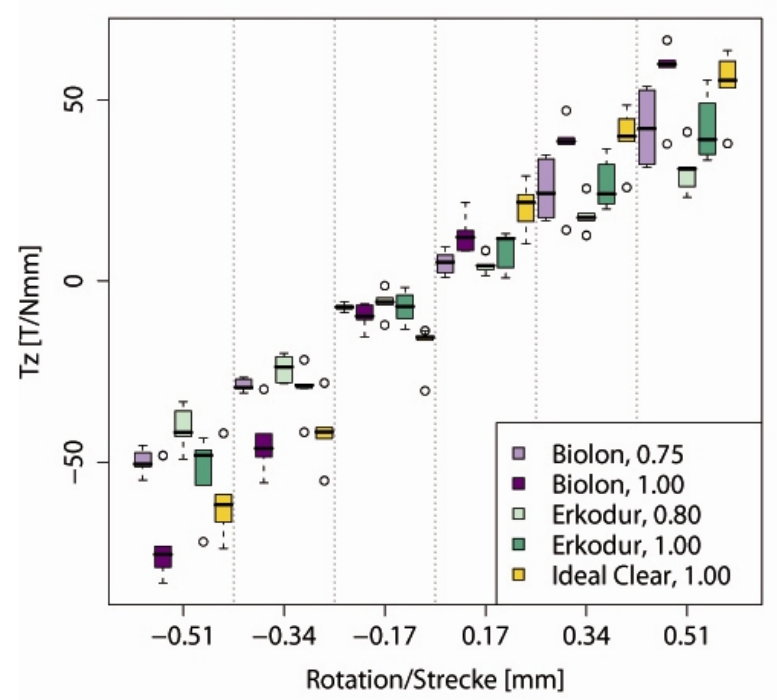

Abbildung 14 Darstellung der rotativen Drehmomente für die gemessenen Materialien bei den Auslenkungsstrecken $\pm 0,17 \mathrm{~mm}, \pm 0,34 \mathrm{~mm}$ und $\pm 0,51 \mathrm{~mm}$

In Tabelle 3 sind für die intrusive Kraft Fz die 25-, 50- \& 75\%-Quantile der verschiedenen Materialien bei den Auslenkungsstrecken $\pm 0,17 \mathrm{~mm}, \pm 0,34 \mathrm{~mm}$ und $\pm 0,51 \mathrm{~mm}$ aufgetragen. Auch hier zeigt sich, dass bei einer Auslenkung von $\pm 0,51 \mathrm{~mm}$ Biolon ${ }^{\circledR}$ in der Schienenstärke 1,0 mm mit einem Medianwert von $-5,8 \mathrm{~N}\left(\mathrm{Q} .25-6,0 \mathrm{~N}, \mathrm{Q}_{.75}-5,0 \mathrm{~N}\right)$ bei Rotation gegen den Uhrzeigersinn und -5,2 N (Q.25 -5,8 N, Q.75 -5,0 N) bei Rotation mit dem Uhrzeigersinn die höchsten Kräfte verursacht. Die niedrigsten intrusiven Kräfte erzeugten wiederum die Erkodur $^{\circledR}$-Schienen der Stärke 0,8 mm bei einem Median von -3,6 N (Q.25 -3,6 N, Q.75 -3,6 N) gegen den Uhrzeigersinn und $-2,8 \mathrm{~N}(\mathrm{Q} .25-3,1 \mathrm{~N}, \mathrm{Q} .75-2,4 \mathrm{~N})$ mit dem Uhrzeigersinn. Für die Auslenkungsstrecke $\pm 0,34 \mathrm{~mm}$ wurden material- und richtungsabhängig intrusive Kräfte zwischen -1,3 N (Q.25 -1,4 N, Q.75 -1,1 N) bei Biolon ${ }^{\circledR} 0,75 \mathrm{~mm}$ und -2,6 N (Q.25 -3,2 N, Q.75 $2,4 \mathrm{~N}$ ) bei Biolon ${ }^{\circledR} 1,0 \mathrm{~mm}$ gemessen. Bei einer Auslenkung von $\pm 0,17 \mathrm{~mm}$ lagen die Kräfte zwischen $0 \mathrm{~N}\left(\mathrm{Q} .25-0,3 \mathrm{~N}, \mathrm{Q}_{.75} 0,1 \mathrm{~N}\right)$ bei Biolon ${ }^{\circledR} 1,0 \mathrm{~mm}$ und $-0,8 \mathrm{~N}\left(\mathrm{Q} .25-0,9 \mathrm{~N}, \mathrm{Q}_{.75}-0,8\right.$ $\mathrm{N})$ bei Ideal Clear ${ }^{\circledR} 1,0 \mathrm{~mm}$. Abbildung 15 zeigt den dazugehörigen Boxplot. 


\begin{tabular}{|c|c|c|c|c|c|}
\hline $\begin{array}{l}\text { Auslenkungs- } \\
\text { Strecke (mm) }\end{array}$ & Var. & Material & $\begin{array}{l}\text { Material- } \\
\text { Stärke } \\
(\mathrm{mm})\end{array}$ & $\mathbf{N}$ & $\begin{array}{l}\text { 25-,50-\& } \\
\text { 75\%-Quantil }\end{array}$ \\
\hline$-0,51$ & $\mathrm{Fz}$ & $\begin{array}{l}\text { Biolon }^{(B)} \\
\text { Erkodur }^{(B)} \\
\text { Ideal Clear }^{(B)} \\
\text { Biolon } \\
\text { Erkodur }^{(B)} \\
\end{array}$ & $\begin{array}{l}1,0 \\
1,0 \\
1,0 \\
0,75 \\
0,8 \\
\end{array}$ & $\begin{array}{l}25 \\
25 \\
25 \\
25 \\
25 \\
\end{array}$ & $\begin{array}{l}-6.0,-5.8,-5.0 \\
-5.3,-4.7,-4.5 \\
-4.6,-4.6,-4.5 \\
-3.6,-3.6,-3.4 \\
-3.6,-3.6,-3.6\end{array}$ \\
\hline$-0,34$ & $\mathrm{Fz}$ & $\begin{array}{l}\text { Biolon }^{\circledR} \\
\text { Erkodur }^{(} \\
\text {Ideal Clear }^{\circledR} \\
\text { Biolon } \\
\text { Erkodur }^{\circledR} \\
\end{array}$ & $\begin{array}{l}1,0 \\
1,0 \\
1,0 \\
0,75 \\
0,8 \\
\end{array}$ & $\begin{array}{l}25 \\
25 \\
25 \\
25 \\
25 \\
\end{array}$ & $\begin{array}{l}-2.7,-2.4,-2.1 \\
-2.4,-2.3,-2.3 \\
-2.8,-2.6,-2.5 \\
-1.4,-1.3,-1.1 \\
-2.0,-2.0,-1.8\end{array}$ \\
\hline$-0,17$ & $\mathrm{Fz}$ & $\begin{array}{l}\text { Biolon }^{(B)} \\
\text { Erkodur }^{(} \\
\text {Ideal Clear }^{(\mathbb{R}} \\
\text { Biolon }^{\circledR} \\
\text { Erkodur }^{(B)}\end{array}$ & $\begin{array}{l}1,0 \\
1,0 \\
1,0 \\
0,75 \\
0,8 \\
\end{array}$ & $\begin{array}{l}25 \\
25 \\
25 \\
25 \\
25\end{array}$ & $\begin{array}{l}-0.3,-0.0,0.1 \\
-0.5,-0.4,-0.2 \\
-0.8,-0.5,-0.5 \\
0.0,0.1,0.1 \\
-0.4,-0.2,-0.2\end{array}$ \\
\hline 0,17 & $\mathrm{Fz}$ & $\begin{array}{l}\text { Biolon }^{\circledR} \\
\text { Erkodur }^{(} \\
\text {Ideal Clear }^{\circledR} \\
\text { Biolon } \\
\text { Erkodur }^{\circledR} \\
\end{array}$ & $\begin{array}{l}1,0 \\
1,0 \\
1,0 \\
0,75 \\
0,8 \\
\end{array}$ & $\begin{array}{l}25 \\
25 \\
25 \\
25 \\
25 \\
\end{array}$ & $\begin{array}{l}-0.7,-0.4,-0.3 \\
-0.6,-0.6,-0.4 \\
-0.9,-0.8,-0.8 \\
-0.3,-0.3,-0.2 \\
-0.2,-0.2,-0.2\end{array}$ \\
\hline 0,34 & $\mathrm{Fz}$ & $\begin{array}{l}\text { Biolon }^{\circledR} \\
\text { Erkodur }^{(B} \\
\text { Ideal Clear }^{(B)} \\
\text { Biolon }^{\circledR} \\
\text { Erkodur }^{(B}\end{array}$ & $\begin{array}{l}1,0 \\
1,0 \\
1,0 \\
0,75 \\
0,8\end{array}$ & $\begin{array}{l}25 \\
25 \\
25 \\
25 \\
25\end{array}$ & $\begin{array}{l}-3.2,-2.6,-2.4 \\
-2.3,-1.8,-1.8 \\
-2.7,-2.6,-2.6 \\
-1.5,-1.4,-1.3 \\
-1.6,-1.4,-1.4\end{array}$ \\
\hline 0,51 & $\mathrm{Fz}$ & $\begin{array}{l}\text { Biolon }^{(B)} \\
\text { Erkodur }^{(B)} \\
\text { Ideal Clear }^{\circledR} \\
\text { Biolon } \\
\text { Erkodur }^{(B}\end{array}$ & $\begin{array}{l}1,0 \\
1,0 \\
1,0 \\
0,75 \\
0,8\end{array}$ & $\begin{array}{l}25 \\
25 \\
25 \\
25 \\
25\end{array}$ & $\begin{array}{l}-5.8,-5.2,-5.0 \\
-4.3,-3.5,-3.2 \\
-4.6,-4.4,-4.4 \\
-3.4,-3.2,-3.2 \\
-3.1,-2.8,-2.4\end{array}$ \\
\hline
\end{tabular}

Tabelle 3 25-,50-\&75\%-Quantil der gemessenen Materialien bei den Auslenkungsstrecken $\pm 0,17 \mathrm{~mm}, \pm 0,34 \mathrm{~mm}$ und $\pm 0,51 \mathrm{~mm}$ für die Variable $\mathrm{Fz}$

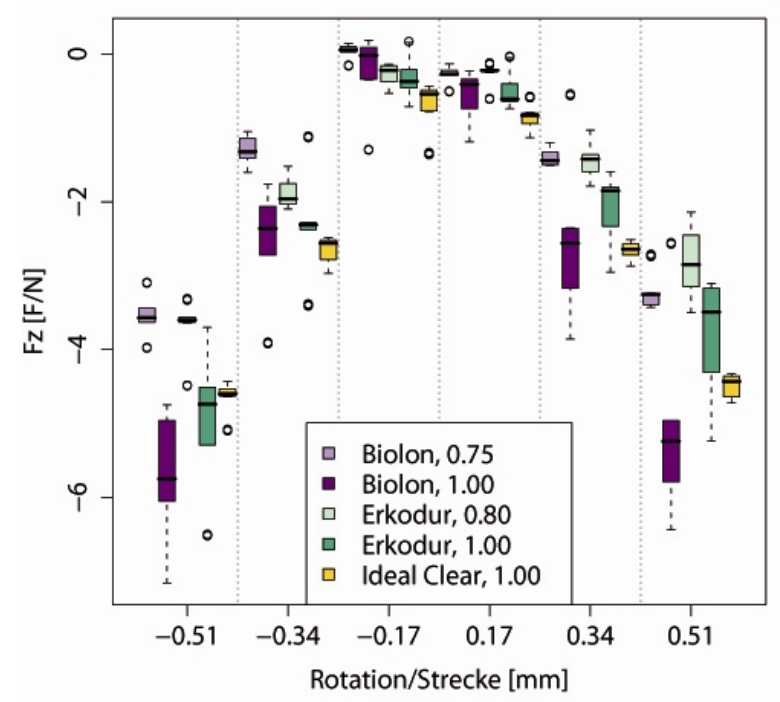

Abbildung 15 Darstellung der intrusiven Kräfte für die gemessenen Materialien bei den Auslenkungsstrecken $\pm 0,17 \mathrm{~mm}, \pm 0,34 \mathrm{~mm}$ und $\pm 0,51 \mathrm{~mm}$ 


\subsection{Einfluss der Materialstärke}

Die Biolon ${ }^{\circledR}$-Schienen der Stärke 1,0 mm produzierte stets statistisch signifikant höhere Drehmomente $(\mathrm{p}<0.01)$ als die Biolon ${ }^{\circledR}$-Schienen der Stärke 0,75 mm (Tab. 4). Abgesehen von der Auslenkung $-2,5^{\circ}(\mathrm{p}=0.06)$ zeigten sich bei Erkodur ${ }^{\circledR}$ in der Schienenstärke 1,0 mm ebenfalls statistisch signifikant höhere Drehmomente $(\mathrm{p}<0.01)$ als bei der Stärke $0,75 \mathrm{~mm}$ (Tab. 4). Auch für die Variablen Fz zeigte sich, dass die Materialstärke sowohl bei Biolon ${ }^{\circledR}$, als auch bei Erkodur ${ }^{\circledR}$ einen statistisch signifikanten Einfluss auf die gemessenen intrusiven Kräfte hat. Der p-Wert lag mit Ausnahme der Auslenkungsstrecke $-0,17 \mathrm{~mm}$ bei dem Vergleich von Biolon ${ }^{\circledR} 1,0 \mathrm{~mm}$ mit Biolon ${ }^{\circledR} 0,7 \mathrm{~mm}(\mathrm{p}=0,5)$ bei unter 0,01 . Bei allen Winkeln wurden für Biolon ${ }^{\circledR}$ in der Stärke 1,0 mm höhere Kräfte gemessen als bei Biolon ${ }^{\circledR}$ in der Stärke 0,75 mm. Gleiches gilt für Erkodur ${ }^{\circledR} 1,0 \mathrm{~mm}$ gegenüber Erkodur ${ }^{\circledR} 0,8 \mathrm{~mm}$.

Des Weiteren ist festzustellen, dass bei der Variable Tz der Standartfehler von Biolon ${ }^{\circledR}$ in der Stärke 0,75 mm kleiner ausfällt, als bei Biolon ${ }^{\circledR}$ in der Stärke 1,0 $\mathrm{mm}$ (Tab. 4). Gleiches gilt für Erkodur $^{\circledR}$ in der Stärke 0,8 mm gegenüber Erkodur ${ }^{\circledR}$ in 1,0 mm. Auch bei der Variable Fz zeigen die 25\% bzw. 75\% Quantile gegenüber dem Medianwert geringere Abweichungen für die Materialstärken 0,75 mm bzw. 0,8 mm (Tab. 5). In den Abbildungen 16 und 17 wird dieser Sachverhalt graphisch veranschaulicht.

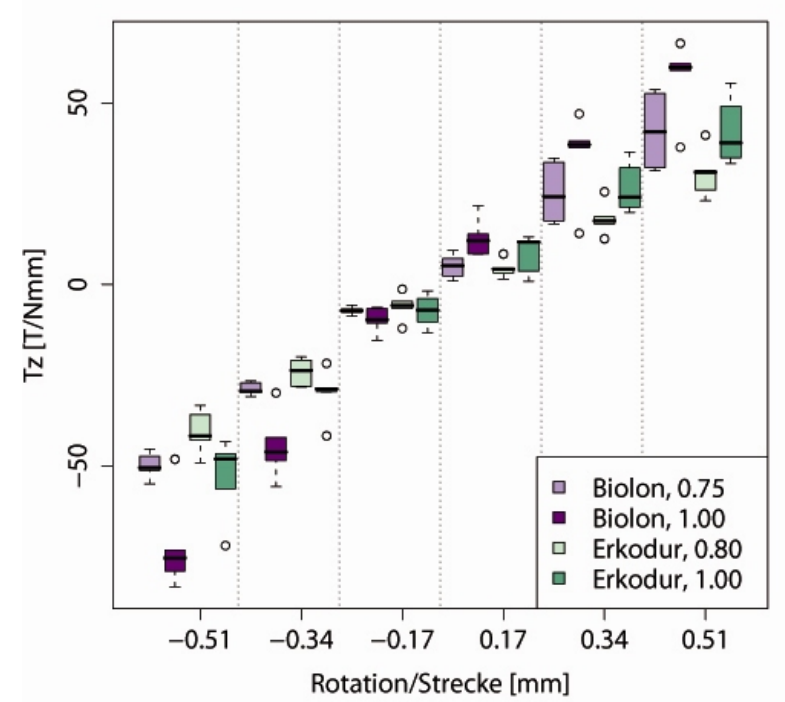

Abbildung 16 Box-Plots der Rotative Drehmomente der Materialien Biolon ${ }^{\circledR}$ und Erkodur ${ }^{\circledR}$ in ihren zwei verschiedenen Stärken bei den Auslenkungsstrecken $\pm 0,17 \mathrm{~mm}, \pm 0,34 \mathrm{~mm}$ und $\pm 0,51 \mathrm{~mm}$ 


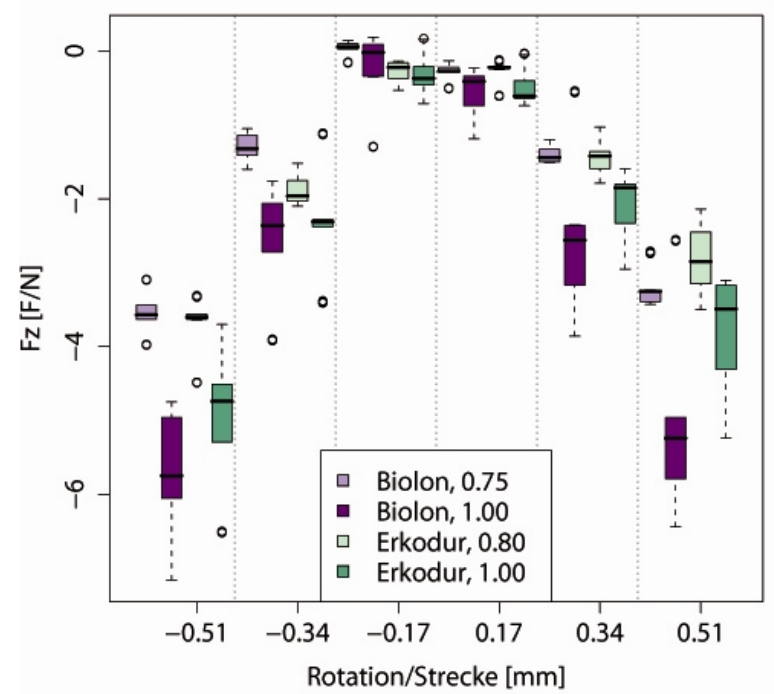

Abbildung 17 Box-Plots der intrusiven Kräfte der Materialien Biolon ${ }^{\circledR}$ und Erkodur ${ }^{\circledR}$ in ihren zwei verschiedenen Stärken bei den Auslenkungsstrecken $\pm 0,17 \mathrm{~mm}, \pm 0,34 \mathrm{~mm}$ und $\pm 0,51 \mathrm{~mm}$

\begin{tabular}{|c|c|c|c|c|c|c|}
\hline $\begin{array}{l}\text { Auslenkungs- } \\
\text { Strecke (mm) }\end{array}$ & Var. & Material & $\begin{array}{l}\text { Material- } \\
\text { Stärke } \\
(\mathbf{m m})\end{array}$ & $\mathbf{N}$ & $\begin{array}{l}\text { Mittelwert } \\
\pm \text { Standardfehler }\end{array}$ & $\begin{array}{l}\text { p } \\
\text { (Anova) }\end{array}$ \\
\hline$-0,51$ & $\mathrm{Tz}$ & $\begin{array}{l}\text { Biolon }^{(B)} \\
\left.\text { Biolon }^{(}\right)\end{array}$ & $\begin{array}{l}0,75 \\
1,0\end{array}$ & $\begin{array}{l}25 \\
25\end{array}$ & $\begin{array}{l}-49.9 \pm 0.7 \\
-71.8 \pm 2.5\end{array}$ & $<0.01$ \\
\hline$-0,34$ & $\mathrm{Tz}$ & $\begin{array}{l}\text { Biolon }^{\circledR} \\
\text { Biolon }^{\circledR}\end{array}$ & $\begin{array}{l}0,75 \\
1,0\end{array}$ & $\begin{array}{l}25 \\
25\end{array}$ & $\begin{array}{l}-28.8 \pm 0.3 \\
-44.5 \pm 1.7\end{array}$ & $<0.01$ \\
\hline$-0,17$ & $\mathrm{Tz}$ & $\begin{array}{l}\text { Biolon }^{\circledR} \\
\text { Biolon }^{\circledR}\end{array}$ & $\begin{array}{l}0,75 \\
1,0\end{array}$ & $\begin{array}{l}25 \\
25\end{array}$ & $\begin{array}{l}-7.26 \pm 0.2 \\
-9.78 \pm 0.7\end{array}$ & $<0.01$ \\
\hline 0,17 & $\mathrm{Tz}$ & $\begin{array}{l}\text { Biolon }^{(B)} \\
\left.\text { Biolon }^{(}\right)\end{array}$ & $\begin{array}{l}0,75 \\
1,0\end{array}$ & $\begin{array}{l}25 \\
25\end{array}$ & $\begin{array}{l}4.97 \pm 0.6 \\
12.9 \pm 1.0\end{array}$ & $<0.01$ \\
\hline 0,34 & $\mathrm{Tz}$ & $\begin{array}{l}\text { Biolon }^{\circledR} \\
\text { Biolon }^{\circledR}\end{array}$ & $\begin{array}{l}0,75 \\
1,0 \\
\end{array}$ & $\begin{array}{l}25 \\
25\end{array}$ & $\begin{array}{l}25.3 \pm 1.6 \\
35.3 \pm 2.3 \\
\end{array}$ & $<0.01$ \\
\hline 0,51 & $\mathrm{Tz}$ & $\begin{array}{l}\text { Biolon }{ }^{(B)} \\
\text { Biolon }^{\circledR}\end{array}$ & $\begin{array}{l}0,75 \\
1,0 \\
\end{array}$ & $\begin{array}{l}25 \\
25 \\
\end{array}$ & $\begin{array}{l}42.3 \pm 2.0 \\
56.7 \pm 2.0\end{array}$ & $<0.01$ \\
\hline$-0,51$ & $\mathrm{Tz}$ & $\begin{array}{l}\text { Erkodur }^{(B)} \\
\text { Erkodur }^{(\mathbb{R}}\end{array}$ & $\begin{array}{l}0,8 \\
1,0 \\
\end{array}$ & $\begin{array}{l}25 \\
25 \\
\end{array}$ & $\begin{array}{r}-40.6 \pm 1.1 \\
-53.3 \pm 2.1 \\
\end{array}$ & $<0.01$ \\
\hline$-0,34$ & $\mathrm{Tz}$ & $\begin{array}{l}\text { Erkodur }^{(\mathbb{R}} \\
\text { Erkodur }^{\circledR}\end{array}$ & $\begin{array}{l}0,8 \\
1,0 \\
\end{array}$ & $\begin{array}{l}25 \\
25 \\
\end{array}$ & $\begin{array}{r}-24.2 \pm 0.7 \\
-30.1 \pm 1.3 \\
\end{array}$ & $<0.01$ \\
\hline$-0,17$ & $\mathrm{Tz}$ & $\begin{array}{l}\text { Erkodur }^{(\mathbb{B}} \\
\text { Erkodur }^{\circledR}\end{array}$ & $\begin{array}{l}0,8 \\
1,0\end{array}$ & $\begin{array}{l}25 \\
25\end{array}$ & $\begin{array}{l}-6.1 \pm 0.7 \\
-7.3 \pm 0.9\end{array}$ & 0.06 \\
\hline 0,17 & $\mathrm{Tz}$ & $\begin{array}{l}\text { Erkodur }^{(\mathbb{R}} \\
\left.\text { Erkodur }^{(}\right)\end{array}$ & $\begin{array}{l}0,8 \\
1,0 \\
\end{array}$ & $\begin{array}{l}25 \\
25 \\
\end{array}$ & $\begin{array}{l}4.3 \pm 0.4 \\
8.2 \pm 1.0\end{array}$ & $<0.01$ \\
\hline 0,34 & $\mathrm{Tz}$ & $\begin{array}{l}\text { Erkodur }^{(B)} \\
\text { Erkodur }^{\circledR}\end{array}$ & $\begin{array}{l}0,8 \\
1,0\end{array}$ & $\begin{array}{l}25 \\
25\end{array}$ & $\begin{array}{l}18.2 \pm 0.9 \\
26.7 \pm 1.3\end{array}$ & $<0.01$ \\
\hline 0,51 & $\mathrm{Tz}$ & $\begin{array}{l}\text { Erkodur }^{(\mathbb{R}} \\
\text { Erkodur }^{\circledR}\end{array}$ & $\begin{array}{l}0,8 \\
1,0\end{array}$ & $\begin{array}{l}25 \\
25\end{array}$ & $\begin{array}{l}30.5 \pm 1.3 \\
42.3 \pm 1.7\end{array}$ & $<0.01$ \\
\hline
\end{tabular}

Tabelle 4 Tabellarische Darstellung der Ergebnisse der Varianzanalyse des Vergleichs der zwei verschiedenen Stärken von Biolon ${ }^{\circledR}$ bzw. Erkodur ${ }^{\circledR}$ bei den Auslenkungsstrecken $\pm 0,17 \mathrm{~mm}, \pm 0,34 \mathrm{~mm}$ und $\pm 0,51 \mathrm{~mm}$ für die Variabel $T z$ 


\begin{tabular}{|c|c|c|c|c|c|c|}
\hline $\begin{array}{l}\text { Auslenkungs- } \\
\text { Strecke (mm) }\end{array}$ & Var. & Material & $\begin{array}{l}\text { Material- } \\
\text { Stärke } \\
(\mathbf{m m})\end{array}$ & $\mathbf{N}$ & $\begin{array}{l}\text { 25-, 50- \& } \\
75 \%-Q u a n t i l\end{array}$ & $\begin{array}{l}\text { p } \\
\text { (Anova) }\end{array}$ \\
\hline$-0,51$ & $\mathrm{Fz}$ & $\begin{array}{l}\text { Biolon }^{\circledR} \\
\text { Biolon }^{\circledR}\end{array}$ & $\begin{array}{l}0,75 \\
1,0\end{array}$ & $\begin{array}{l}25 \\
25\end{array}$ & $\begin{array}{l}-3.6,-3.6,-3.4 \\
-6.0,-5.8,-5.0\end{array}$ & $<0.01$ \\
\hline$-0,34$ & $\mathrm{Fz}$ & $\begin{array}{l}\text { Biolon }^{(\mathbb{R}} \\
\text { Biolon }^{(\mathbb{R}}\end{array}$ & $\begin{array}{l}0,75 \\
1,0\end{array}$ & $\begin{array}{l}25 \\
25\end{array}$ & $\begin{array}{l}-1.4,-1.3,-1.1 \\
-2.7,-2.4,-2.1\end{array}$ & $<0.01$ \\
\hline$-0,17$ & $\mathrm{Fz}$ & $\begin{array}{l}\left.\text { Biolon }^{(}\right) \\
\left.\text {Biolon }^{(}\right)\end{array}$ & $\begin{array}{l}0,75 \\
1,0 \\
\end{array}$ & $\begin{array}{l}25 \\
25 \\
\end{array}$ & $\begin{array}{l}0.0,0.1,0.1 \\
-0.3,0.0,0.1\end{array}$ & 0.05 \\
\hline 0,17 & $\mathrm{Fz}$ & $\begin{array}{l}\left.\text { Biolon }^{(}\right) \\
\text {Biolon }^{(}\end{array}$ & $\begin{array}{l}0,75 \\
1,0\end{array}$ & $\begin{array}{l}25 \\
25\end{array}$ & $\begin{array}{l}-0.3,-0.3,-0.2 \\
-0.7,-0.4,-0.3\end{array}$ & $<0.01$ \\
\hline 0,34 & $\mathrm{Fz}$ & $\begin{array}{l}\text { Biolon }^{(B)} \\
\text { Biolon }^{\circledR}\end{array}$ & $\begin{array}{l}0,75 \\
1,0\end{array}$ & $\begin{array}{l}25 \\
25\end{array}$ & $\begin{array}{l}-1.5,-1.4,-1.3 \\
-3.2,-2.6,-2.4\end{array}$ & $<0.01$ \\
\hline 0,51 & $\mathrm{Fz}$ & $\begin{array}{l}\left.\text { Biolon }^{(}\right) \\
\text {Biolon }^{\circledR}\end{array}$ & $\begin{array}{l}0,75 \\
1,0\end{array}$ & $\begin{array}{l}25 \\
25\end{array}$ & $\begin{array}{l}-3.4,-3.2,-3.2 \\
-5.8,-5.2,-5.0\end{array}$ & $<0.01$ \\
\hline$-0,51$ & $\mathrm{Fz}$ & $\begin{array}{l}\text { Erkodur }^{(B)} \\
\text { Erkodur }^{(B)}\end{array}$ & $\begin{array}{l}0,8 \\
1,0\end{array}$ & $\begin{array}{l}25 \\
25\end{array}$ & $\begin{array}{l}-3.6,-3.6,-3.6 \\
-5.3,-4.7,-4.5\end{array}$ & $<0.01$ \\
\hline$-0,34$ & $\mathrm{Fz}$ & $\begin{array}{l}\text { Erkodur }^{(R)} \\
\text { Erkodur }^{(B)}\end{array}$ & $\begin{array}{l}0,8 \\
1,0\end{array}$ & $\begin{array}{l}25 \\
25\end{array}$ & $\begin{array}{l}-2.0,-2.0,-1.8 \\
-2.4,-2.3,-2.3\end{array}$ & $<0.01$ \\
\hline$-0,17$ & $\mathrm{Fz}$ & $\begin{array}{l}\left.\text { Erkodur }^{(}\right) \\
\left.\text {Erkodur }^{(}\right)\end{array}$ & $\begin{array}{l}0,8 \\
1,0\end{array}$ & $\begin{array}{l}25 \\
25\end{array}$ & $\begin{array}{l}-0.4,-0.2,-0.2 \\
-0.5,-0.4,-0.2\end{array}$ & $<0.01$ \\
\hline 0,17 & $\mathrm{Fz}$ & $\begin{array}{l}\text { Erkodur }^{(R)} \\
\left.\text { Erkodur }^{(}\right)\end{array}$ & $\begin{array}{l}0,8 \\
1,0 \\
\end{array}$ & $\begin{array}{l}25 \\
25 \\
\end{array}$ & $\begin{array}{l}-0.2,-0.2,-0.2 \\
-0.6,-0.6,-0.4\end{array}$ & $<0.01$ \\
\hline 0,34 & $\mathrm{Fz}$ & $\begin{array}{l}\text { Erkodur }^{(B)} \\
\text { Erkodur }^{(B)}\end{array}$ & $\begin{array}{l}0,8 \\
1,0\end{array}$ & $\begin{array}{l}25 \\
25\end{array}$ & $\begin{array}{l}-1.6,-1.4,-1.4 \\
-2.3,-1.9,-1.8\end{array}$ & $<0.01$ \\
\hline 0,17 & $\mathrm{Fz}$ & $\begin{array}{l}\text { Erkodur }^{(R)} \\
\left.\text { Erkodur }^{(}\right)\end{array}$ & $\begin{array}{l}0,8 \\
1,0\end{array}$ & $\begin{array}{l}25 \\
25 \\
\end{array}$ & $\begin{array}{l}-3.1,-2.9,-2.5 \\
-4.3,-3.5,-3.2\end{array}$ & $<0.01$ \\
\hline
\end{tabular}

Tabelle 5 Tabellarische Darstellung der Ergebnisse der Varianzanalyse des Vergleichs der zwei verschiedenen Stärken von Biolon ${ }^{\circledR}$ bzw. Erkodur ${ }^{\circledR}$ bei den Auslenkungsstrecken $\pm 0,17 \mathrm{~mm}, \pm 0,34 \mathrm{~mm}$ und $\pm 0,51 \mathrm{~mm}$ für die Variabel Fz

\subsection{Einfluss des Tiefziehverfahrens}

Erkodur $^{\circledR}$ in der Stärke 1,0 mm zeigte bei den Auslenkungsstrecken $\pm 0,17 \mathrm{~mm}, \pm 0,34 \mathrm{~mm}$ und $\pm 0,51 \mathrm{~mm}$ statistisch signifikant verschiedene Drehmomente zu Biolon ${ }^{\circledR}$ und Ideal Clear $^{\circledR}$ in der Stärke 1,0 mm (Tab. 6). Hierbei waren die produzierten Drehmomente von Erkodur ${ }^{\circledR}$ stets schwächer als die Momente von Biolon ${ }^{\circledR}$ oder Ideal Clear ${ }^{\circledR}$ (Abb. 18). Biolon ${ }^{\circledR}$ und Ideal Clear $^{\circledR}$ unterscheiden sich in Tz abgesehen von der Auslenkungsstrecke 0,51 mm $(p=0,18)$ und $-0,34 \mathrm{~mm}(\mathrm{p}=0,07)$ auch statistisch signifikant voneinander (Tabelle 6). Während Ideal Clear $^{\circledR}$ in den niedrigen Auslenkungsstrecken die höheren Momente produziert, ist Biolon ${ }^{\circledR}$ bei den hohen Auslenkungsstrecken das Material mit den größten rotativen Drehmomenten (Abb. 18).

Betrachtet man Tabelle 7, so zeigt sich, dass bei der Auslenkungsstrecke von $\pm 0,51 \mathrm{~mm}$ die intrusiven Kräfte der drei Materialien statistisch signifikant voneinander verschieden sind. Wie in Abbildung 19 ersichtlich, so erzeugen die Biolon ${ }^{\circledR}$-Schienen in diesem Bereich gegenüber den Schienen aus dem Material Erkodur ${ }^{\circledR}$ und Ideal Clear ${ }^{\circledR}$ die höchsten Kräfte. Bei $\pm 0,51 \mathrm{~mm}$ erzeugen im negativen Auslenkungsbereich die Erkodur ${ }^{\circledR}$-Schienen und im positiven Bereich die Ideal Clear ${ }^{\circledR}$-Schienen die zweithöchsten Kräfte (Abb. 19). Bei den Auslenkungsstrecken von $\pm 0,34 \mathrm{~mm}$ und $\pm 0,17 \mathrm{~mm}$ finden sich zwar auch statistisch signifikante Unterschiede (Tab. 7), jedoch zeigt sich in Abbildung 19, dass trotz signifikanten 
Differenzen keine eindeutige Hierarchie bezüglich der Stärke der produzierten Drehmomente unter den Materialien festzustellen ist.

\begin{tabular}{|c|c|c|c|}
\hline Auslenkungsstrecke (mm) & Var. & Material & P (Anova) \\
\hline$-0,51$ & $\mathrm{Tz}$ & $\begin{array}{l}\text { Biolon }^{\circledR} \text { vs. Erkodur }{ }^{\mathbb{R}} \\
\text { Biolon }^{\circledR} \text { vs. Ideal Clear }{ }^{\circledR} \\
\text { Erkodur }^{\mathbb{B}} \text { vs. Ideal Clear }\end{array}$ & $\begin{array}{l}<0.01 \\
<0.01 \\
<0.01\end{array}$ \\
\hline$-0,34$ & $\mathrm{Tz}$ & $\begin{array}{l}\text { Biolon }^{\mathbb{Q}} \text { vs. Erkodur } \\
\text { Biolon }^{\mathbb{B}} \text { vs. Ideal Clear } \\
\text { Erkodur }^{\mathbb{Q}}{ }^{\mathbb{Q}} \text { vs. Ideal Clear }\end{array}$ & $\begin{array}{l}<0.01 \\
0.07 \\
<0.01 \\
\end{array}$ \\
\hline$-0,17$ & $\mathrm{Tz}$ & $\begin{array}{l}\text { Biolon }^{\mathbb{R}} \text { vs. Erkodur } \\
\text { Biolon }^{\mathbb{R}} \text { vs. Ideal Clear } \\
\text { Erkodur }^{\mathbb{R}} \text { vs. Ideal Clear }^{\mathbb{R}}\end{array}$ & $\begin{array}{l}0.03 \\
<0.01 \\
<0.01\end{array}$ \\
\hline 0,17 & $\mathrm{Tz}$ & $\begin{array}{l}\text { Biolon }^{\circledR} \text { vs. Erkodur } \\
\text { Biolon }^{\circledR} \text { vs. Ideal Clear } \\
\text { Erkodur }^{\circledR} \text { vs. Ideal Clear }\end{array}$ & $\begin{array}{l}<0.01 \\
<0.01 \\
<0.01\end{array}$ \\
\hline 0,34 & $\mathrm{Tz}$ & $\begin{array}{l}\text { Biolon }^{\circledR} \text { vs. Erkodur } \\
\text { Biolon }^{\circledR} \text { vs. Ideal Clear } \\
\text { Erkodur }^{\circledR} \text { vs. Ideal Clear }\end{array}$ & $\begin{array}{l}<0.01 \\
0.03 \\
<0.01\end{array}$ \\
\hline 0,51 & $\mathrm{Tz}$ & $\begin{array}{l}\text { Biolon }^{\mathbb{Q}} \text { vs. Erkodur } \\
\text { Biolon }^{\mathbb{B}}{ }^{\mathbb{B}} \text { vs. Ideal Clear } \\
\text { Erkodur }^{\mathbb{Q}}{ }^{\mathbb{2}} \text { vs. Ideal Clear }\end{array}$ & $\begin{array}{l}<0.01 \\
0.18 \\
<0.01\end{array}$ \\
\hline
\end{tabular}

Tabelle 6 Tabellarische Darstellung der Ergebnisse der Varianzanalyse der drei Materialien Biolon ${ }^{\circledR}$, Erkodur ${ }^{\circledR}$ und Ideal Clear ${ }^{\circledR}$ in der Stärke 1,0 mm für die Variable Tz bei den Auslenkungsstrecken $\pm 0,17 \mathrm{~mm}, \pm 0,34 \mathrm{~mm}$ und $\pm 0,51 \mathrm{~mm}$

\begin{tabular}{|c|c|c|c|}
\hline Auslenkungsstrecke (mm) & Var. & Material & P (Anova) \\
\hline$-0,51$ & $\mathrm{Fz}$ & $\begin{array}{l}\text { Biolon }^{\circledR} \text { vs. Erkodur } \\
\text { Biolon }^{\circledR} \text { vs. Ideal Clear } \\
\text { Erkodur }^{\circledR} \text { vs. Ideal Clear }\end{array}$ & $\begin{array}{l}<0.01 \\
<0.01 \\
0.05\end{array}$ \\
\hline$-0,34$ & $\mathrm{Fz}$ & $\begin{array}{l}\text { Biolon }^{\circledR} \text { vs. Erkodur } \\
\text { Biolon }{ }^{\circledR} \text { vs. Ideal Clear } \\
\text { Erkodur }^{\circledR} \text { vs. Ideal Clear }\end{array}$ & $\begin{array}{l}0.38 \\
<0.01 \\
<0.01\end{array}$ \\
\hline$-0,17$ & $\mathrm{Fz}$ & $\begin{array}{l}\text { Biolon }^{\mathbb{B}} \text { vs. Erkodur } \\
\text { Biolon }^{\mathbb{B}}{ }^{\mathbb{2}} \text { vs. Ideal Clear } \\
\text { Erkodur }^{\mathbb{B}} \text { vs. Ideal Clear }\end{array}$ & $\begin{array}{l}0.03 \\
<0.01 \\
<0.01\end{array}$ \\
\hline 0,17 & $\mathrm{Fz}$ & $\begin{array}{l}\text { Biolon }^{\mathbb{Q}} \text { vs. Erkodur } \\
\text { Biolon }^{\circledR} \text { vs. Ideal Clear } \\
\text { Erkodur }^{\circledR} \text { vs. Ideal Clear }\end{array}$ & $\begin{array}{l}0.48 \\
<0.01 \\
<0.01\end{array}$ \\
\hline 0,34 & $\mathrm{Fz}$ & $\begin{array}{l}\text { Biolon }^{\circledR} \text { vs. Erkodur }{ }^{\circledR} \\
\text { Biolon }^{\circledR} \text { vs. Ideal Clear } \\
\text { Erkodur }^{\circledR} \text { vs. Ideal Clear }\end{array}$ & $\begin{array}{l}<0.01 \\
0.20 \\
<0.01\end{array}$ \\
\hline 0,51 & $\mathrm{Fz}$ & $\begin{array}{l}\text { Biolon }^{\mathbb{Q}} \text { vs. Erkodur } \\
\text { Biolon }^{\mathbb{B}} \text { vs. Ideal Clear } \\
\text { Erkodur }^{\mathbb{B}}{ }^{\mathbb{B}} \text { vs. Ideal Clear }\end{array}$ & $\begin{array}{l}<0.01 \\
<0.01 \\
<0.01\end{array}$ \\
\hline
\end{tabular}

Tabelle 7 Tabellarische Darstellung der Ergebnisse der Varianzanalyse der drei Materialien Biolon ${ }^{\circledR}$, Erkodur ${ }^{\circledR}$ und Ideal Clear ${ }^{\circledR}$ in der Stärke 1,0 mm für die Variable Fz bei den Auslenkungsstrecken $\pm 0,17 \mathrm{~mm}, \pm 0,34 \mathrm{~mm}$ und $\pm 0,51 \mathrm{~mm}$ 


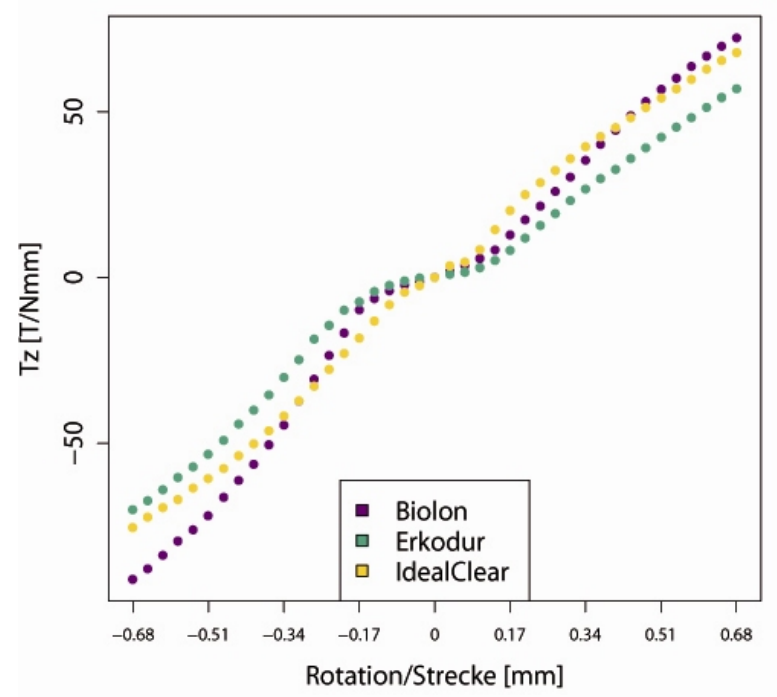

Abbildung 18 Graphische Darstellung der gemessenen durchschnittlichen rotativen Drehmomente (Tz) für die Materialien Biolon $^{\circledR}$, Erkodur ${ }^{\circledR}$ und Ideal Clear ${ }^{\circledR}$ in der Stärke 1,0 $\mathrm{mm}$ bei allen Messwerten die bei zunehmender Auslenkung des Zahnes erhoben wurden

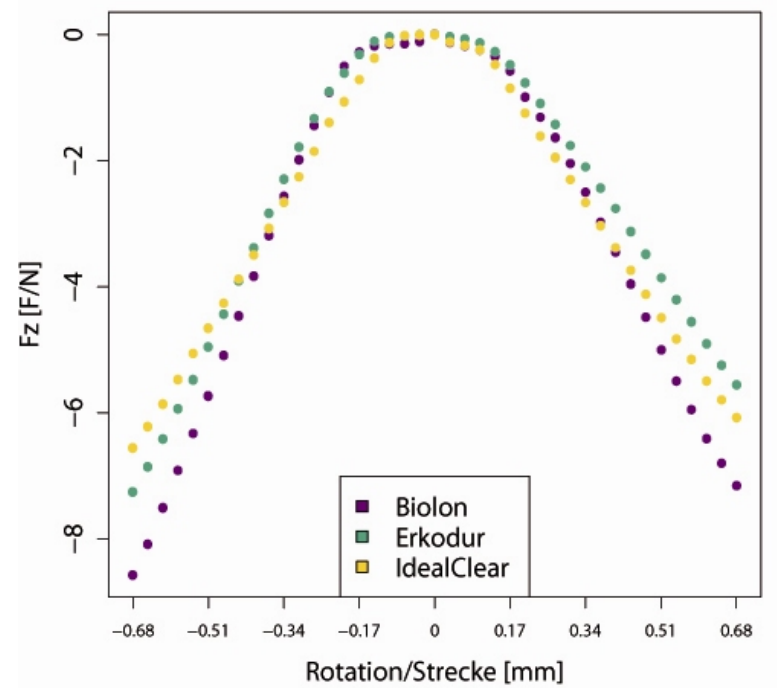

Abbildung 19 Graphische Darstellung der gemessenen durchschnittlichen intrusiven Kräfte (Fz) für die Materialien Biolon $^{\circledR}$, Erkodur ${ }^{\circledR}$ und Ideal Clear ${ }^{\circledR}$ in der Stärke 1,0 $\mathrm{mm}$ bei allen Messwerten die bei zunehmender Auslenkung des Zahnes erhoben wurden

\subsection{Einfluss des Schluckaktes}

Sowohl das rotative Drehmoment als auch die intrusive Kraft waren bei der Messreihe mit Gewicht statistisch signifikant höher (Tab. 8 und 9). Bei allen Auslenkungsstrecken lag der pWert diesbezüglich bei $<0,01$.

In Abbildung 20 und 21 sind die Ergebnisse für Tz bzw. Fz bei der Auslenkungsstrecke 0,34 $\mathrm{mm}$ als Boxplot materialabhängig dargestellt. 


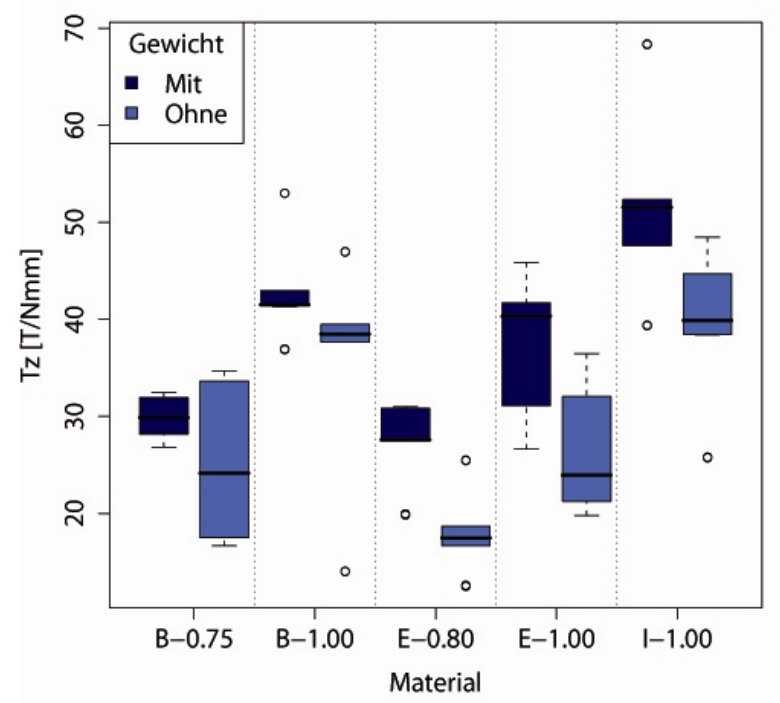

Abbildung 20 Gewichtsabhängige Veränderung des rotativen Drehmomentes (Tz) der verschiedenen Materialien bei einer Auslenkungsstrecke von 0,34 mm

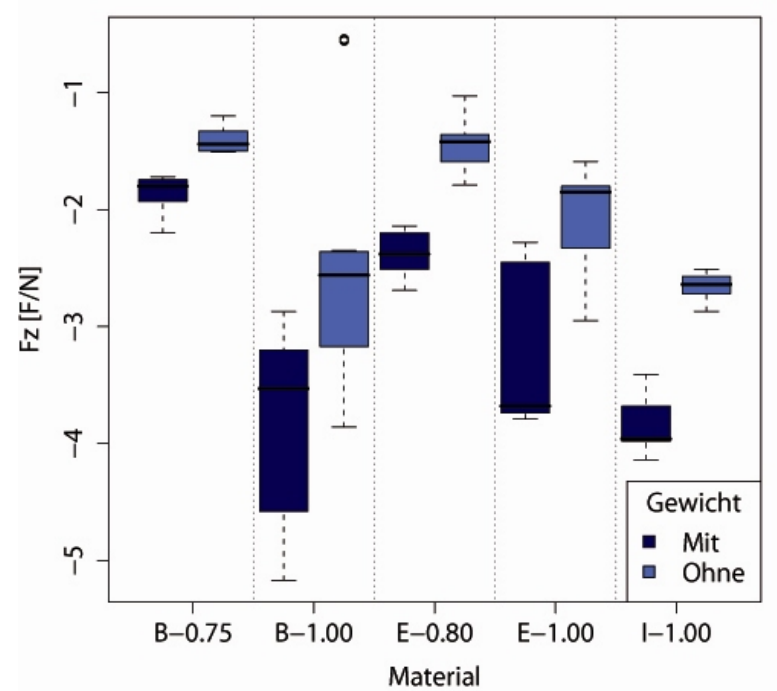

Abbildung 21 Gewichtsabhängige Veränderung der intrusiven Kraft (Fz) der verschiedenen Materialien bei einer Auslenkungsstrecke von 0,34 mm 


\begin{tabular}{|c|c|c|c|c|c|c|c|c|}
\hline Winkel & Strecke & Var. & $\mathbf{N}$ & Material & $\begin{array}{l}\text { Stärke } \\
\text { (mm) }\end{array}$ & Gewicht & $\begin{array}{l}\text { Mittelwert } \\
\pm \text { Standardfehler }\end{array}$ & $\begin{array}{l}\text { P } \\
\text { (Anova) }\end{array}$ \\
\hline-7.5 & $-0,51$ & $\mathrm{Tz}$ & $\begin{array}{l}25 \\
25 \\
25 \\
25 \\
25 \\
25 \\
25 \\
25 \\
25 \\
25\end{array}$ & $\begin{array}{l}\text { Biolon }^{\circledR} \\
\text { Biolon }^{\circledR} \\
\text { Biolon }^{\circledR} \\
\text { Biolon }^{\circledR} \\
\text { Erkodur }^{\circledR} \\
\text { Erkodur }^{\circledR} \\
\text { Erkodur }^{\circledR} \\
\text { Erkodur }^{\circledR} \\
\text { Ideal Clear }^{\circledR} \\
\text { Ideal Clear }^{\circledR}\end{array}$ & $\begin{array}{l}0,75 \mathrm{~mm} \\
0,75 \mathrm{~mm} \\
1,0 \mathrm{~mm} \\
1,0 \mathrm{~mm} \\
0,8 \mathrm{~mm} \\
0,8 \mathrm{~mm} \\
1,0 \mathrm{~mm} \\
1,0 \mathrm{~mm} \\
1,0 \mathrm{~mm} \\
1,0 \mathrm{~mm}\end{array}$ & $\begin{array}{l}\mathrm{o} \\
\mathrm{m} \\
\mathrm{o} \\
\mathrm{m} \\
\mathrm{o} \\
\mathrm{m} \\
\mathrm{o} \\
\mathrm{m} \\
\mathrm{o} \\
\mathrm{m}\end{array}$ & $\begin{array}{l}-49.9 \pm 0.7 \\
-57.3 \pm 1.3 \\
-71.8 \pm 2.5 \\
-86.8 \pm 1.1 \\
-40.6 \pm 1.1 \\
-57.6 \pm 1.2 \\
-53.3 \pm 2.1 \\
-72.3 \pm 1.9 \\
-60.6 \pm 2.2 \\
-84.9 \pm 1.9\end{array}$ & $\begin{array}{l}<0.01 \\
<0.01 \\
<0.01 \\
<0.01 \\
<0.01\end{array}$ \\
\hline-5.0 & $-0,34$ & $\mathrm{Tz}$ & $\begin{array}{l}25 \\
25 \\
25 \\
25 \\
25 \\
25 \\
25 \\
25 \\
25 \\
25\end{array}$ & $\begin{array}{l}\text { Biolon }^{(\mathbb{}} \\
\text { Biolon }^{\circledR} \\
\text { Biolon }^{\circledR} \\
\text { Biolon }^{\circledR} \\
\text { Erkodur }^{\circledR} \\
\text { Erkodur }^{\circledR} \\
\text { Erkodur }^{\circledR} \\
\text { Erkodur }^{\circledR} \\
\text { Ideal Clear }^{\circledR} \\
\text { Ideal Clear }^{\circledR}\end{array}$ & $\begin{array}{l}0,75 \mathrm{~mm} \\
0,75 \mathrm{~mm} \\
1,0 \mathrm{~mm} \\
1,0 \mathrm{~mm} \\
0,8 \mathrm{~mm} \\
0,8 \mathrm{~mm} \\
1,0 \mathrm{~mm} \\
1,0 \mathrm{~mm} \\
1,0 \mathrm{~mm} \\
1,0 \mathrm{~mm}\end{array}$ & $\begin{array}{l}\mathrm{o} \\
\mathrm{m} \\
\mathrm{o} \\
\mathrm{m} \\
\mathrm{o} \\
\mathrm{m} \\
\mathrm{o} \\
\mathrm{m} \\
\mathrm{o} \\
\mathrm{m}\end{array}$ & $\begin{aligned}-28.8 & \pm 0.3 \\
-32.1 & \pm 0.8 \\
-44.5 & \pm 1.7 \\
-50.8 & \pm 0.8 \\
-24.2 & \pm 0.7 \\
-35.4 & \pm 1.3 \\
-30.1 & \pm 1.3 \\
-42.5 & \pm 1.5 \\
-41.8 & \pm 1.8 \\
-59.9 & \pm 1.4\end{aligned}$ & $\begin{array}{l}<0.01 \\
<0.01 \\
<0.01 \\
<0.01 \\
<0.01\end{array}$ \\
\hline-2.5 & $-0,17$ & $\mathrm{Tz}$ & $\begin{array}{l}25 \\
25 \\
25 \\
25 \\
25 \\
25 \\
25 \\
25 \\
25 \\
25\end{array}$ & $\begin{array}{l}\text { Biolon }^{(\mathbb{R}} \\
\text { Biolon }^{\circledR} \\
\text { Biolon }^{\circledR} \\
\text { Biolon }^{\circledR} \\
\text { Erkodur }^{\circledR} \\
\text { Erkodur }^{\circledR} \\
\text { Erkodur }^{\circledR} \\
\text { Erkodur }^{\circledR} \\
\text { Ideal Clear }^{\circledR} \\
\text { Ideal Clear }^{\circledR}\end{array}$ & $\begin{array}{l}0,75 \mathrm{~mm} \\
0,75 \mathrm{~mm} \\
1,0 \mathrm{~mm} \\
1,0 \mathrm{~mm} \\
0,8 \mathrm{~mm} \\
0,8 \mathrm{~mm} \\
1,0 \mathrm{~mm} \\
1,0 \mathrm{~mm} \\
1,0 \mathrm{~mm} \\
1,0 \mathrm{~mm}\end{array}$ & $\begin{array}{l}\mathrm{o} \\
\mathrm{m} \\
\mathrm{o} \\
\mathrm{m} \\
\mathrm{o} \\
\mathrm{m} \\
\mathrm{o} \\
\mathrm{m} \\
\mathrm{o} \\
\mathrm{m}\end{array}$ & $\begin{array}{l}-7.3 \pm 0.2 \\
-9.8 \pm 0.3 \\
-9.8 \pm 0.7 \\
-11.7 \pm 0.5 \\
-6.1 \pm 0.7 \\
-10.3 \pm 1.3 \\
-7.3 \pm 0.8 \\
-11.6 \pm 1.0 \\
-18.3 \pm 1.2 \\
-27.9 \pm 1.2\end{array}$ & $\begin{array}{l}<0.01 \\
<0.01 \\
<0.01 \\
<0.01 \\
<0.01\end{array}$ \\
\hline 2.5 & 0,17 & $\mathrm{Tz}$ & $\begin{array}{l}25 \\
25 \\
25 \\
25 \\
25 \\
25 \\
25 \\
25 \\
25 \\
25\end{array}$ & $\begin{array}{l}\left.\text { Biolon }^{(}\right) \\
\text {Biolon }^{\circledR} \\
\text { Biolon }^{\circledR} \\
\text { Biolon }^{\circledR} \\
\text { Erkodur }^{\circledR} \\
\text { Erkodur }^{\circledR} \\
\text { Erkodur }^{\circledR} \\
\text { Erkodur }^{\circledR} \\
\text { Ideal Clear }^{\circledR} \\
\text { Ideal Clear }^{\circledR}\end{array}$ & $\begin{array}{l}0,75 \mathrm{~mm} \\
0,75 \mathrm{~mm} \\
1,0 \mathrm{~mm} \\
1,0 \mathrm{~mm} \\
0,8 \mathrm{~mm} \\
0,8 \mathrm{~mm} \\
1,0 \mathrm{~mm} \\
1,0 \mathrm{~mm} \\
1,0 \mathrm{~mm} \\
1,0 \mathrm{~mm}\end{array}$ & $\begin{array}{l}\mathrm{o} \\
\mathrm{m} \\
\mathrm{o} \\
\mathrm{m} \\
\mathrm{o} \\
\mathrm{m} \\
\mathrm{o} \\
\mathrm{m} \\
\mathrm{o} \\
\mathrm{m}\end{array}$ & $\begin{array}{l}5.0 \pm 0.9 \\
7.8 \pm 0.1 \\
12.8 \pm 1.0 \\
14.7 \pm 0.8 \\
4.3 \pm 0.5 \\
9.2 \pm 0.6 \\
8.2 \pm 1.0 \\
13.3 \pm 1.4 \\
20.2 \pm 1.3 \\
25.5 \pm 1.3\end{array}$ & $\begin{array}{l}<0.01 \\
<0.01 \\
<0.01 \\
<0.01 \\
<0.01\end{array}$ \\
\hline 5.0 & 0,34 & $\mathrm{Tz}$ & $\begin{array}{l}25 \\
25 \\
25 \\
25 \\
25 \\
25 \\
25 \\
25 \\
25 \\
25\end{array}$ & $\begin{array}{l}\text { Biolon }^{\circledR} \\
\text { Biolon }^{\circledR} \\
\text { Biolon } \\
\text { Biolon }^{\circledR} \\
\text { Erkodur }^{\circledR} \\
\text { Erkodur }^{\circledR} \\
\text { Erkodur }^{\circledR} \\
\text { Erkodur }^{\circledR} \\
\text { Ideal Clear }^{\circledR} \\
\text { Ideal Clear }^{\circledR}\end{array}$ & $\begin{array}{l}0,75 \mathrm{~mm} \\
0,75 \mathrm{~mm} \\
1,0 \mathrm{~mm} \\
1,0 \mathrm{~mm} \\
0,8 \mathrm{~mm} \\
0,8 \mathrm{~mm} \\
1,0 \mathrm{~mm} \\
1,0 \mathrm{~mm} \\
1,0 \mathrm{~mm} \\
1,0 \mathrm{~mm}\end{array}$ & $\begin{array}{l}\mathrm{o} \\
\mathrm{m} \\
\mathrm{o} \\
\mathrm{m} \\
\mathrm{o} \\
\mathrm{m} \\
\mathrm{o} \\
\mathrm{m} \\
\mathrm{o} \\
\mathrm{m}\end{array}$ & $\begin{array}{l}25.3 \pm 1.6 \\
29.9 \pm 0.4 \\
35.3 \pm 2.3 \\
43.1 \pm 1.1 \\
18.2 \pm 0.9 \\
27.4 \pm 0.8 \\
26.7 \pm 1.3 \\
37.1 \pm 1.5 \\
39.4 \pm 1.6 \\
51.9 \pm 1.9\end{array}$ & $\begin{array}{l}<0.01 \\
<0.01 \\
<0.01 \\
<0.01 \\
<0.01\end{array}$ \\
\hline 7.5 & 0,51 & $\mathrm{Tz}$ & $\begin{array}{l}25 \\
25 \\
25 \\
25 \\
25 \\
25 \\
25 \\
25 \\
25 \\
25\end{array}$ & $\begin{array}{l}\text { Biolon }^{\circledR} \\
\text { Biolon }^{\circledR} \\
\text { Biolon } \\
\text { Biolon }^{\circledR} \\
\text { Erkodur }^{\circledR} \\
\text { Erkodur }^{\circledR} \\
\text { Erkodur }^{\circledR} \\
\text { Erkodur }^{\circledR} \\
\text { Ideal Clear }^{\circledR} \\
\text { Ideal Clear }^{\circledR}\end{array}$ & $\begin{array}{l}0,75 \mathrm{~mm} \\
0,75 \mathrm{~mm} \\
1,0 \mathrm{~mm} \\
1,0 \mathrm{~mm} \\
0,8 \mathrm{~mm} \\
0,8 \mathrm{~mm} \\
1,0 \mathrm{~mm} \\
1,0 \mathrm{~mm} \\
1,0 \mathrm{~mm} \\
1,0 \mathrm{~mm}\end{array}$ & $\begin{array}{l}\mathrm{o} \\
\mathrm{m} \\
\mathrm{o} \\
\mathrm{m} \\
\mathrm{o} \\
\mathrm{m} \\
\mathrm{o} \\
\mathrm{m} \\
\mathrm{o} \\
\mathrm{m}\end{array}$ & $\begin{array}{l}42.3 \pm 1.9 \\
49.8 \pm 0.6 \\
56.7 \pm 2.0 \\
66.9 \pm 1.3 \\
30.5 \pm 1.3 \\
45.0 \pm 1.0 \\
42.3 \pm 1.7 \\
60.2 \pm 1.5 \\
54.1 \pm 1.8 \\
73.0 \pm 2.2\end{array}$ & $\begin{array}{l}<0.01 \\
<0.01 \\
<0.01 \\
<0.01 \\
<0.01\end{array}$ \\
\hline
\end{tabular}

Tabelle 8 Darstellung der Ergebnisse der Varianzanalyse für die Gegenüberstellung mit/ohne Gewicht der Materialien Biolon $^{\circledR}$ 1,0mm, Biolon ${ }^{\circledR}$ 0,75mm, Erkodur ${ }^{\circledR}$ 1,0mm, Erkodur ${ }^{\circledR}$ 0,8 $\mathrm{mm}^{\text {und Ideal Clear }}{ }^{\circledR}$ bei den Auslenkungsstrecken $\pm 0,17 \mathrm{~mm}, \pm 0,34 \mathrm{~mm}$ und $\pm 0,51 \mathrm{~mm}$ für die Variable $T \mathrm{z}$ 


\begin{tabular}{|c|c|c|c|c|c|c|c|c|}
\hline Winkel & Strecke & Var. & $\mathbf{N}$ & Material & $\begin{array}{l}\text { Stärke } \\
(\mathrm{mm})\end{array}$ & Gewicht & $\begin{array}{l}25-, \quad 50-\quad \& \\
75 \%-Q u a n t i l\end{array}$ & $\begin{array}{l}\mathbf{P} \\
\text { (Anova) }\end{array}$ \\
\hline-7.5 & $-0,51$ & $\mathrm{Fz}$ & $\begin{array}{l}25 \\
25 \\
25 \\
25 \\
25 \\
25 \\
25 \\
25 \\
25 \\
25\end{array}$ & $\begin{array}{l}\text { Biolon }^{\circledR} \\
\text { Biolon }^{\circledR} \\
\text { Biolon } \\
{ }^{\circledR} \\
\text { Biolon } \\
\text { Erkodur }^{\circledR} \\
\text { Erkodur }^{\circledR} \\
\text { Erkodur }^{\circledR} \\
\text { Erkodur }^{\circledR} \\
\text { Ideal Clear }^{\circledR} \\
\text { Ideal Clear }^{\circledR}\end{array}$ & $\begin{array}{l}0,75 \mathrm{~mm} \\
0,75 \mathrm{~mm} \\
1,0 \mathrm{~mm} \\
1,0 \mathrm{~mm} \\
0,8 \mathrm{~mm} \\
0,8 \mathrm{~mm} \\
1,0 \mathrm{~mm} \\
1,0 \mathrm{~mm} \\
1,0 \mathrm{~mm} \\
1,0 \mathrm{~mm}\end{array}$ & $\begin{array}{l}\mathrm{o} \\
\mathrm{m} \\
\mathrm{o} \\
\mathrm{m} \\
\mathrm{o} \\
\mathrm{m} \\
\mathrm{o} \\
\mathrm{m} \\
\mathrm{o} \\
\mathrm{m}\end{array}$ & $\begin{array}{l}-3.6,-3.6,-3.4 \\
-4.7,-4.5,-4.2 \\
-6.0,-5.8,-5.0 \\
-7.5,-6.9,-6.4 \\
-3.6,-3.6,-3.6 \\
-5.6,-5.3,-5.2 \\
-5.3,-4.7,-4.5 \\
-7.4,-6.6,-6.0 \\
-4.6,-4.6,-4.5 \\
-7.8,-7.7,-7.6\end{array}$ & $\begin{array}{l}<0.01 \\
<0.01 \\
<0.01 \\
<0.01 \\
<0.01\end{array}$ \\
\hline-5.0 & $-0,34$ & $\mathrm{Fz}$ & $\begin{array}{l}25 \\
25 \\
25 \\
25 \\
25 \\
25 \\
25 \\
25 \\
25 \\
25\end{array}$ & $\begin{array}{l}\text { Biolon }^{\circledR} \\
\text { Biolon }^{\circledR} \\
\text { Biolon }^{\circledR} \\
\text { Biolon }^{\circledR} \\
\text { Erkodur }^{\circledR} \\
\text { Erkodur }^{\circledR} \\
\text { Erkodur }^{\circledR} \\
\text { Erkodur }^{\circledR} \\
\text { Ideal Clear }^{\circledR} \\
\text { Ideal Clear }^{\circledR}\end{array}$ & $\begin{array}{l}0,75 \mathrm{~mm} \\
0,75 \mathrm{~mm} \\
1,0 \mathrm{~mm} \\
1,0 \mathrm{~mm} \\
0,8 \mathrm{~mm} \\
0,8 \mathrm{~mm} \\
1,0 \mathrm{~mm} \\
1,0 \mathrm{~mm} \\
1,0 \mathrm{~mm} \\
1,0 \mathrm{~mm}\end{array}$ & $\begin{array}{l}\mathrm{o} \\
\mathrm{m} \\
\mathrm{o} \\
\mathrm{m} \\
\mathrm{o} \\
\mathrm{m} \\
\mathrm{o} \\
\mathrm{m} \\
\mathrm{o} \\
\mathrm{m}\end{array}$ & $\begin{array}{l}-1.4,-1.3,-1.1 \\
-2.1,-2.0,-1.9 \\
-2.7,-2.4,-2.1 \\
-3.6,-3.2,-2.8 \\
-2.0,-2.0,-1.8 \\
-3.2,-2.7,-2.6 \\
-2.4,-2.3,-2.3 \\
-4.4,-3.4,-2.9 \\
-2.8,-2.6,-2.5 \\
-5.4,-5.0,-5.0\end{array}$ & $\begin{array}{l}<0.01 \\
<0.01 \\
<0.01 \\
<0.01 \\
<0.01\end{array}$ \\
\hline-2.5 & $-0,17$ & $\mathrm{Fz}$ & $\begin{array}{l}25 \\
25 \\
25 \\
25 \\
25 \\
25 \\
25 \\
25 \\
25 \\
25 \\
\end{array}$ & $\begin{array}{l}\text { Biolon }^{(\circledR)} \\
\text { Biolon }^{\circledR} \\
\text { Biolon } \\
{ }^{\circledR} \\
\text { Biolon } \\
\text { Erkodur }^{\circledR} \\
\text { Erkodur }^{\circledR} \\
\text { Erkodur }^{\circledR} \\
\text { Erkodur }^{\circledR} \\
\text { Ideal Clear }^{\circledR} \\
\text { Ideal Clear }^{\circledR}\end{array}$ & $\begin{array}{l}0,75 \mathrm{~mm} \\
0,75 \mathrm{~mm} \\
1,0 \mathrm{~mm} \\
1,0 \mathrm{~mm} \\
0,8 \mathrm{~mm} \\
0,8 \mathrm{~mm} \\
1,0 \mathrm{~mm} \\
1,0 \mathrm{~mm} \\
1,0 \mathrm{~mm} \\
1,0 \mathrm{~mm}\end{array}$ & $\begin{array}{l}\mathrm{o} \\
\mathrm{m} \\
\mathrm{o} \\
\mathrm{m} \\
\mathrm{o} \\
\mathrm{m} \\
\mathrm{o} \\
\mathrm{m} \\
\mathrm{o} \\
\mathrm{m}\end{array}$ & $\begin{array}{l}0.0,0.1,0.1 \\
-0.2,-0.2,-0.2 \\
-0.3,-0.0,0.1 \\
-0.6,-0.2,-0.1 \\
-0.4,-0.2,-0.2 \\
-0.9,-0.7,-0.3 \\
-0.5,-0.4,-0.2 \\
-1.2,-0.6,-0.2 \\
-0.8,-0.5,-0.5 \\
-2.7,-2.5,-1.8\end{array}$ & $\begin{array}{l}<0.01 \\
<0.01 \\
<0.01 \\
<0.01 \\
<0.01\end{array}$ \\
\hline 2.5 & 0,17 & $\mathrm{Fz}$ & $\begin{array}{l}25 \\
25 \\
25 \\
25 \\
25 \\
25 \\
25 \\
25 \\
25 \\
25\end{array}$ & $\begin{array}{l}\text { Biolon }^{\circledR} \\
\text { Biolon }^{\circledR} \\
\text { Biolon }^{\circledR} \\
\text { Biolon }^{\circledR} \\
\text { Erkodur }^{\circledR} \\
\text { Erkodur }^{\circledR} \\
\text { Erkodur }^{\circledR} \\
\text { Erkodur }^{\circledR} \\
\text { Ideal Clear }^{\circledR} \\
\text { Ideal Clear }^{\circledR}\end{array}$ & $\begin{array}{l}0,75 \mathrm{~mm} \\
0,75 \mathrm{~mm} \\
1,0 \mathrm{~mm} \\
1,0 \mathrm{~mm} \\
0,8 \mathrm{~mm} \\
0,8 \mathrm{~mm} \\
1,0 \mathrm{~mm} \\
1,0 \mathrm{~mm} \\
1,0 \mathrm{~mm} \\
1,0 \mathrm{~mm}\end{array}$ & $\begin{array}{l}\mathrm{o} \\
\mathrm{m} \\
\mathrm{o} \\
\mathrm{m} \\
\mathrm{o} \\
\mathrm{m} \\
\mathrm{o} \\
\mathrm{m} \\
\mathrm{o} \\
\mathrm{m}\end{array}$ & $\begin{array}{l}-0.3,-0.3,-0.2 \\
-0.3,-0.2,-0.2 \\
-0.7,-0.4,-0.3 \\
-1.3,-0.9,-0.7 \\
-0.2,-0.2,-0.2 \\
-0.8,-0.6,-0.6 \\
-0.6,-0.6,-0.4 \\
-1.2,-1.2,-0.3 \\
-0.9,-0.8,-0.8 \\
-1.5,-1.3,-1.1\end{array}$ & $\begin{array}{l}0.46 \\
<0.01 \\
<0.01 \\
<0.01 \\
<0.01\end{array}$ \\
\hline 5.0 & 0,34 & $\mathrm{Fz}$ & $\begin{array}{l}25 \\
25 \\
25 \\
25 \\
25 \\
25 \\
25 \\
25 \\
25 \\
25 \\
\end{array}$ & $\begin{array}{l}\text { Biolon }^{\circledR} \\
\text { Biolon }^{\circledR} \\
\text { Biolon }^{\circledR} \\
\text { Biolon } \\
\text { Erkodur }^{\circledR} \\
\text { Erkodur }^{\circledR} \\
\text { Erkodur }^{\circledR} \\
\text { Erkodur }^{\circledR} \\
\text { Ideal Clear }^{\circledR} \\
\text { Ideal Clear }^{\circledR} \\
\end{array}$ & $\begin{array}{l}0,75 \mathrm{~mm} \\
0,75 \mathrm{~mm} \\
1,0 \mathrm{~mm} \\
1,0 \mathrm{~mm} \\
0,8 \mathrm{~mm} \\
0,8 \mathrm{~mm} \\
1,0 \mathrm{~mm} \\
1,0 \mathrm{~mm} \\
1,0 \mathrm{~mm} \\
1,0 \mathrm{~mm} \\
\end{array}$ & $\begin{array}{l}\mathrm{o} \\
\mathrm{m} \\
\mathrm{o} \\
\mathrm{m} \\
\mathrm{o} \\
\mathrm{m} \\
\mathrm{o} \\
\mathrm{m} \\
\mathrm{o} \\
\mathrm{m}\end{array}$ & $\begin{array}{l}-1.5,-1.4,-1.3 \\
-1.9,-1.8,-1.8 \\
-3.2,-2.6,-2.4 \\
-4.6,-3.5,-3.2 \\
-1.6,-1.4,-1.4 \\
-2.5,-2.4,-2.2 \\
-2.3,-1.8,-1.8 \\
-3.7,-3.7,-2.4 \\
-2.7,-2.6,-2.6 \\
-4.0,-4.0,-3.7 \\
\end{array}$ & $\begin{array}{l}<0.01 \\
<0.01 \\
<0.01 \\
<0.01 \\
<0.01\end{array}$ \\
\hline 7.5 & 0,51 & $\mathrm{Fz}$ & $\begin{array}{l}25 \\
25 \\
25 \\
25 \\
25 \\
25 \\
25 \\
25 \\
25 \\
25\end{array}$ & $\begin{array}{l}\text { Biolon }^{\circledR} \\
\text { Biolon }^{\circledR} \\
\text { Biolon } \\
\text { Biolon }^{\circledR} \\
\text { Erkodur }^{\circledR} \\
\text { Erkodur }^{\circledR} \\
\text { Erkodur }^{\circledR} \\
\text { Erkodur }^{\circledR} \\
\text { Ideal Clear }^{\circledR} \\
\text { Ideal Clear }^{\circledR}\end{array}$ & $\begin{array}{l}0,75 \mathrm{~mm} \\
0,75 \mathrm{~mm} \\
1,0 \mathrm{~mm} \\
1,0 \mathrm{~mm} \\
0,8 \mathrm{~mm} \\
0,8 \mathrm{~mm} \\
1,0 \mathrm{~mm} \\
1,0 \mathrm{~mm} \\
1,0 \mathrm{~mm} \\
1,0 \mathrm{~mm}\end{array}$ & $\begin{array}{l}\mathrm{o} \\
\mathrm{m} \\
\mathrm{o} \\
\mathrm{m} \\
\mathrm{o} \\
\mathrm{m} \\
\mathrm{o} \\
\mathrm{m} \\
\mathrm{o} \\
\mathrm{m}\end{array}$ & $\begin{array}{l}-3.4,-3.2,-3.2 \\
-4.3,-4.3,-3.8 \\
-5.8,-5.2,-5.0 \\
-8.0,-6.8,-6.1 \\
-3.1,-2.8,-2.4 \\
-4.5,-4.5,-4.2 \\
-4.3,-3.5,-3.2 \\
-6.7,-6.3,-5.0 \\
-4.6,-4.4,-4.4 \\
-6.3,-6.2,-6.2\end{array}$ & $\begin{array}{l}<0.01 \\
<0.01 \\
<0.01 \\
<0.01 \\
<0.01\end{array}$ \\
\hline
\end{tabular}

Tabelle 9 Darstellung der Ergebnisse der Varianzanalyse für die Gegenüberstellung mit/ohne Gewicht der Materialien Biolon $^{\circledR}$ 1,0mm, Biolon ${ }^{\circledR}$ 0,75mm, Erkodur ${ }^{\circledR}$ 1,0mm, Erkodur ${ }^{\circledR}$ 0,8 $\mathrm{mm}^{\text {und Ideal Clear }}{ }^{\circledR}$ bei den Auslenkungsstrecken $\pm 0,17 \mathrm{~mm}, \pm 0,34 \mathrm{~mm}$ und $\pm 0,51 \mathrm{~mm}$ für die Variable $\mathrm{Fz}$ 


\subsection{Einfluss der Alterungssimulation}

Es konnte eindeutig gezeigt werden, dass eine simulierte Alterung zu einer statistisch signifikanten Minderung der intrusiven Kräfte und rotativen Drehmomente führt (Tab. 10 und 11). Lediglich das Material Biolon ${ }^{\circledR}$ in der Stärke 1,0 mm war mit einem p-Wert von 0,06 für die Variable Fz bei der Gegenüberstellung vor vs. nach Alterung nicht im statistisch signifikanten Bereich. Die Abbildungen 22 und 23 veranschaulichen die Ergebnisse beispielhaft für alle Materialien bei der Auslenkungsstrecke -0,34 mm.

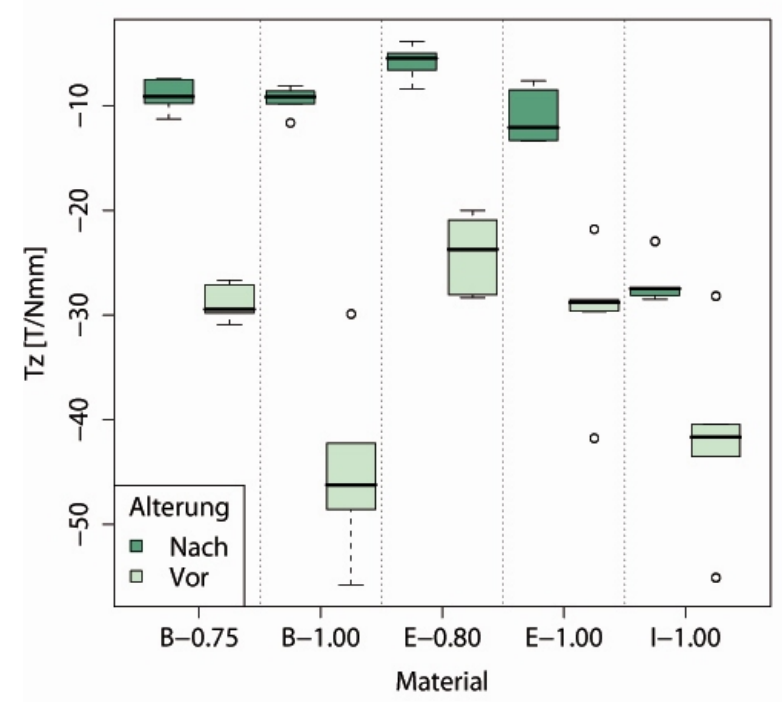

Abbildung 22 Rotative Drehmomente der verschiedenen Materialien vor und nach Alterung bei einer Auslenkungsstrecke von $-0,34 \mathrm{~mm}$

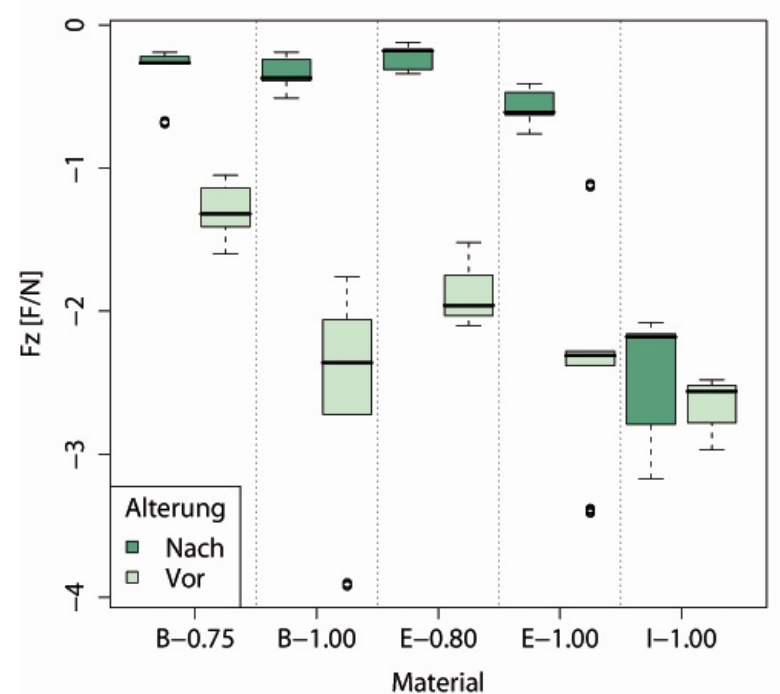

Abbildung 23 Intrusive Kräfte der verschiedenen Materialien vor und nach der Alterung bei einer Auslenkungsstrecke von $-0,34 \mathrm{~mm}$ 


\begin{tabular}{|c|c|c|c|c|c|c|c|c|}
\hline Winkel & Strecke & Var. & $\mathbf{N}$ & Material & $\begin{array}{l}\text { Stärke } \\
(\mathbf{m m})\end{array}$ & $\begin{array}{l}\text { Alte } \\
\text { rung }\end{array}$ & $\begin{array}{l}\text { Mittelwert } \\
\pm \text { Standardfehler }\end{array}$ & P (Anova) \\
\hline-7.5 & $-0,51$ & $\mathrm{Tz}$ & $\begin{array}{l}25 \\
25 \\
25 \\
25 \\
25 \\
25 \\
25 \\
25 \\
25 \\
25 \\
\end{array}$ & $\begin{array}{l}\text { Biolon }^{\circledR} \\
\text { Biolon }^{\circledR} \\
\text { Biolon }^{\circledR} \\
\text { Biolon }^{\circledR} \\
\text { Erkodur }^{\circledR} \\
\text { Erkodur }^{\circledR} \\
\text { Erkodur }^{\circledR} \\
\text { Erkodur }^{\circledR} \\
\text { Ideal Clear }^{\circledR} \\
\text { Ideal Clear }^{\circledR} \\
\end{array}$ & $\begin{array}{l}0,75 \mathrm{~mm} \\
0,75 \mathrm{~mm} \\
1,0 \mathrm{~mm} \\
1,0 \mathrm{~mm} \\
0,8 \mathrm{~mm} \\
0,8 \mathrm{~mm} \\
1,0 \mathrm{~mm} \\
1,0 \mathrm{~mm} \\
1,0 \mathrm{~mm} \\
1,0 \mathrm{~mm} \\
\end{array}$ & $\begin{array}{l}\mathrm{v} \\
\mathrm{n} \\
\mathrm{v} \\
\mathrm{n} \\
\mathrm{v} \\
\mathrm{n} \\
\mathrm{v} \\
\mathrm{n} \\
\mathrm{v} \\
\mathrm{n}\end{array}$ & $\begin{array}{l}-49.9 \pm 0.7 \\
-15.6 \pm 0.4 \\
-71.8 \pm 2.5 \\
-18.4 \pm 0.4 \\
-40.6 \pm 1.1 \\
-15.9 \pm 0.4 \\
-53.3 \pm 2.1 \\
-26.0 \pm 0.7 \\
-60.6 \pm 2.2 \\
-41.5 \pm 0.6\end{array}$ & $\begin{array}{l}<0.01 \\
<0.01 \\
<0.01 \\
<0.01 \\
<0.01\end{array}$ \\
\hline-5.0 & $-0,34$ & $\mathrm{Tz}$ & $\begin{array}{l}25 \\
25 \\
25 \\
25 \\
25 \\
25 \\
25 \\
25 \\
25 \\
25 \\
\end{array}$ & $\begin{array}{l}\text { Biolon }^{\circledR} \\
\text { Biolon }^{\circledR} \\
\text { Biolon } \\
\text { Biolon }^{\circledR} \\
\text { Erkodur }^{\circledR} \\
\text { Erkodur }^{\circledR} \\
\text { Erkodur }^{\circledR} \\
\text { Erkodur }^{\circledR} \\
\text { Ideal Clear }^{\circledR} \\
\text { Ideal Clear }^{\circledR} \\
\end{array}$ & $\begin{array}{l}0,75 \mathrm{~mm} \\
0,75 \mathrm{~mm} \\
1,0 \mathrm{~mm} \\
1,0 \mathrm{~mm} \\
0,8 \mathrm{~mm} \\
0,8 \mathrm{~mm} \\
1,0 \mathrm{~mm} \\
1,0 \mathrm{~mm} \\
1,0 \mathrm{~mm} \\
1,0 \mathrm{~mm} \\
\end{array}$ & $\begin{array}{l}\mathrm{v} \\
\mathrm{n} \\
\mathrm{v} \\
\mathrm{n} \\
\mathrm{v} \\
\mathrm{n} \\
\mathrm{v} \\
\mathrm{n} \\
\mathrm{v} \\
\mathrm{n} \\
\end{array}$ & $\begin{array}{l}-28.8 \pm 0.3 \\
-9.0 \pm 0.3 \\
-44.5 \pm 1.7 \\
-9.5 \pm 0.2 \\
-24.2 \pm 0.7 \\
-5.8 \pm 0.3 \\
-30.1 \pm 1.3 \\
-11.0 \pm 0.5 \\
-41.8 \pm 1.8 \\
-26.9 \pm 0.4 \\
\end{array}$ & $\begin{array}{l}<0.01 \\
<0.01 \\
<0.01 \\
<0.01 \\
<0.01\end{array}$ \\
\hline-2.5 & $-0,17$ & $\mathrm{Tz}$ & $\begin{array}{l}25 \\
25 \\
25 \\
25 \\
25 \\
25 \\
25 \\
25 \\
25 \\
25 \\
\end{array}$ & $\begin{array}{l}\text { Biolon }^{\circledR} \\
\text { Biolon }^{\circledR} \\
\text { Biolon }^{\circledR} \\
\text { Biolon }^{\circledR} \\
\text { Erkodur }^{(B)} \\
\text { Erkodur }^{\circledR} \\
\text { Erkodur }^{(B)} \\
\text { Erkodur }^{\circledR} \\
\left.\text { Ideal Clear }^{(}\right) \\
\text {Ideal Clear }^{(}\end{array}$ & $\begin{array}{l}0,75 \mathrm{~mm} \\
0,75 \mathrm{~mm} \\
1,0 \mathrm{~mm} \\
1,0 \mathrm{~mm} \\
0,8 \mathrm{~mm} \\
0,8 \mathrm{~mm} \\
1,0 \mathrm{~mm} \\
1,0 \mathrm{~mm} \\
1,0 \mathrm{~mm} \\
1,0 \mathrm{~mm}\end{array}$ & $\begin{array}{l}\mathrm{v} \\
\mathrm{n} \\
\mathrm{v} \\
\mathrm{n} \\
\mathrm{v} \\
\mathrm{n} \\
\mathrm{v} \\
\mathrm{n} \\
\mathrm{v} \\
\mathrm{n}\end{array}$ & $\begin{array}{l}-7.3 \pm 0.2 \\
-5.0 \pm 0.3 \\
-9.8 \pm 0.67 \\
-4.9 \pm 0.10 \\
-6.1 \pm 0.7 \\
-2.5 \pm 0.3 \\
-7.3 \pm 0.85 \\
-4.1 \pm 0.34 \\
-18.3 \pm 1.24 \\
-9.2 \pm 0.31\end{array}$ & $\begin{array}{l}<0.01 \\
<0.01 \\
<0.01 \\
<0.01 \\
<0.01\end{array}$ \\
\hline
\end{tabular}

Tabelle 10 Darstellung der Ergebnisse der Varianzanalyse für die Gegenüberstellung vor/nach Alterung der Materialien Biolon ${ }^{\circledR}$ 1,0mm, Biolon ${ }^{\circledR}$ 0,75mm, Erkodur ${ }^{\circledR}$ 1,0mm, Erkodur ${ }^{\circledR}$ 0,8 mm und Ideal Clear ${ }^{\circledR}$ bei den Auslenkungsstrecken -0,17 mm, -0,34 mm und -0,51 mm für die Variable Fz

\begin{tabular}{|c|c|c|c|c|c|c|c|c|}
\hline Winkel & Strecke & Var. & $\mathbf{N}$ & Material & $\begin{array}{l}\text { Stärke } \\
(\mathbf{m m})\end{array}$ & $\begin{array}{l}\text { Alte } \\
\text { rung }\end{array}$ & 25-, 50- \& 75\%-Quantil & P (Anova) \\
\hline-7.5 & $-0,51$ & $\mathrm{Fz}$ & $\begin{array}{l}25 \\
25 \\
25 \\
25 \\
25 \\
25 \\
25 \\
25 \\
25 \\
25\end{array}$ & $\begin{array}{l}\text { Biolon }^{\circledR} \\
\text { Biolon }^{\circledR} \\
\text { Biolon }^{\circledR} \\
\text { Biolon }^{\circledR} \\
\text { Erkodur }^{\circledR} \\
\text { Erkodur }^{\circledR} \\
\text { Erkodur }^{\circledR} \\
\text { Erkodur }^{\circledR} \\
\text { Ideal Clear }^{\circledR} \\
\text { Ideal Clear }^{\circledR}\end{array}$ & $\begin{array}{l}0,75 \mathrm{~mm} \\
0,75 \mathrm{~mm} \\
1,0 \mathrm{~mm} \\
1,0 \mathrm{~mm} \\
0,8 \mathrm{~mm} \\
0,8 \mathrm{~mm} \\
1,0 \mathrm{~mm} \\
1,0 \mathrm{~mm} \\
1,0 \mathrm{~mm} \\
1,0 \mathrm{~mm}\end{array}$ & $\begin{array}{l}\mathrm{v} \\
\mathrm{n} \\
\mathrm{v} \\
\mathrm{n} \\
\mathrm{v} \\
\mathrm{n} \\
\mathrm{v} \\
\mathrm{n} \\
\mathrm{v} \\
\mathrm{n}\end{array}$ & $\begin{array}{l}-3.6,-3.6,-3.4 \\
-1.1,-0.9,-0.9 \\
-7.5,-6.9,-6.4 \\
-4.7,-4.0,-3.6 \\
-3.6,-3.6,-3.6 \\
-1.4,-1.1,-0.9 \\
-7.4,-6.6,-6.0 \\
-5.5,-5.3,-4.6 \\
-7.8,-7.7,-7.6 \\
-7.6,-7.6,-7.5\end{array}$ & $\begin{array}{l}<0.01 \\
<0.01 \\
<0.01 \\
<0.01 \\
<0.01\end{array}$ \\
\hline-5.0 & $-0,34$ & $\mathrm{Fz}$ & $\begin{array}{l}25 \\
25 \\
25 \\
25 \\
25 \\
25 \\
25 \\
25 \\
25 \\
25 \\
\end{array}$ & $\begin{array}{l}\text { Biolon }^{\circledR} \\
\text { Biolon }^{\circledR} \\
\text { Biolon }^{\circledR} \\
\text { Biolon }^{\circledR} \\
\text { Erkodur }^{\circledR} \\
\text { Erkodur }^{\circledR} \\
\text { Erkodur }^{\circledR} \\
\text { Erkodur }^{\circledR} \\
\text { Ideal Clear }^{\circledR} \\
\text { Ideal Clear }^{\circledR} \\
\end{array}$ & $\begin{array}{l}0,75 \mathrm{~mm} \\
0,75 \mathrm{~mm} \\
1,0 \mathrm{~mm} \\
1,0 \mathrm{~mm} \\
0,8 \mathrm{~mm} \\
0,8 \mathrm{~mm} \\
1,0 \mathrm{~mm} \\
1,0 \mathrm{~mm} \\
1,0 \mathrm{~mm} \\
1,0 \mathrm{~mm} \\
\end{array}$ & $\begin{array}{l}\mathrm{v} \\
\mathrm{n} \\
\mathrm{v} \\
\mathrm{n} \\
\mathrm{v} \\
\mathrm{n} \\
\mathrm{v} \\
\mathrm{n} \\
\mathrm{v} \\
\mathrm{n}\end{array}$ & $\begin{array}{l}-1.4,-1.3,-1.1 \\
-0.3,-0.3,-0.2 \\
-3.6,-3.2,-2.8 \\
-2.4,-2.2,-1.1 \\
-2.0,-2.0,-1.8 \\
-0.3,-0.2,-0.2 \\
-4.4,-3.4,-2.9 \\
-3.4,-3.1,-2.3 \\
-5.4,-5.0,-5.0 \\
-5.2,-5.1,-5.1 \\
\end{array}$ & $\begin{array}{l}<0.01 \\
<0.01 \\
<0.01 \\
<0.01 \\
<0.01\end{array}$ \\
\hline-2.5 & $-0,17$ & $\mathrm{Fz}$ & $\begin{array}{l}25 \\
25 \\
25 \\
25 \\
25 \\
25 \\
25 \\
25 \\
25 \\
25 \\
\end{array}$ & $\begin{array}{l}\text { Biolon }^{\circledR} \\
\text { Biolon }^{\circledR} \\
\text { Biolon }^{\circledR} \\
\text { Biolon }^{\circledR} \\
\text { Erkodur }^{\circledR} \\
\text { Erkodur }^{\circledR} \\
\text { Erkodur }^{\circledR} \\
\text { Erkodur }^{\circledR} \\
\text { Ideal Clear }^{\circledR} \\
\text { Ideal Clear }^{\circledR} \\
\end{array}$ & $\begin{array}{l}0,75 \mathrm{~mm} \\
0,75 \mathrm{~mm} \\
1,0 \mathrm{~mm} \\
1,0 \mathrm{~mm} \\
0,8 \mathrm{~mm} \\
0,8 \mathrm{~mm} \\
1,0 \mathrm{~mm} \\
1,0 \mathrm{~mm} \\
1,0 \mathrm{~mm} \\
1,0 \mathrm{~mm}\end{array}$ & $\begin{array}{l}\mathrm{v} \\
\mathrm{n} \\
\mathrm{v} \\
\mathrm{n} \\
\mathrm{v} \\
\mathrm{n} \\
\mathrm{v} \\
\mathrm{n} \\
\mathrm{v} \\
\mathrm{n}\end{array}$ & $\begin{array}{l}0.0,0.1,0.1 \\
-0.2,-0.2,-0.2 \\
-0.6,-0.2,-0.1 \\
-0.6,-0.5,-0.5 \\
-0.4,-0.2,-0.2 \\
-0.1,-0.1,-0.1 \\
-1.2,-0.6,-0.2 \\
-0.6,-0.3,-0.2 \\
-2.7,-2.5,-1.8 \\
-2.6,-2.5,-2.0\end{array}$ & $\begin{array}{l}<0.01 \\
0.06 \\
<0.01 \\
<0.01 \\
0.04\end{array}$ \\
\hline
\end{tabular}

Tabelle 11 Darstellung der Ergebnisse der Varianzanalyse für die Gegenüberstellung vor/nach Alterung der Materialien Biolon ${ }^{\circledR}$ 1,0mm, Biolon ${ }^{\circledR}$ 0,75mm, Erkodur ${ }^{\circledR}$ 1,0mm, Erkodur ${ }^{\circledR}$ 0,8 mm und Ideal Clear ${ }^{\circledR}$ bei den Auslenkungsstrecken -0,17 mm, -0,34 mm und -0,51 mm für die Variable Fz 


\section{Diskussion}

Nach einer Studie von Meier et al. aus dem Jahre 2003 ist die Nachfrage vor allem weiblicher Erwachsener nach einer kieferorthopädischen Behandlung beachtlich. Viele dieser potentiellen Patienten scheuen jedoch die ästhetische Beeinträchtigung durch eine festsitzende labiale oder die Sprechbeeinträchtigung durch eine linguale Behandlungsapparatur. Vor allem auf Grund der ästhetischen und phonetischen Vorteile und der besseren Hygienefähigkeit erfreut sich die orthodontische Therapie mittels transparenter Tiefziehschienen einer zunehmenden Beliebtheit (Meier et al. 2003, Nedwed und Miethke 2005).

Obgleich anhand diverser klinischer Studien und Fallbeispielen erfolgreiche Behandlungen mittels Tiefziehschienen dokumentiert wurden (Bollen et al. 2003, Clements et al. 2003, Djeu et al. 2005, Vlaskalic und Boyd 2002, Wong 2002), sind die komplexen Mechanismen der Kraftübertragung und deren mögliche Einflussgrößen bis dato nicht systematisch untersucht worden. Bislang wurden erst wenige Studien zu dieser Thematik veröffentlicht (Barbagallo et al. 2008 b, Kwon et al. 2008, Rost et al. 1995, Warunek et al. 1989).

In der vorliegenden Arbeit wurden die initial auftretenden Kräfte und Drehmomente bei der Rotation eines Oberkieferinzisivus mittels Tiefziehschienen in vitro untersucht. Die Rotation des Messzahnes erfolgte dabei um eine Achse durch das Zentrum der Inzisalkante und die horizontale Wurzelmitte in und gegen den Uhrzeigersinn von $0^{\circ}$ bis $\pm 10^{\circ}$ in $0,5^{\circ}$ Schritten. Von Interesse waren dabei das rotative Drehmoment und die intrusive Kraft bei einer Auslenkung von $\pm 2,5^{\circ}, \pm 5^{\circ}$ und $\pm 7,5^{\circ}$. Dies entspricht einer Bewegungsstrecke von $\pm 0,17$ $\mathrm{mm}, \pm 0,34 \mathrm{~mm}$ und $\pm 0,51 \mathrm{~mm}$, gemessen von den äußersten mesialen und distalen Endpunkten der Inzisalkante des Messzahnes.

Des Weitern wurde der Frage nachgegangen, ob und inwieweit die Materialstärke der Tiefziehschienen oder der Tiefziehvorgang einen Einfluss auf die Kräfte bzw. Drehmomente haben. Ferner war von Interesse, ob eine simulierte Schluckkraft eine Veränderung der generierten Kräfte und Drehmomente bewirkt. Als letztes wurde der Frage nachgegangen, ob eine simulierte 14tägige Alterung einen Einfluss auf die auftretenden Kräfte bzw. Momente hat.

Im Folgenden werden nach einer Diskussion von Material und Methode die einzelnen Resultate dieser Studie näher betrachtet und vor dem Hintergrund der aktuellen wissenschaftlichen Erkenntnisse diskutiert. 


\subsection{Diskussion von Material und Methode}

Betrachtet man zunächst die Herstellung des Urmodells zur Schienenherstellung, so wird in der Literatur generell empfohlen, einen hochpräzisen Abdruck mittels Silikon oder Impregum zu verwenden (Joffe 2003, Vlaskalic et al. 2001). Der Vorteil dieser Materialien gegenüber Alginat liegt neben der höheren Präzision der Abformung (Peutzfeldt und Asmussen 1989, Sawyer et al. 1976) auch in der Dimensionsstabilität des Abdruckes. So ist es laut Herstellerangaben möglich, Silikone und Polyether noch bis zu 14 Tage nach Abformung ohne Volumenänderung auszugießen. Das auspolymerisierte Alginat hingegen trocknet nach der Entnahme aus dem Mund schnell aus, was zu einer deutlichen Volumenänderung führt. Alginatabdrücke sollten daher rasch ausgegossen werden oder zumindest bis zum Ausgießen feucht gelagert werden (Schopf 2000).

Da die Abformungen für die Herstellung der Invisalign ${ }^{\circledR}$-Aligner an die Align Technology GmbH versandt werden (Joffe 2003, Vlaskalic 2001), ist vor allem in diesem Fall ein Silikonoder Polyetherabdruck angezeigt. Alginat würde den Postweg nicht volumenstabil überstehen. In der vorliegenden Studie wurden die für die Schienenherstellung verwendeten Urmodelle jedoch mittels eines Alginatabdrucks gewonnen. Während der Abformung befand sich der Messzahn in starrer Verbindung mit dem Sensor. Somit wirkten auch die Abzugskräfte bei Entfernung des Löffels auf die Messeinheit. Es zeigte sich in Vorversuchen ohne Verwendung des Sensors, dass die Abzugskräfte für Abformungen des Frasacomodells mit Impregum oder Silikon deutlich höher waren als jene bei Abformungen mit Alginat. Um eine Überlast des Sensors zu vermeiden, wurden die Abdrücke daher mit Alginat vorgenommen.

Es bleibt die Frage offen, inwieweit die Wahl des Abdruckmaterials einen Einfluss auf die Genauigkeit der Tiefziehschienen hat. Peutzfeldt und Asmussen (1989) konnten in ihrer Studie zwar eine bessere Präzision, also eine geringere Schrumpfung der elastomeren Abdruckmaterialien feststellen, jedoch befanden sich diese lediglich im Mikrometerbereich. Bei den Elastomeren wurden Ungenauigkeiten in den Abdrücken zwischen 39 und $130 \mu \mathrm{m}$ festgestellt, bei Alginat lag die Schrumpfung zwischen 44 und $188 \mu \mathrm{m}$. Bildet man den Mittelwert, so liegen die Ungenauigkeiten der Elastomere bei $84,5 \mu \mathrm{m}$, die von Alginat bei $116 \mu \mathrm{m}$. Die Schrumpfung der Alginatabdrücke ist somit um durchschnittlich 31,5 $\mu \mathrm{m}$ größer als die der elastomeren Abrücke. In Bezug auf die Auslenkungsstrecken von bis zu 0,51 mm ist der Unterschied in der Präzision von Alginat und den Elastomeren zu vernachlässigen.

Eine hochpräzise Abformung ist zwar wünschenswert, jedoch nicht zwingend Grundvoraussetzung für die Herstellung kieferorthopädischer Modelle. Auch Schopf untermauert diese Feststellung, indem er postuliert, dass in der Regel für die Planung und 
Herstellung kieferorthopädischer Apparaturen, die Abformung der Zahnbögen und Alveolarfortsätze mit Alginat durchzuführen sei (Schopf 2000). Eine Studie, die den Vorteil einer Abformung mit Polyether oder Silikon gegenüber Alginat bei der Schienenherstellung belegt, wurde derzeit noch nicht vorgenommen.

Von dem fertig gestellten Urmodell wurde mit Adisil ${ }^{\circledR}$ blau 9:1 (Siladent Dr. Böhme \& Schöps GmbH, Goslar, Deutschland) eine Dublierform gemäß den Herstellerangaben erstellt. Diese wurde 25mal mit Dentalgips der Klasse IV (GC Fujirock ${ }^{\circledR}$ EP, GC Deutschland GmbH, München, Deutschland) ausgegossen. Die verwendete Dubliermasse zeigt laut Herstellerangaben keinerlei Schrumpfung und kann somit als dimensionsstabil angesehen werden. Der verwendete Dentalgips hat nach Herstellerangaben eine geringe Expansion von weniger als 0,08\%. Dimensionsfehler aus diesen Arbeitsschritten sind somit zu vernachlässigen.

In der vorliegenden Studie wurde bei der Messung der initialen Kräfte und Momente auf die Simulation eines parodontalen Ligaments verzichtet. Wie Dorow et al. in ihren 2002 und 2003 veröffentlichten Studien feststellten, zeichnet sich das parodontale Ligament durch viskoelastisches Verhalten aus. Dazu gehören die Kraftrelaxation, die Hysterese, eine Zunahme der Steifigkeit des Parodontalligaments mit wachsender Belastungsgeschwindigkeit und die Abhängigkeit von der Belastungsgeschichte. Das Volumen des Parodontalspaltes variiert bei einwurzeligen Zähnen zwischen 30-100 $\mathrm{mm}^{3}$ und auch in seiner Zusammensetzung ist das Desmodont interindividuellen Schwankungen unterlegen. Des Weiteren ist das Desmodont in der Wurzelmitte dünner als am Apex oder am alveolären Knochenkamm und seine Dicke variiert alters- und funktionsabhängig (Schröder 2000). Da bis dato kein Material existiert, welches die komplexen rheologischen und multiphasischen Eigenschaften des parodontalen Ligaments unter Berücksichtigung der interindividuellen Unterschiede adäquat zu simulieren vermag, wurde hierauf verzichtet. Dieser Verzicht zugunsten einer starren Fixation des Messzahnes mit dem Sensor ist eine weit verbreitete Methode bei der Messung orthodontischen Kräfte (Baccetti et al. 2008, Bartzela et al. 2007, Lim et al. 2008, Pandis et al 2008 a, Pandis et al. 2008 b, Walker et al. 2007, Wang et al. 2007) und wurde aus diesem Grund auch in der vorliegenden Arbeit benutzt. Jedoch können die gemessenen Werte lediglich auf die Situation unmittelbar nach Einsetzen der kieferorthopädischen Apparatur bezogen werden, wenn aufgrund der viscoelastischen Eigenschaften des Parodontiums keine nennenswerte Zahnbewegung stattgefunden hat (Nakamura et al. 2008, Synge 1933). 


\subsection{Drehmomente und intrusive Kräfte bei der Derotation eines zentralen Oberkieferschneidezahnes}

Die in der Literatur als ideal angesehenen Drehmomente für die Derotation schwanken von Autor zu Autor. So werden Werte zwischen 5-10 Nmm (Diedrich 1990) und $30 \mathrm{Nmm}$ (Melsen und Burstone 1990) für das therapeutische Drehmoment angegeben, wobei sich der letztgenannte Wert lediglich auf die Derotation von Molaren bezieht und immer noch ein Drittel über der Empfehlung von Wichelhaus et al. liegt, welche lediglich Drehmomente von unter $20 \mathrm{Nmm}$ befürworten, um die Zähne vor einer Überlast zu schützen (Wichelhaus et al. 2004). Proffit sieht in der Rotation von Zähnen eine der Kippung ähnliche Belastungsverteilung und postuliert daher, dass auch die auf den Zahn ausgeübte Kraft im Bereich der für die Kippung empfohlenen 0,35-0,6 N liegen sollte (Proffit 1999). Er macht jedoch keine Angaben über Kraftansatz oder Abstand zum Widerstandszentrum, welcher die Berechnung des äquivalenten Drehmomentes zulassen würde.

Bei der Ausrotation von Prämolaren und Eckzähnen mit Teilbögen aus Nickel-Titan wurden von Sander et al. Momente von 12 Nmm gemessen (Sander et al. 2006). Diese waren deutlich höher, als die von Fuck und Drescher ermittelten initialen rotativen Drehmomente des Frontzahnsegments bei verschiedenen Nivellierungsbögen. Hier lagen die Werte abhängig vom verwendeten Bogen zwischen 1,25 $\pm 1,05 \mathrm{Nmm}$ und 3,36 $\pm 1,97 \mathrm{Nmm}$ (Fuck und Drescher 2006). Neben diesen deskriptiven Untersuchungen liegen jedoch keine evidenten Aussagen zu dem therapeutisch anzuwendenden Optimalbereich rotativer Drehmomente vor, was eine klare Aussage in diesem Zusammenhang erschwert.

Als Kriterium für eine sinnvolle Kraftgröße kann jedoch die Wurzeloberfläche eines zu bewegenden Zahnes herangezogen werden (Göz 2000). Zähne mit großer Wurzeloberfläche tolerieren größere Kräfte bzw. Drehmomente als solche mit kleinerer Wurzeloberfläche. Die durchschnittliche Wurzeloberfläche eines Oberkiefermolaren von $530 \mathrm{~mm}^{2}$ ist gegenüber der eines zentralen Oberkieferschneidezahnes mit $230 \mathrm{~mm}^{2}$ 2,3fach größer und toleriert somit auch eine Mehrbelastung um diesen Faktor (Göz 2000). Da die Empfehlungen für das rotative Drehmoment eines Molaren bei einem Höchstwert von 30 Nmm (Melsen und Burstone 1990) bzw. $20 \mathrm{Nmm}$ (Wichelhaus et al. 2004) liegen, dürfte die Obergrenze für das Drehmoment eines zentralen Oberkieferschneidezahnes dementsprechend bei $13 \mathrm{Nmm}$ bzw. 8,7 Nmm anzusiedeln sein. Diese Werte bewegen sich in etwa in dem Bereich für die von Sander et al. tatsächlich gemessenen maximalen Momente von $12 \mathrm{Nmm}$ bei der Ausrotation von Eckzähnen (Sander et al. 2006). Da ein Frontzahn jedoch lediglich die 0,8fache Wurzeloberfläche eines Eckzahnes besitzt (Göz 2000), sollte das maximale Drehmoment bei 
einem zentralen Oberkieferfrontzahn nicht über $10 \mathrm{Nmm}$ liegen, was auch in etwa dem aus 13 Nmm und 8,7 Nmm gebildeten Mittelwert von 10,85 Nmm entspricht.

Fraglich bleibt jedoch, ob eine Übertragung der für den Molar empfohlenen Werte auf den Frontzahn überhaupt möglich ist, da hierbei zwar die unterschiedliche Wurzeloberfläche Berücksichtigung findet, jedoch die Bewegungsart der Wurzel im Knochen außer Acht gelassen wird. Da sich bei einem Molar das Rotationszentrum zwischen den Wurzeln befindet, kommt es hier zu einer körperlichen Bewegung der Wurzeln im Knochen um die Rotationsachse. Bei einem Frontzahn hingegen liegt die Rotationsachse im Zentrum der Wurzel, so dass sich der Zahn lediglich in seinem Alveolarfach dreht und es nur zu geringfügigen Knochenumbauprozessen kommt.

Betrachtet man die $10 \mathrm{Nmm}$ als relativen Richtwert für das maximale rotative Drehmoment eines Oberkieferfrontzahns, so zeigt sich, dass lediglich bei der Auslenkungsstrecke $\pm 0,17$ $\mathrm{mm}$ die Materialien Biolon ${ }^{\circledR} 0,75 \mathrm{~mm}$, Erkodur ${ }^{\circledR} 1,0 \mathrm{~mm}$ und Erkodur ${ }^{\circledR} 0,75 \mathrm{~mm}$ niedrigere Drehmomente produzieren (Tab. 2). Biolon ${ }^{\circledR}$ in der Stärke 1,0 mm liegt mit Werten von 9,8 Nmm (SD 0,7) für die Rotation gegen den Uhrzeigersinn und 12,8 $\mathrm{Nmm}$ (SD 1,0) für Rotation im Uhrzeigersinn tendenziell über dem Richtwert von $10 \mathrm{Nmm}$. Ideal Clear ${ }^{\circledR}$ produziert schon bei der Auslenkung von $\pm 0,17 \mathrm{~mm}$ mit 18,3 $\mathrm{Nmm}$ (SD 1,2) bzw. 20,2 Nmm (SD 1,3) nahezu doppelt so hohe Drehmomente. Bei den Auslenkungsstrecken $\pm 0,34 \mathrm{~mm}$ und $\pm 0,51 \mathrm{~mm}$ liegen die Drehmomente aller getesteten Materialien weit oberhalb der 10 Nmm (Tab. 2).

Proffit postulierte 1999, dass eine Kraft, die bei einer bestimmten Applikationsform als zu hoch erachtet wird, bei einer anderen ideal sein könnte. Im Vergleich zu der Multibandapparatur werden die Zähne bei der orthodontischen Therapie mit Tiefziehschienen über eine in das Setup einprogrammierte definitive Strecke bewegt. Liegt diese Strecke unterhalb der Breite des Desmodontalspalts, kann es zu keiner vollständigen Unterbrechung des kapillären Blutstroms mit daraus resultierender unterminierender Resorption und einer erhöhten Gefahr für ausgeprägte Wurzelresorptionen kommen. Die Breite des Parodontalspaltes variiert im Bereich einzelner Zahnwurzeln, zwischen Zähnen, die verschiedenartig funktionell belastet werden und nimmt mit zunehmendem Alter ab (Schroeder 2000). Im Mittel liegt sie bei ca. 0,2 mm. Bei Auslenkungsstrecken unterhalb dieses Wertes wäre die Größenordnung der Kraft oder des Drehmoments irrelevant, da die Bewegungsstrecke an die breite des Parodontalspaltes angepasst wäre. Unter diesem Aspekt könnten alle getesteten Materialien bei Auslenkungsstrecken unterhalb von 0,2 mm unabhängig von den generierten Kräften und Drehmomenten verwendet werden. Dies gilt 
auch für die Rotationsbewegung eines Oberkieferfrontzahnes, da auch hier, bedingt durch den ovalen bzw. sanduhrförmigen Wurzelquerschnitt, Kompressionszonen im parodontalen Ligament auftreten können.

Die Frage, ob und inwieweit bei der orthodontischen Schienentherapie unerwünschte externe Wurzelresorptionen auftreten, wird in der Literatur kontrovers diskutiert. So spricht Boyd in seinem 2008 veröffentlichten Artikel über den Einsatz von Invisalignschienen bei moderaten und komplexen Malokklusionen von einer noch nicht veröffentlichten Studie von T. Wheeler, in welcher bei 100 Invisalignpatienten keinerlei messbare Wurzelresorptionen auftraten. Demgegenüber kamen Brezniak und Wasserstein in einem 2008 veröffentlichten Fallbericht einer Patientenbehandlung mit Invisalign ${ }^{\circledR} \mathrm{zu}$ dem Schluss, dass es in der orthodontischen Schienentherapie zu unerwünschten Wurzelresorptionen kommen kann. Lediglich Barbagallo et al. (2008 a) stellten ein Ausmaß von Wurzelresorptionen, vergleichbar mit denen in der konventionellen Therapie mit leichten orthodontischen Kräften fest. Sie verwendeten in ihrer Studie jedoch Aligner der Firma Clear Smile ${ }^{\circledR}$ mit einer in das Setup einprogrammierten Auslenkungsstrecke von 0,5 mm pro Schiene. Die Zahnbewegungen pro Behandlungsstadium in der Invisaligntherapie betragen dagegen laut Literaturangaben 0,15-0,33 mm (Boyd et al. 2000, Faltin et al. 2003, Joffe 2003, Melkos 2005, Owen 2001, Vlaskalic et al. 2001) und liegen somit deutlich unter den Auslenkungsstrecken der Clear Smile ${ }^{\circledR}$-Aligner. Da, wie bereits zuvor erwähnt, neben der Größe der applizierten Kraft auch die Strecke, über die sie wirkt (Hub), eine entscheidende Rolle spielt, wäre so gesehen das Auftreten von unerwünschten Wurzelresorptionen bei Clear Smile ${ }^{\circledR}$ wahrscheinlicher.

Obwohl die Auslenkungsstrecken die Breite des Desmodontalspalts zum Teil deutlich überschreiten und die dabei generierten Kräfte und Momente klar über den als ideal angesehenen Bereichen liegen, werden Wurzelresorptionen nur teilweise beobachtet (Barbagallo et al. 2008 a, Boyd 2008, Brezniak und Wasserstein 2008). Dies kann zum einen damit erklärt werden, dass es sich bei Schienen um herausnehmbare Apparaturen handelt, bei denen in der Literatur weniger Wurzelresorptionen beschrieben wurden (Linge und Linge 1983, 1991). Des Weiteren konnte in der vorliegenden Arbeit eine vom Ausmaß der Bewegung abhängige Anhebung der Schienen im Bereich des Messzahns festgestellt werden, was bedeutet, dass die in der Schiene eingestellte Auslenkungsstrecke des Zahnes nicht voll wirksam werden kann. Da das Ausmaß der Wurzelresorption neben der Größe der eingeleiteten Kraft auch vom Hub abhängig ist, könnte in dem beobachteten Effekt eine Art passiver Schutzmechanismus vor Überlast angenommen werden. Zur Beantwortung dieser Frage sind jedoch weitere klinische Studien notwendig. 
Bis dato wurde keine Studie veröffentlicht, welche sich mit den rotativen Momenten bei der orthodontischen Schienentherapie beschäftigt. Barbagallo et al (2008 b) führten jedoch Untersuchungen zu den initialen Kräften bei der Kippung eines Oberkieferprämolaren mittels thermoplastischer Schienen durch. Da sich sowohl Bewegungsmodalität als auch Messzahn von der vorliegenden Studie unterscheiden, wird im Folgenden lediglich vergleichend auf die gemessene Grenzwertüberschreitung eingegangen.

Barbagallo et al. (2008 b) untersuchten unter anderem die initialen Kräfte bei Kippung eines Oberkieferprämolaren durch druckempfindliche Folien mit Farbindikator (Pressurex ${ }^{\circledR}$, Fuji Photo Film Co., Ltd, Tokyo, Japan), welche formkongruent auf die palatinale Innenfläche der Schiene im Bereich des zu untersuchenden Zahnes geklebt wurde. Abhängig vom aufgebrachten Druck ändern diese Folien ihre Farbe und erlauben somit einen Rückschluss auf die applizierte Kraft. Die in das Setup der Clear Smile ${ }^{\circledR}$-Schienen einprogrammierte Auslenkungsstrecke des Prämolaren betrug in diesem Fall 0,5 mm. Die Aligner wurden aus 0,8 mm dicker Erkodurfolie ${ }^{\circledR}$ hergestellt. Die initialen Kräfte lagen in der Studie bei 5,12 N und waren somit um den 8,5 bis 14,6 fachen Faktor höher als die von Proffit 1999 als ideal angegebenen Kräfte von 0,35-0,6 N bei Kippbewegungen. Bei identischer Auslenkungsstrecke und der Verwendung desselben Materials wurden in der vorliegenden Studie Drehmomente von 30,5 Nmm (SD 1,3) bei Rotation im Uhrzeigersinn und 40,6 Nmm (SD 1,1) bei Rotation gegen den Uhrzeigersinn gemessen (Tab. 2). Die Werte lagen um den 3-4 fachen Faktor über dem mit $10 \mathrm{Nmm}$ als ideal postulierten Grenzwert des rotativen Drehmoments eines Oberkieferfrontzahnes. Es konnte also auch in der vorliegenden Arbeit gezeigt werden, dass die generierten initialen Drehmomente bei einer Auslenkungsstrecke von 0,5 mm wesentlich höher sind als die empfohlenen Grenzwerte. Der bei Barbagallo et al. (2008 b) wesentlich höhere Faktor der Grenzwertüberschreitung im Vergleich zur vorliegenden Studie, könnte darin begründet sein, dass die verwendete Sensorfolie zwischen Messzahn und Schiene positioniert wurde, ohne dass die Schiene an der Innenseite um den Betrag der Sensorfoliendicke ausgedünnt wurde. Die inhärente Dicke der Pressurex ${ }^{\circledR}$ - Folie müsste erwartungsgemäß einen größeren Druck auf den Zahn ausüben, als wenn diese Extraschicht fehlen würde. Außerdem kann bei der Verwendung von Pressurex ${ }^{\circledR}$ - Folie eine genaue Trennung der vertikalen und horizontalen Kraftkomponenten nicht erfolgen. Es bleibt also fragwürdig, inwieweit die gemessenen Werte die kippende Kraftkomponente widerspiegeln. Hinzu kommt, dass in der Studie von Barbagallo et al. die Kräfte an einem Prämolar gemessen wurden, wohingegen in der vorliegenden Arbeit ein Frontzahn mit einer im Vergleich zum Prämolaren unterschiedlichen Kronenmorphologie untersucht wurde. Da 
die Form der Schiene sehr stark von der Form des Zahnes, über den sie geformt wurde, abhängig ist, sind auf Grund der resultierenden Unterschiede in der Schienenmorphologie für jeden Zahn unterschiedliche Kraftverhältnisse in Bezug auf Kraftgröße und Kraftwirkungsrichtung zu erwarten.

Kwon et al. 2008 untersuchten die Kraft und Energieabgabe thermoplastisch geformter flacher Probenkörper aus verschiedenen Schienenmaterialien. Sie benutzen über ein flaches Steinmodell tiefgezogene Proben, um die bei der Kippung eines Oberkieferfrontzahnes entstehenden Kräfte mittels Drei-Punkt-Biegeversuch zu messen. Bei gleichen untersuchten Materialien einer Stärke von 0,762 mm und einer Auslenkungsstrecke von 0,5 mm lag die gemessene Kraft, gegenüber den von Barbagallo et al (2008 b) gemessenen 5,12 N, lediglich bei 1,691 N. In Bezug zu den von Proffit 1999 postulierten idealen Kräften bei der orthodontischen Kippung überschreitet der gemessene Wert den Idealbereich um das 2,8 bis 4,8fache.

Im Gegensatz zu flachen Probenkörpern zeichnet sich die Schiene nach dem Tiefziehvorgang durch komplexe geometrischer Formen bedingt durch die Anatomie des Zahnes aus, welche vor allem in Bereichen starker Krümmung eine Versteifung des Materials erzeugen. Dies ist in etwa vergleichbar mit der Steigerung der Steifigkeit von einem Blatt Papier hin zur Wellpappe. Der Kraftansatzpunkt innerhalb der Schiene müsste folglich einen Einfluss auf die generierten Kräfte haben. Liegt dieser zum Beispiel nahe der gingivalen Grenzlinie, so würden theoretisch andere Kräfte generiert werden, als wenn der Ansatzpunkt nahe dem Knick der Inzisalkante, also in einem Bereich starker Materialversteifung, liegt. Da ein DreiPunkt-Biegeversuch diesen Sachverhalt nicht berücksichtigt, bleibt eine klinische Übertragung der Messergebnisse von Kwon et al. 2008 fragwürdig.

Wie in dieser Studie gezeigt, treten bei der Ausrotation eines Oberkieferfrontzahnes neben den rotativen Momenten auch intrusive Kräfte auf. Der Medianwert der intrusiven Kraft lag in Abhängigkeit vom verwendeten Material, der Auslenkungsstrecke und der Rotationsrichtung zwischen $0 \mathrm{~N}$ und 5,8 N (Tab. 3). Schon bei einer Auslenkung von $\pm 0,17 \mathrm{~mm}$ wurden die von Proffit 1999 als ideal angesehen intrusiven Kräfte von 0,1-0,2 N teilweise überschritten. Bei den Auslenkungsstrecken $\pm 0,34 \mathrm{~mm}$ und $\pm 0,51 \mathrm{~mm}$ lagen alle gemessenen Werte für die intrusive Kraft weit über dem empfohlenen Bereich (Tab. 3). Die Tatsache, dass bei reinen Rotationsbewegungen auch intrusive Kraftkomponenten auftreten, kann eine Erklärung für die von Brezniak 2008 festgestellten unerwünschten posttherapeutischen Intrusionen sein. Die orthodontische Intrusion von Zähnen gehört neben Extrusion oder Jigglingbelastung zu den Bewegungsmodalitäten, bei denen vermehrt Wurzelresorptionen beobachtet werden 
(Baumrind et al. 1996, Göz und Rakosi 1989, Harry und Sims 1982, Mirabella und Artun 1995, Proffit und Fields 1999). Aus diesem Grund wird gerade bei dieser Bewegungsart gefordert, geringere Kräfte anzuwenden (Schopf 2000). Da sich die Kräfte schon bei einer Auslenkungsstrecke von $\pm 0,34 \mathrm{~mm}$ materialunabhängig weit über dem empfohlenen Bereich der anzuwendenden orthodontischen Kraft befanden, kann dies ein Risikofaktor für das vermehrte Auftreten von unerwünschten Wurzelresorptionen sein.

Insgesamt waren die Kräfte und Drehmomente bei Rotation gegen den Uhrzeigersinn größer als bei Rotation mit dem Uhrzeigersinn (Tab. 2 und 3). Eine mögliche Erklärung für dieses Ergebnis könnte in der Zahnmorphologie des Messzahnes zu finden sein.

Der idealisierten Oberkieferinzisivus wurde der Form des Zahnes einer männlichen 15 bis 20 jährigen Person nachempfunden und zeigt die für diesen Zahn typischen morphologischen Charakteristika. Dazu gehört unter anderem, dass Winkel- und das Krümmungsmerkmal (Lehmann und Hellwig 1998). Unter Winkelmerkmal versteht man, dass bei Betrachtung der vestibulären Kronenfläche der Winkel zwischen Schneidekante und Seitenfläche mesial spitzer als distal ist. Krümmungsmerkmal bedeutet, dass bei Betrachtung von inzisal die Approximalfläche der Zähne mesial einen größeren Krümmungsradius aufweist als distal. Diese Asymmetrie des Messzahnes wird beim Tiefziehvorgang auf den Aligner übertragen. Von Inzisal betrachtet weist die Schiene im Bereich des Messzahnes somit mesial und distal unterschiedlich stark ausgeprägte Knickstellen und Rundungen auf, was einen Einfluss auf die Spannungs-Dehnungs-Eigenschaften und somit die generierten Kräfte und Drehmomente haben könnte. Des Weiteren unterscheiden sich die in direkter Nachbarschaft befindlichen Zähne 21 und 12 in Form und Größe, was zu einer unterschiedlichen Ausformung des Schienenmaterials, mesial und distal des Messzahns, führt. Die unterschiedliche geometrische Ausformung des Schienenmaterials, distal und mesial des Messzahnes, kann einen weiteren Erklärungsansatz für dieses Messergebnis sein.

Proffits 1999 postulierte These, dass auch bei reinen Rotationsbewegungen kippende Kraftkomponenten auftreten, konnte durch die vorliegende Arbeit für den Einsatz von Tiefziehschienen in der orthodontischen Therapie bestätigt werden (Abb. 13). Um ein reines rotatives Drehmoment in der Längsachse des Zahnes zu erzeugen, benötigt es eines Kräftepaares in Fx bestehend aus zwei Kräften gleicher Größe mit parallelem jedoch gegenläufigem Kraftangriff (Abb. 1). Dies würde jedoch bedeuten, dass bei den durchgeführten Messungen für die Kraftkomponente Fx der gemessene Wert unabhängig von der Auslenkungsstrecke $0 \mathrm{~N}$ sein müsste. Es wurden jedoch auch in Fx stets Werte gemessen 
(Abb. 13). Dies bedeutet, dass ein Fx des gegenläufigen Kräftepaares größer sein muss und somit neben dem rotativen Drehmoment eine kippende Kraft resultiert.

\subsection{Einfluss der Materialstärke}

Die hauptsächlich aus Polyethylen oder Polypropylen bestehenden Schienen haben eine Dicke zwischen 0,7mm und 1,016mm (Boyd und Vlaskalic 2001, Faltin et al. 2003, Kwon et al. 2008, Sheridan 2003). Um den Einfluss der Materialstärke auf die generierten Kräfte und Drehmomente zu untersuchen, wurden jeweils zwei verschiedene Stärken der Materialien Erkodur $^{\circledR}$ und Biolon ${ }^{\circledR}$ einander gegenübergestellt. Es stellte sich heraus, dass sowohl rotatives Drehmoment als auch intrusive Kraft der jeweils dickeren Folie signifikant größer waren (Tab. 4 und 5). Einzige Ausnahme hierbei war das Material Erkodur ${ }^{\circledR}$ bei der Auslenkungsstrecke $-0,17 \mathrm{~mm}$. Mit einem p-Wert von 0,6 lag der gemessene Unterschied nicht mehr im statistisch signifikanten Bereich.

Was den Einfluss der Materialstärke auf die abgegebenen Kräfte angeht, so stimmen die Ergebnisse mit jenen von Kwon et al. 2008 überein. Kwon et al. untersuchten die Kraftübertragungseigenschaften verschiedener thermoplastischer Materialien mittels DreiPunkt-Biegeversuch. Auch sie kamen zu der Erkenntnis, dass die Materialstärke einen signifikanten Einfluss auf die generierten Kräfte hat.

Eine Erklärung könnte in der Materialsteifigkeit zu finden sein. Die Eigenschaften eines verwendeten Materials hinsichtlich Festigkeit, Plastizität oder Elastizität werden unter anderem durch ihr Spannungs- und Dehnungsverhalten beim Zugversuch definiert. Die Einheit der Spannung ist N/m² und errechnet sich aus dem Quotienten von angewandter Kraft $F$ und dem Querschnitt des verwendeten Materials $A(\sigma=\mathrm{F} / \mathrm{A})$. Die Dehnung ist eine dimensionslose Größe und wird häufig in Promille oder Prozent angegeben. Sie errechnet sich aus dem Quotienten von Längenänderung $\Delta L$ und Ausgangslänge $L_{0}\left(\varepsilon=\Delta L / L_{0}\right)$. Bezogen auf den Schienenkörper könnte ein dickeres Schienenmaterial bei identischer Spannung (=Auslenkungsstrecke) eine höhere Kraft generieren, da sich die Kraft aus dem Multiplikator von Spannung $\sigma$ und Materialquerschnitt $A$ errechnet $\left(\mathrm{F}=\sigma^{*} \mathrm{~A}\right)$.

Auch Kwon et al. 2008 schließen aus ihren Ergebnissen, dass in Tiefziehschienen aus dünnerem Folienmaterial größere Auslenkungsstrecken einprogrammiert werden können, da diese eine Überlast durch zu hohe Kräfte erst bei größeren Auslenkungsstrecken erreichen. Ein weiterer Effekt, der in diesem Kontext beobachtet werden konnte, ist die geringere Abweichung der 25\% und 50\% Quantile vom Medianwert bei $\mathrm{Fz}$ und der niedrigere Standardfehler bei Tz bei den dünneren Folienmaterialien (Tab. 4 und 5). Dies deutet auf eine 
bessere Passgenauigkeit dünnerer Folienmaterialien hin. Da das Vakuum bzw. der Anpressdruck der Tiefziehgeräte bei allen Folienstärken gerätespezifisch konstant ist, kann hier ein Erklärungsansatz für diesen Effekt zu finden sein. Eine dünnere Folie könnte bei konstantem Anpressdruck oder Vakuum präziser auf das Modell tiefgezogen werden und sich somit detailgetreuer an die Oberfläche des Zahnes anlegen.

\subsection{Einfluss des Tiefziehverfahrens}

Tiefziehen ist nach DIN 8584 das Zugdruckumformen eines Blechzuschnitts, einer Folie oder einer Platte in einen einseitig offenen Hohlkörper oder eines vorgezogenen Hohlkörpers in einen solchen mit geringerem Querschnitt ohne gewollte Veränderung der Materialdicke. In der Zahnheilkunde ist dieser Prozess ein gebräuchliches Verfahren zur Herstellung von Kunststoffschienen. Hierbei wird eine Kunststofffolie ausgewählter Stärke erwärmt und im nun plastischen Zustand über ein Gipsmodell der Zahnreihen mittels Drucktiefziehverfahren gepresst oder durch ein Vakuumverfahren tiefgezogen. Durch diesen Vorgang kommt es jedoch zu einer Wanddickenänderung, da die Folien in Richtung der Dehnung gestreckt werden. Auch wenn eine gewollte Veränderung der Materialdicke nicht angestrebt ist, so zeigt sich doch, dass die Folien nach dem Tiefziehvorgang dünner sind (Kwon et al. 2008).

In der vorliegenden Studie kam für den Bereich des Drucktiefziehverfahrens der Drufomat TE (Dreve Dentamid GmbH, Unna, Deutschland) unter Verwendung der Folien Biolon ${ }^{\circledR}$ in den Stärken 1,0 $\mathrm{mm}$ und 0,75 $\mathrm{mm}$ zum Einsatz. Der Drufomat TE arbeitet mit einem Anformdruck von 6 bar auf die vertikal anformende Folie.

Für den Bereich des Vakuumtiefziehverfahrens wurde zum einen der Erkoform RVE (ERKODENT ${ }^{\circledR}$ Erich Kopp GmbH, Deutschland, Pfalzgreifenweiler) unter Verwendung der Folien Erkodur ${ }^{\circledR}$ in den Stärken 1,0 mm und 0,8 $\mathrm{mm}$ und zum anderen die „Vacuum Forming Machine“ Modellnr.202 (Dentsply GAC, Gräfelfing, Deutschland) unter Verwendung der Folien Ideal Clear ${ }^{\circledR}$ in der Stärke 1,0 mm verwendet. Der Erkoform RVE erzeugt ein Vakuum von 0,8 bar. Für die „Vakuum Forming Machine“ wurde vom Hersteller lediglich die Leistung in Watt mit einem Wert von 1450 angegeben.

Um Aussagen über den Einfluss des Tiefziehverfahrens zu treffen, wurden die Daten der Materialien Biolon ${ }^{\circledR}$, Erkodur $^{\circledR}$ und Ideal Clear ${ }^{\circledR}$ in den Stärken $1,0 \mathrm{~mm}$ einander gegenübergestellt. Biolon ${ }^{\circledR}$ bestehen laut Herstellerangaben aus Polyethylenterephthalat (PET). Erkodur ${ }^{\circledR}$ und Ideal Clear ${ }^{\circledR}$ bestehen nach Angaben des Herstellers aus glykolmodifiziertem Polyethylenterephthalat (PETG). In ihren Materialeigenschaften weichen die Folienmaterialien nur geringfügig voneinander ab. So liegt das Elastizitätsmodul der 
Materialien Erkodur $^{\circledR}$ und Biolon ${ }^{\circledR}$ bei $2050 \mathrm{~N} / \mathrm{mm}^{2}$, das von Ideal Clear ${ }^{\circledR}$ bei $2020 \mathrm{~N} / \mathrm{mm}^{2}$. Die Dichte der drei Materialien liegt bei $1,27 \mathrm{~g} / \mathrm{cm}^{3}$. Die Feuchtigkeitsaufnahme der drei Materialien liegt nach ISO $62-4$ bei $0,2 \%$. Unter der Annahme zu vernachlässigender Unterschiede der Materialeigenschaften wurde das Hauptunterscheidungskriterium in diesem Fall auf das Herstellungsverfahren gelegt. Ob und inwieweit die minimalen Differenzen in der Materialzusammensetzung einen Einfluss ausüben können, bleibt jedoch ungeklärt.

Erkodur $^{\circledR}$ - und Ideal Clear ${ }^{\circledR}$-Schienen werden zwar durch Vakuum-Tiefziehgeräte hergestellt, jedoch verwendet Erkodur ${ }^{\circledR}$ im Gegensatz zu Ideal Clear ${ }^{\circledR}$ eine Unterziehfolie in der Stärke 0,05 mm, welche im Anschluss des Tiefziehvorgangs von der eigentlichen Folie entfernt wird und somit als eine Platzhalterfolie angesehen werden kann. Biolon ${ }^{\circledR}$-Schienen werden demgegenüber durch ein Druckverfahren hergestellt.

Betrachtet man die Ergebnisse für das rotative Drehmoment, so zeigt sich, dass Erkodur ${ }^{\circledR}$ gegenüber Ideal Clear ${ }^{\circledR}$ und Biolon ${ }^{\circledR}$ bei den Auslenkungsstrecken $\pm 0,17 \mathrm{~mm}, \pm 0,34 \mathrm{~mm}$ und $\pm 0,51 \mathrm{~mm}$ stets signifikant geringere Drehmomente erzeugt (Tab. 6 und Abb. 18). Eine Erklärung hierfür könnte darin gesehen werden, dass bei den Erkodur ${ }^{\circledR}$-Schienen Rohlinge mit einer Unterziehfolie von 0,05 mm zwischen Zahn und Schiene verwendet werden, die während des Tiefziehvorgangs noch weiter ausgedünnt wird. Sie wird nach dem Tiefziehen entfernt und verringert so die Friktion der gesamten Schiene. Bei steigender Inkongruenz zwischen reeller Zahnposition und Schienensetup wird der Aligner im Bereich des Messzahnes zunehmend abgehoben. Dabei kommt es zu einer Gesamtverformung des Schienenkörpers mit entsprechender Rückstellkraft, die wiederum auf den Messzahn wirkt. Diese Rückstellkraft ist im wesentlichen von der, dem Abheben entgegenwirkenden Friktion im Seitenzahngebiet abhängig. Die durch die Platzhalterfolie verringerte Friktion kann also ein Erklärungsansatz für die niedrigeren Drehmomente im Vergleich zu Biolon ${ }^{\circledR}$ und Ideal Clear $^{\circledR}$ sein. Des Weiteren verringert sich durch die Platzhalterfolie die Kontaktfläche zwischen Schiene und Messzahn. Demzufolge wäre bei identischer Auslenkungsstrecke der Widerstand, den der zu bewegende Zahn der Schiene im Kontaktbereich entgegenbringt, bei Erkodur ${ }^{\circledR}$-Schienen geringer. Die dadurch bedingte elastische Verformung des Schienenkörpers mit entsprechender Rückstellkraft würde somit bei den Erkodur ${ }^{\circledR}$-Schienen im Vergleich zu den anderen beiden Materialien geringer ausfallen. Eine weitere Ursache könnte in dem mit 0,8 bar sehr niedrigen Vakuum des Erkoform RVE liegen. Im Vergleich dazu wird bei den Biolonschienen ein Anformdruck von 6 bar aufgebaut. Durch einen höherer Druck oder ein höheres Vakuum könnte die Tiefziehfolie stärker an das Modell gepresst bzw. 
gezogen werden, was die Passungsqualität und somit die Friktion der Aligner verbessern würde.

Biolon ${ }^{\circledR}$ und Ideal Clear ${ }^{\circledR}$ unterscheiden sich in Tz abgesehen von den Auslenkungsstrecken $0,51 \mathrm{~mm}(\mathrm{p}=0,18)$ und $-0,34 \mathrm{~mm}(\mathrm{p}=0,07)$ statistisch signifikant voneinander (Tab. 6). Jedoch erkennt man in der Abbildung 18 keine eindeutige Hierarchie unter den beiden Materialien. Tendenziell kann man jedoch sagen, dass Biolon ${ }^{\circledR}$ in den höheren Auslenkungsstrecken $(\mathrm{ab} \pm 0,51 \mathrm{~mm})$ und Ideal $\mathrm{Clear}^{\circledR}$ in den niedrigen Bereichen (unter \pm 0,34 mm) höhere Drehmomente generiert (Abb. 18).

Die stärkeren Drehmomente der Biolonschienen bei hohen Auslenkungsstrecken könnten durch eine bessere Passung der Aligner auf dem Modell begründet sein. Wie weiter oben beschrieben erhöht sich mit der Passungsqualität auch die Friktion der Schiene auf dem Modell, was wiederum einen direkten Einfluss auf die Rückstellkräfte hat. Jedoch bleibt bei diesem Erklärungsansatz immer noch die Frage offen, wieso Ideal Clear ${ }^{\circledR}$ im niedrigen Auslenkungsbereich gegenüber Biolon ${ }^{\circledR}$ höhere rotative Drehmomente erzeugt. Unterschiede im Produktionsprozess, physikalische oder chemische Materialcharakteristika und andere unbekannte Einflussgrößen wie die Friktion im Kontaktbereich zwischen Messzahn und Schieneninnenfläche könnten hierbei eine Rolle spielen.

Die für das rotative Drehmoment gewonnenen Erkenntnisse sind auf die Ergebnisse für die intrusive Kraft nicht eindeutig übertragbar. So unterscheidet sich Erkodur $^{\circledR}$ bei den Auslenkungsstrecken $0,17 \mathrm{~mm}(\mathrm{p}=0,48)$ und $-0,34 \mathrm{~mm}(\mathrm{p}=0,38)$ nicht statistisch signifikant von Biolon ${ }^{\circledR}$ und zeigt im hohen negativen Auslenkungsbereich stärkere Kräfte als Ideal Clear $^{\circledR}$ (Abb. 19 und Tab. 7). Beim Vergleich von Ideal Clear ${ }^{\circledR}$ mit Biolon ${ }^{\circledR}$ zeigte sich ein ähnliches, wie zuvor für das rotative Moment beschriebene Verhalten. Erst bei höheren Auslenkungsstrecken generiert Biolon ${ }^{\circledR}$ gegenüber Ideal Clear ${ }^{\circledR}$ höhere Kräfte. Sowohl bei Tz als auch bei $\mathrm{Fz}$ erzeugen im maximalen Auslenkungsbereich die Biolon ${ }^{\circledR}$-Schienen die höchsten Drehmomente bzw. Kräfte (Abb. 18 und 19).

Eine Erklärung für die abweichenden Resultate bei der intrusiven Kraft könnte darin begründet liegen, dass diese Komponente als Nebeneffekt der gewollten Derotation angesehen werden muss. Bei Insertion der Schiene kommt es zu einem Aufdehnen der vestibulären und palatinalen Schienenwände. Da der Aligner durch die unter sich gehenden Bereiche und die Friktion der Schiene auf dem Modell an seiner Position gehalten wird, übertragen sich die Rückstellkräfte der Schiene auf den zu rotierenden Zahn. Hierbei treten sowohl horizontale als auch vertikale Kraftkomponenten auf. Überschreitet die Auslenkung einen gewissen Schwellenwert, so kommt es zusätzlich zu einem Abheben der Schiene vom 
Modell im Bereich des Messzahnes. Die Friktion im Seitenzahnbereich und Passungsdifferenzen am verstellten Messzahn führen zu einer Verformung des gesamten Schienenkörpers mit einer verstärkt wirkenden intrusiven Kraftkomponente. FZ unterliegt als Nebenprodukt der gewollten Rotation somit größeren Schwankungen. Verdeutlicht wird dies durch eine höhere Fehleranfälligkeit gegenüber $\mathrm{Tz}$, was sich durch einen größeren Interquartilsabstand und die längeren Whisker bemerkbar macht (Abb. 14 und 15). Abweichende Ergebnisse der intrusiven Kraft gegenüber dem rotativen Drehmoment sind so gesehen zu erwarten.

Um weitergehende Erkenntnisse über den Einfluss des Herstellungsverfahrens auf die generierten Kräfte und Drehmomente und die damit verbundene Passungsqualität zu erlangen, müsste ein identisches Folienmaterial mit verschiedenen Verfahren tief gezogen werden. Eventuelle, durch Additiva bedingte materialspezifische Unterschiede der Folien wären somit beseitigt. Anschließend müssten die erstellten Schienen miteinander verglichen und gleichzeitig die Abhebungsstrecke bei der jeweiligen Auslenkung gemessen werden. Somit sind die vorliegenden Ergebnisse bezüglich des Einflusses des Tiefziehverfahrens nur beschränkt nutzbar und können allenfalls Anhaltspunkte und Hinweise für zukünftige Forschungsansätze bieten.

\subsection{Einfluss der Schluckkraft}

Bis Dato gibt es keinerlei Studien, die sich mit dem Einfluss der Schluckkraft auf die Kräfte und Drehmomente in der orthodontischen Schienentherapie beschäftigen. Aus diesem Grund wurde in der vorliegenden Studie versucht, diese Fragestellung durch Simulation der Schluckkraft mit einem Gewichtsäquivalent in vitro zu simulieren. Die Angaben in der Literatur zu den beim Schlucken auftretenden interokklusalen Kräften weichen deutlich voneinander ab. Karl Eichner gab in seiner 1963 veröffentlichten Arbeit an, dass die von ihm gemessene Schluckkraft zwischen den Werten der durchschnittlichen und maximalen Kaukraft liegt. Also zwischen ca. 20 und 40 N. Proffit et al. stellten 1983 bei einem Vergleich von Normal- und Langgesicht eine Schluckkraft zwischen 29 und 48 N fest. In der 1993 veröffentlichten Arbeit von Dos Santos und de Rijk lagen die Angaben für Schluckkräfte bei 5 bis 15 N. Für unsere Studie verwendeten wir einen aufgerundeten Mittelwert aus verschiedenen Studien von 30 N. Da bei der Studie von Proffit et al. (1983) bei einer Bissöffnung von 2,5mm eine durchschnittliche Schluckkraft von $29 \mathrm{~N}$ angegeben wurde, und auch durch das tragen der Aligner eine leichte Bissöffnung bewirkt wird, erscheint der gewählte Wert von $30 \mathrm{~N}$ als geeignet. Das Gewichtsäquivalent von $3 \mathrm{~kg}$ wurde vor jedem 
Messzyklus mit einem speziell hergestellten Silikonschlüssel auf der Tiefziehschiene positioniert. Um einen direkten Einfluss des Gewichtes auf die generierten Kräfte und Momente auszuschließen, wurden nach Positionierung des Gewichtsäquivalents und vor Beginn des Messdurchlaufes Kräfte und Momente über die DAQ F/T-Software genullt. Erst im Anschluss daran wurden der Messzahn ausgelenkt und Kräfte und Drehmomente gemessen. Dabei stellte sich heraus, dass sowohl intrusive Kraft als auch rotatives Drehmoment im Vergleich zu der Messreihe ohne Gewicht statistisch signifikant höher waren. Die Materialien Biolon ${ }^{\circledR}$, Ideal Clear $^{\circledR}$ und Erkodur $^{\circledR}$ in der Stärke 1,0 mm lagen schon bei der Auslenkungsstrecke von $\pm 0,17 \mathrm{~mm}$ über dem als relativen Richtwert für das maximale Drehmoment eines Oberkieferfrontzahnes gemittelten $10 \mathrm{Nmm}$ (s.o.) und dem idealen Kraftbereich von 0,1-0,2 N bei der Intrusion (Proffit 1999). Biolon ${ }^{\circledR} 0,75 \mathrm{~mm}$ und Erkodur ${ }^{\circledR}$ 0,8 mm lagen bei der Auslenkungsstrecke von $\pm 0,17 \mathrm{~mm}$ nur teilweise im Rahmen für die in der Literatur als optimal Angegebene intrusive Kraft und das rotative Drehmoment (Tab. 8 und 9).

Wie in dieser Studie beobachtet, so kommt es bei Erhöhung der Auslenkungsstrecke zu einem Abheben der Schiene vom Modell. Eine okklusale Kraft (z.B. Schluckkraft/Bruxissmus) wirkt dieser Tendenz entgegen. Folglich wird die Schiene bis zu einem gewissen Maße aktiv in ihrer Position gehalten. Dies wiederum erhöht die von der Schiene abgegebene Kraft, da die Schiene dem verstellten Zahn vertikal nicht ausweichen kann und es somit zu einer stärkeren Auslenkung des Schienenkörpers im Kontaktbereich zwischen Zahn und Schiene kommt. Folglich sind rotatives Drehmoment und intrusive Kraft im Vergleich zur Messreihe ohne Gewicht höher.

Die durchschnittliche Schluckdauer beträgt nach Witt und Timper 1,4 Sekunden (1974). Cleall gab eine Dauer von 1,5 Sekunden an (1965). Was die Schluckhäufigkeit angeht, so wurden in der Literatur Werte von 590 bis 2400 Schluckvorgängen pro 24 Stunden angegeben (Brückl und Träger 1962, Kincaid 1951, Lear et al. 1965, Straub 1961, Witt und Timper 1974), wobei die Schluckhäufigkeit während des Schlafens niedriger ist und auch mit dem Alter abnimmt (Witt und Timper 1974). Aus diesen Werten resultiert eine effektive Schluckzeit von 13,7-60 Minuten pro Tag. Da der Aligner mindestens 20 Stunden am Tag getragen werden soll (Joffe 2003), ist es jedoch fragwürdig, ob eine durch den Schluckakt bedingte Erhöhung der orthodontischen Kräfte Auswirkungen auf das Behandlungsergebnis zeigen kann. Andererseits kann man in einem vollzogenen Schluckakt eine Nachjustierung der Schiene sehen, da der Aligner durch die okklusal wirkende Kraft aktiv auf die vorgesehene Endposition gedrückt wird. Diese Nachjustierung würde bei durchschnittlich 40- 
60 Schluckvorgängen in der Stunde (Witt und Timper 1974) sehr regelmäßig stattfinden. Zwar hat sie, bedingt durch die kurze Schluckzeit von 1,4 bis 1,5 Sekunden eher einen impulsartigen Charakter, eine impulsartige Rückstellung ist aufgrund des Hystereseverhaltens des Schienenmaterials jedoch fragwürdig. Wie lange die erhöhte Kraft letztendlich auf den Zahn einwirkt, kann also nicht beantwortet werden. Weitere Untersuchungen in diesem Zusammenhang sind nötig.

Betrachtet man in dem Abheben der Tiefziehschiene einen, wie oben beschriebenen indirekten Schutzmechanismus, welcher den Zahn vor einer Überlast bewahrt, so könnte das rezidivierende Aufpressen der Schiene durch die beim Schlucken auftretenden interokklusalen Kräfte diesem Effekt entgegenwirken. Leidet der Patient an dentalen Parafunktionen wie Knirschen oder Pressen könnte bei starker initialer Auslenkung ein impulsartiges Trauma evoziert werden, da die durchschnittlich aufgewendete Kraft eines bruxierenden Patienten mit 220 N (Nishigawa et al. 2001) deutlich über der durchschnittlichen Schluckkraft liegt.

Der gewählte Versuchsaufbau geht von einer zentral wirkenden, gleichmäßig verteilten okklusalen Kraft aus. Bedingt durch die individuellen okklusalen Verhältnisse in vivo kann es jedoch zu spezifisch verteilten unterschiedlichen Vorkontakten durch die Gegenbezahnung auf dem Schienekörper kommen, was eine in vivo nicht immer gleiche Kraftverteilung wahrscheinlich macht.

\subsection{Alterungssimulation}

In der vorliegenden in-vitro-Studie wurde unter anderem versucht, die verwendeten Schienen einer möglichst realitätsnahen Alterung zu unterziehen, um Rückschlüsse auf das in-vivoVerhalten in Bezug auf das Kraftabgabeverhalten der Aligner am Ende einer 14tägigen Trageperiode ziehen zu können. Bei Insertion des Aligners kommt es, bedingt durch das von der oralen Ist-Situation abweichende Schienensetup, zu lokalen elastischen Verformung des Schienenkörpers. Es resultiert eine entsprechende Rückstellkraft, welche wiederum auf den Zahn wirkt. Die Frage, ob und wie weit sich diese Kraft ausschließlich gegen den orthodontisch $\mathrm{zu}$ bewegenden Zahn richtet, ist bis dato nicht geklärt. Eine reziproke Auswirkung auf das Schienenmaterial, mit daraus resultierender Minderung der gemessenen Kräfte und Drehmomente, ist nicht ausschließen.

Zur Klärung dieser Fragestellung wurden die Kräfte und Drehmomente der verwendeten Tiefziehschienen nach Abschluss der Alterungssimulation erneut gemessen und mit den Ergebnissen aus der Messreihe vor Alterungssimulation verglichen. Für sämtliche Messreihen wurden in dieser Studie dieselben Schienen verwendet, um einen direkten Vergleich der 
Messdaten vor und nach Alterung zu gewährleisten. Das Versuchsprotokoll beschränkte sich hierbei auf die Messungen gegen den Uhrzeigersinn und ohne Gewicht. Auf eine Messung im Uhrzeigersinn oder mit Gewicht wurde verzichtet, da lediglich die Effekte der Alterung und nicht der Einfluss der Rotationsrichtung oder der Schluckkraft von Interesse waren. Der Zeitrahmen der Alterung wurde mit 14 Tagen festgelegt, da dies einer durchschnittlichen in vivo Trageperiode entspricht (Barbagallo et al. 2008 b, Joffe 2003). Das Versuchsprotokoll der Alterungssimulation umfasste die Auslagerung der Aligner in einer wässrigen Umgebung unter mechanischer Vorbelastung für insgesamt 14 Tage sowie eine thermische Wechselbelastung.

\subsubsection{Wasserlagerung unter mechanischer Vorbelastung}

Wie oben erwähnt, werden Tiefziehschienen bei klinischer Anwendung ca. 14 Tage getragen. Die Tiefziehschienen befinden sich in dem genannten Zeitraum, abgesehen von der Zeit der Nahrungsaufnahme und der Zahnreinigung, im feuchten Milieu des Mundraumes. In dem beschriebenen Versuchsaufbau wurde versucht, durch die Lagerung in $37^{\circ} \mathrm{C}$ warmen Wasser, dass Feuchtigkeitsmilieu der Mundhöhle zu simulieren. Eine der orthodontischen Therapie am ehesten entsprechende Belastung auf die Schiene wurde durch eine $3^{\circ}$ Rotation des Messzahnes bei der Abdrucknahme zur Herstellung des Versuchsmodells erzielt.

Zwar wurde in der Literatur ein derartiges Verfahren zur Alterungssimulation von Tiefziehschienen bis dato nicht beschrieben, jedoch wird die Wasserlagerung in vielen werkstoffkundlichen Untersuchungen begleitend zur künstlichen Alterung eingesetzt (Drummond 1989, Drummond und Savers 1993, Kohorst 2007). Auch bei der Untersuchung der physikalischen und mechanischen Eigenschaften von Positionern wurde eine Wasserlagerung zur Messung der Wasserresorption durchgeführt (Warunek et al. 1989). Bei den Tiefziehschienen findet sich lediglich eine Studie, die eine Wasserlagerung zur Alterung einsetzt. Schuster et al. beschreiben in ihrer 2004 veröffentlichten Studie eine 2wöchige Lagerung der Aligner in einer $23{ }^{\circ} \mathrm{C}$ warmen $75 \%(\mathrm{v} / \mathrm{v})$ Ethanol-25\% Wasser Immersion (Schuster et al. 2004).

Kritisch $\mathrm{zu}$ bewerten ist jedoch, dass eine Wasserlagerung oder die Verwendung einer anderen Flüssigkeit, wie z.B. Wasser-Ethanolgemische oder künstlicher Speichel das feuchte Milieu der Mundhöhle nicht ausreichend simulieren kann (Eliades und Bourauel 2005). Der größte Unterschied zwischen den zur Alterung verwendeten Medien und der Mundhöhle ist die Präsenz der komplexen oralen Flora und ihren Nebenprodukten genauso wie die Akkumulation von Plaque auf dem Material (Eliades et al. 2003). Diese Effekte, gekoppelt 
mit der Varietät und Potenz verschiedener anderer Faktoren, welche die ökologischen Konditionen der Mundhöhle ausmachen, könnten die morphologischen, strukturellen und mechanischen Eigenschaften orthodontischer Materialien beeinflussen. Dies würde bedeuten, dass sich orthodontische Materialien in der Mundhöhle anders verhalten könnten als ihre in vitro gealterten Gegenstücke (Eliades und Bourauel 2005). Auch Einflüsse durch mastikatorische und enzymatische Prozesse, denen die Schiene in vivo unterliegt (Schuster et al. 2004), wurden in dieser Studie nicht berücksichtigt. Somit handelt es sich bei der durchgeführten Wasserlagerung lediglich um eine Annäherung an die Konditionen der Mundhöhle, welche zwar den Effekt des Wassers bei Mundtemperatur auf das Material zeigt, jedoch alle weiteren Einflussfaktoren der Mundflora und die mastikatorischen Effekte außer Betracht lässt.

Während der Trageperiode üben die Tiefziehschienen Kräfte auf die zu bewegenden Zähne aus, was jedoch eine reziproke Wirkung auf die Aligner nicht ausschließt. Um diesen Effekt $\mathrm{zu}$ simulieren, wurden die Aligner während der Wasserlagerung einer mechanischen Belastung ausgesetzt. Diese wurde dadurch erzielt, dass bei der Herstellung der Modelle zur Wasserlagerung der Zahn 11 um $3^{\circ}$ rotiert wurde und somit die Schienen beim Aufsetzen auf das Modell an diesem Zahn eine Vorbelastung erfuhren, welche einer Auslenkungsstrecke von ca. 0,2 mm gleichkam.

Kritisch ist jedoch $\mathrm{zu}$ bewerten, dass die durch das Modell vorgegebene mechanische Belastung im Versuchszeitraum konstant bleibt, wohingegen in vivo von einer Abnahme der reziprok auf die Schiene wirkenden Kräfte durch dentoalveolär-parodontale Adaptationsprozesse an die, durch den Aligner erzwungene neue Ist-Position ausgegangen werden kann. Aus diesem Grund wurde eine geringe Auslenkungsstrecke für die Alterungssimulation gewählt. Diese liegt mit $0,2 \mathrm{~mm}$ im unteren Bereich für die Zahnauslenkung zur Herstellung eines Invisalign ${ }^{\circledR}$-Aligners (Boyd et al. 2000, Faltin et al. 2003, Joffe 2003, Melkos 2005, Vlaskalic et al. 2001) und weit unter derer einer Clear Smile ${ }^{\circledR}$ Therapie mit Auslenkungsstrecken von 0,5 mm (Barbagallo et al. 2008 b).

\subsubsection{Thermische Wechsellast}

Während der 14tägigen Wasserlagerung wurden die Schienen zusätzlich für 70 Zyklen einer thermischen Wechselbelastung in zwei Temperierbädern unterzogen, die Temperaturen von $+5{ }^{\circ} \mathrm{C}$ bzw. $+55^{\circ} \mathrm{C}$ aufwiesen. Dieser Versuchsabschnitt sollte die Temperaturschwankungen simulieren, denen die Aligner während der Trageperiode ausgesetzt sind. Während des 
Versuchablaufes wurden die Schienen nicht von den Modellen entfernt, so dass die oben erwähnte mechanische Vorbelastung bestehen blieb.

Die niedrigste mögliche Temperatur an der Zahnoberfläche ist laut Palmer et al. 1992 wohl $0^{\circ}$ $\mathrm{C}$, da es ungewöhnlich ist, etwas kälteres als schmelzendes Eis zu essen oder zu trinken. Höchsttemperaturen von bis $\mathrm{zu} \quad 67{ }^{\circ} \mathrm{C}$ wurden demgegenüber als Temperaturmaxima festgestellt, was die Autoren zu der Schlussfolgerung brachte, dass ein Temperaturbereich zwischen 0 und $67^{\circ} \mathrm{C}$ adäquat für eine thermische Wechselbelastung dentaler Materialien sei. Auch Plant et al. 1974 stellten bei der Untersuchung von Probanden fest, dass Kaffee bei einer Temperatur zwischen 60 und $68^{\circ} \mathrm{C}$ unter subjektivem Diskomfort gerade so genippt werden konnte. Kaffee im Temperaturbereich zwischen 55 und $60{ }^{\circ} \mathrm{C}$ konnte getrunken werden, auch wenn er als sehr heiß empfunden wurde. 50 bis $55{ }^{\circ} \mathrm{C}$ heißer Kaffee konnte auch in großen Schlücken konsumiert werden.

Im Rahmen der Untersuchungen von dentalen Materialien und Restaurationen werden daher von den meisten Arbeitsgruppen Temperaturen von $+5{ }^{\circ} \mathrm{C}$ und $+55^{\circ} \mathrm{C}$ angewandt (Eakle et al. 1992, Kanca 1989, Kwon et al. 2008, Mixson et al. 1992, O'Brien et al. 1988, Siduh 1992, Swift et al. 1993). Bei der Verweildauer der Proben in den Bädern lassen sich in der Literatur Werte zwischen $4 \mathrm{~s}$ (Crim et al. 1985) und 20 min (Reid et al. 1991) bei einem Medianwert von 30 s (Gale und Darvell 1999) feststellen. Da die meisten Studien auch eine Verweildauer von 30 s angeben (Eakle et al. 1992, Kanca 1989, Mixson et al. 1992, O'Brien et al. 1988, Siduh 1992, Swift et al. 1993), wurde sie auch in dieser Studie angewandt.

Die Anzahl der alltäglich in der Mundhöhle auftretenden Temperaturwechsel war bislang noch nicht Gegenstand eingehender wissenschaftlicher Untersuchungen (Gale und Darvell 1999). Brown et al. postulierten in ihrer 1972 veröffentlichten Arbeit, dass 10 Zyklen pro Tag zur Simulation ausreichen (Brown et al. 1972). Auch Gale und Darvell kommen in ihrem Review-Artikel zu dem Schluss, dass bis dato keine evidenz-basierten Daten über täglich auftretenden Temperaturschwankungen existieren. Jedoch geben sie die Empfehlung, für ein Jahr Alterung ca. 10000 Zyklen thermische Wechsellast anzusetzen (Gale und Darvell 1999). Die Anzahl der in dieser Studie durchgeführten Zyklen richtet sich nicht nach den von Brown et al. 1972 oder Gale und Darvell 1999 angegebenen Empfehlungen, welche sich auf Zähne bzw. dentale Restaurationen beziehen, die täglich 24 Stunden den potentiellen Temperaturschwankungen der Mundhöhle ausgesetzt sind. Im Gegensatz dazu handelt es sich bei den Alignern um eine herausnehmbare orthodontische Apparatur, welche laut Herstellerangaben zur Nahrungsaufnahme und Zahnreinigung entfernt werden soll. Folglich ist eine geringere Exposition der Apparatur gegenüber nahrungsmittelbedingten 
Temperaturschwankungen zu erwarten. Die Wahl der 70 Zyklen zur Simulation der 14tägigen Tragezeit geschah in der Annahme, dass die Schienen bei der Nahrungsaufnahme lediglich beim Trinken eines Kaffees oder kalten Getränkes oder dem Verzehr von Eiscreme im Mund verbleiben und somit eine geringere Anzahl von thermischen Wechselbelastungen zu erwarten ist.

\subsubsection{Diskussion der Ergebnisse}

Es konnte durch die Ergebnisse dieser Studie gezeigt werden, dass eine simulierte Alterung der Tiefziehschienen von 14 Tagen, wie oben beschrieben, zu einer Verringerung des rotativen Drehmoments und der intrusiven Kraft führt (Abb. 22un 23). Lediglich bei einer Auslenkungsstrecke von $-0,17 \mathrm{~mm}$ zeigte sich für das Material Biolon ${ }^{\circledR}$ in der Stärke 1,0 mm, dass die Unterschiede der intrusiven Kraft vor und nach Alterung mit einem $p$ Wert von 0,06 statistisch nicht signifikant waren (Tab. 11).

Diese Ergebnisse stehen im Widerspruch zu den Ergebnissen von Kwon et al. (2008), wonach es bei einer simulierten Alterung durch Thermocycling zwar zu einer Verringerung der Kraftgröße kam, diese jedoch im Bereich von 0,2 bis $0,5 \mathrm{~mm}$ nicht im statistisch signifikanten Bereich lag. Die unterschiedlichen Ergebnisse können durch die verschiedenen Methoden begründet werden. Kwon et al. führten 1000 Zyklen in einem Wechselbad durch. Dabei befanden sich die Proben für jeweils 15 Sekunden in einem $5{ }^{\circ} \mathrm{C}$ kalten und einem $55{ }^{\circ} \mathrm{C}$ warmen Wasserbad. Die Materialproben unterlagen während dieser Zyklenzahl keinerlei mechanischen Belastungseinflüssen, so dass lediglich der Temperaturwechsel als Einflussgröße herangezogen wurde. In vivo kann dieser Einfluss jedoch nicht für sich genommen gesehen werden, da in situ durch die Passungsdifferenz zwischen Zahnstellung und Schienenform es neben einer Kraft auf den Zahn auch zu einer reziproken Kraft auf den Schienenkörper selbst kommt. Gerade weil es sich bei den Tiefziehfolien um thermoplastische Materialien handelt, ist nicht auszuschließen, dass es bei einer Erwärmung des Schienenmaterials auf $55^{\circ} \mathrm{C} \mathrm{zu}$ einer adaptiven plastischen Verformung an die Zahnstellung und somit zu einer Verringerung der auf die Zähne wirkenden Kräfte kommen könnte. Kwon et al. trennten in ihrer Studie die mechanische und thermische Wechsellast methodisch voneinander und konnten somit lediglich für den Bereich der Krafteinwirkung durch wiederholte Belastung eine signifikante Abnahme der gemessenen Kräfte zeigen, aber nicht bei der thermischen Wechsellast.

Da Kwon et al. (2008) einen signifikanten Abfall der generierten Kräfte bei 100 fach wiederholter Belastung ohne Alterungssimulation mit Wasserlagerung und thermischer 
Wechsellast feststellten, bleibt die Frage offen, inwieweit die wiederholte Belastung der Aligner in der vorliegenden Arbeit zu einer Beeinflussung der gemessenen Kräfte und Drehmomente führt. Alle 25 Schienen wurden insgesamt 20mal vor Alterungssimulation und 10mal nach erfolgter Alterung gemessen. Eine Auswirkung auf die gewonnen Messergebnisse kann also nicht ausgeschlossen werden, was bedeuten würde, dass jeder Messdurchgang zu einem sukzessiven Abfall der gemessenen Kräfte und Drehmomente führen könnte.

In der vorliegenden Studie wurde eine Schiene insgesamt 30mal gemessen. Hierbei divergierte die Belastungsrichtung der Aligner abwechselnd, bedingt durch die unterschiedliche Rotationsrichtung. Einer Vorbelastung in die eine Auslenkungsrichtung folgte eine Vorbelastung in die genau entgegengesetzte. Das Schienenmaterial erfuhr also für die entsprechende Auslenkungsrichtung lediglich 15mal eine Belastung, was weit unter der konstanten Vorbelastung von 100 Zyklen der Studie von Kwon et al. 2008 liegt.

Die Materialproben der Studie von Kwon et al. waren bedingt durch die starre Fixierung dem vollen Wirkungsgrad der $1 \mathrm{~mm}$ Auslenkungsstrecke ausgesetzt. In der vorliegenden Arbeit lag zum einen die Auslenkungsstrecke mit maximal 0,68 mm weit unter den $1 \mathrm{~mm}$ von Kwon et al. und zum anderen wurde die Schiene nicht starr auf dem Modell fixiert. Dies ermöglichte ein Abheben der Schiene vom Modell bei hoher Belastung und verringerte somit den Wirkungsgrad der Kraftübertragung.

In Vorversuchen konnte des Weiteren keine statistisch signifikante Beeinträchtigung der Kräfte und Drehmomente bei 5maliger Wiederholungsmessung ermittelt werden. Es bleibt also fraglich, inwieweit die in dieser Studie durchgeführten Wiederholungsmessungen zu einer statistisch relevanten Beeinträchtigung der Messergebnisse geführt haben. Weitere Untersuchungen in diesem Zusammenhang sind von Nöten.

Barbagallo et al. (2008 b) beschreiben in ihrer Studie eine hohe Kraft auf die zu bewegenden Zähne in der Initialphase, gefolgt von einem schnellen Kräfteabfall während der Tragezeit. Da diese Studie am Patienten durchgeführt wurde, bleibt die Frage offen, inwieweit die Ursache für den Kräfteabfall als reine Folge der orthodontischen Zahnbewegung zu verstehen ist, oder auch Materialeigenschaften eine Rolle spielen. Schuster et al. (2004) stellten bei einer invivo-Untersuchung der Alterungsprozesse von Invisalignschienen neben einer Erhöhung der Vickershärte auch Abrasionen und lokalisierte Kalzifikationen des sich während der zweiwöchigen Tragezeit etablierten Biofilms fest. Diese Effekte könnten die Kraftübertragungseigenschaften der Aligner beeinflussen. Eine materialbedingte Komponente in Kombination mit den Bedingungen des jeweiligen oralen Milieus wäre somit als Ursache für den Kräfteabfall auch nicht auszuschließen. 
$\mathrm{Da}$ in der vorliegenden Studie der Messzahn starr fixiert wurde, kann die Ursache für den durch die Alterungssimulation aufgetretenen Kräfteabfall lediglich in der Materialbeschaffenheit der Aligner zu suchen sein. Geht man jedoch davon aus, dass zusätzlich adaptive Zahnbewegungen die orthodontisch wirkenden Kräfte minimieren, so könnte dieser Zusammenhang eine Begründung für den von Barbagallo et al. (2008b) gemessenen starken Kräfteabfall sein. Die zwar initial viel zu hohen Kräfte reduzieren sich während der Tragezeit durch die oben beschriebenen Effekte. 


\section{$5 \quad$ Zusammenfassung}

In der Literatur finden sich zahlreiche Veröffentlichungen, die vornehmlich anhand von Patientenfällen die Einsatzmöglichkeit und Effizienz einer kieferorthopädischen Behandlung mittels Schienentherapie untersuchen. Eine systematische Erforschung der generierten Kräfte und Drehmomente thermoplastischer Materialien wurde bis dato jedoch nicht vorgenommen. Das Ziel dieser Arbeit war deshalb, die Kräfte und Drehmomente, die von Schienen aus verschiedenen Materialien mit unterschiedlichen Materialstärken in Abhängigkeit von der Auslenkungsstrecke abgegeben werden, am Beispiel eines oberen zentralen Schneidezahns in vitro zu erfassen. Als orthodontische Bewegungsform wurde in diesem Fall die reine Rotation des Oberkieferfrontzahnes um seine Längsachse gewählt. Des Weiteren war von Interesse, inwieweit die Materialstärke, das Tiefziehverfahren, die Schluckkraft oder eine künstliche Alterung einen Einfluss auf die generierten Kräfte und Drehmomente haben. Die Messungen erfolgten dabei mithilfe einer neu entwickelten modularen Messapparatur. Für die Simulation der Schluckkraft wurde ein Gewichtsäquivalent verwendet, welches die Schienen zentral in vertikaler Richtung belastete. Die künstliche Alterung, bestand aus einer thermischen Wechsellast und einer Wasserlagerung unter mechanischer Vorbelastung.

Die gemessenen Kräfte und Drehmomente überschritten die in der Literatur als ideal angegebenen Werte zum Teil um ein Mehrfaches. Die diesbezügliche Relevanz für pathologische Nebeneffekte ist Gegenstand weiterer Untersuchungen.

Anhand der vorgenommenen Messungen konnte eine therapeutisch relevante intrusive Kraft für die untersuchte Bewegungsform nachgewiesen werden.

Bei identischer Auslenkungsstrecke erzeugten die dünneren Materialstärken statistisch signifikant niedrigere Kräfte und Drehmomente. Für die klinische Anwendung muss jedoch berücksichtigt werden, dass auch dünnere Schienen, die zwar geringere Kräfte erzeugen, bei größeren Auslenkungsstrecken immer noch Kräfte über den als biologisch ideal postulierten Werten generieren.

Auch die Tiefziehverfahren hatten teilweise einen signifikanten Einfluss auf die Kraftabgabe. Eine eindeutige Hierarchie unter den verschiedenen Tiefziehverfahren in Bezug auf die Krafthöhe ließ sich jedoch nicht feststellen.

Des Weiteren zeigte sich, dass durch einen simulierten Schluckakt die Kräfte und Drehmomente auf den orthodontisch zu bewegenden Zahn signifikant verstärkt werden.

Bei den Ergebnissen bezüglich der auftretenden Kräfte und Drehmomente handelt es sich um eine Momentaufnahme bei initialer Eingliederung der Aligner. Durch die in dieser Studie durchgeführte Alterungssimulation konnte ein statistisch signifikanter Abfall der gemessenen 
Kräfte und Drehmomente gezeigt werden, was dafür spricht, dass auch unter klinischen Bedingungen ein Abfall der Kräfte und Drehmomente zu erwarten ist.

Aus biomechanischer Sicht konnte in der vorliegenden Arbeit gezeigt werden, dass die Mechanismen der Kraftübertragung weitaus komplexer sind, als dies bisher in der Literatur dargestellt wurde. Um diese Komplexität und die tatsächlichen Effekte und verschiedenen Möglichkeiten der orthodontischen Schienentherapie näher zu erfassen, sind sowohl klinische als auch weitere biomechanisch-physikalische Laborstudien notwendig. 


\section{$6 \quad$ Literaturverzeichnis}

Andersen KL, Mortensen HT, Pedersen EH,Melsen B (1991): Determination of stress levels and profiles in the periodontal ligament by means of an improved three-dimensional finite element model for various types of orthodontic and natural force systems. J Biomed Eng $\underline{13}$, 293-303

Baccetti T, Franchi L, Camporesi M (2008): Forces in the presence of ceramic versus stainless steel brackets with unconventional vs conventional ligatures. Angle Orthod $\underline{78}(1)$, $120-124$

Barbagallo LJ, Jones AS, Petocz P, Darendeliler MA (2008 a): Physical properties of root cementum: Part 10. Comparison of the effects of invisible removable thermoplastic appliances with light and heavy orthodontic forces on premolar cementum. A microcomputed-tomography study. Am J Orthod Dentofacial Orthop 133(2), 218-227

Barbagallo LJ, Shen G, Jones AS, Swain MV, Petocz P, Darendeller AM (2008 b): A Novel Pressure Film Approach for Determining the Force Imparted by Clear Removable Thermoplastic Appliances. Ann Biomed Eng 36(2), 335-341

Bartzela TN, Senn C, Wichelhaus A (2007): Load-deflection characteristics of superelastic nickel-titanium wires. Angle Orthod 77(6), 991-998

Baumrind S, Korn EL, Boyd RL (1996): Apical root resorption in orthodontically treated adults. Am J Orthod Dentofac Orthop 110(3), 311-320

Bollen AM, Huang G, King G, Hujoel P, Ma T (2003): Activation time and material stiffness of sequential removable orthodontic appliances. Part 1: Ability to complete treatment. Am J Orthod Dentofacial Orthop 124(5), 496-501

Boyd RL (2008): Esthetic Orthodontic Treatment Using the Invisalign Appliance for Moderate to Complex Malocclusions. J Dent Educ 72(8), 948-967 
Boyd RL, Vlaskalic V (2001): Three-Dimensional Diagnosis and Orthodontic Treatment of Complex Malocclusions with the Invisalign Appliance. Sem Orthodont $\underline{7}(4), 274-293$

Boyd RL, Miller RJ, Vlaskalic V (2000): The Invisalign system in adult orthodontics: mild crowding and space closure case. J Clin Orthod 34(4), 203-212

Brezniak N (2008): The clear plastic appliance: a biomechanical point of view. Angle Orthod $\underline{78}(2), 381-382$

Brezniak N, Wasserstein A (2008): Root Resorption Following Treatment with Aligners. Case Report. Angle Orthod 78(6), 1119-1122

Brown WS, Jacobs HR, Thompson RE (1972): Thermal fatigue in teeth. J Dent Res. 51(2), $461-467$

Brudvik P, Rygh P (1993): Non-clast cells start orthodontic root resorption in the periphery of hyalinized zones. Eur J Orthod 15(6), 467-480

Brudvik P, Rygh P (1994 a): The initial phase of orthodontic root resorption incident to local compression of the periodontal ligament. Eur J Orthod 15(4), 249-263

Brudvik P, Rygh P (1994 b): Root resorption beneath the main hyalinized zone. Eur J Orthod 16(4), 249-263

Brudvik P, Rygh P (1994 c): Multi-nucleated cells remove the main hyalinized tissue and start resorption of adjacent root surfaces. Eur J Orthod 16(4), 265-273

Brudvik P, Rygh P (1995 a): Transition and determinants of orthodontic root resorption-repair sequence. Eur J Orthod 17(3), 177-88

Brudvik P, Rygh P (1995 b): The repair of orthodontic root resorption: an ultrastructural study. Eur J Orthod 17(3), 189-98 
Brückl H, Träger E (1962): Untersuchungen über Art und Häufigkeit anomaler Schluckgewohnheiten. J Orofac Orthop 23(1-2), 197-202

Burstone CJ: The biophysis of bone remodelling during orthodontics - optimal force considerations; in: The biology of Tooth Movement; hrsg. v. Norton LA, Burstone CJ Boca Raton; CRC Press, Boca Raton 1989, 321-334

Chenin DA, Trosien AH, Fong PF, Miller RA, Lee RS (2003): Orthodontic treatment with a series of removable appliances. J Am Dent Assoc 134(9), 1232-1239

Christensen GJ (2002): Orthodontics and the general practitioner. J Am Dent Assoc 133(3), $369-3671$

Cleall JF (1965): Deglutition: A Study of Form and Function. Am J Orthod 51, 566-594

Crim GA, Swartz ML, Phillips RW (1985): Comparison of four thermocycling techniques. J Prosthet Dent $\underline{53}(1), 50-53$

Diedrich P (1990): Biomechanische Prinzipien für orthodontische Bewegungen bei reduziertem Attachment. Dtsch Zahnärztl Z $\underline{45}, 78-81$

Djeu G, Shelton C, Maganzini A (2005): Outcome assessment of Invisalign and traditional orthodontic treatment compared with the American Board of Orthodontics objective grading system. Am J Orthod Dentofacial Orthop 128(3):292-298

Dorow C, Krstin N, Sander FG (2002): Experiments to determine the material properties of the periodontal ligament. J Orofac Orthop 63(2), 94-104

Dorow C, Krstin N, Sander FG (2003): Determination of the mechanical properties of the periodontal ligament in a uniaxial tensional experiment. J Orofac Orthop 64(2), 100-107

Dos Santos Junior J, de Rijk WG (1993): Occlusal contacts: vectorial analysis of forces transmitted to temporomandibular joint and teeth. Cranio $\underline{11}(2), 118-125$ 
Drummond JL (1989): In vitro aging of yttria stabilized zirconia. J Am Ceram Soc 72, 675676

Drummond JL, Savers EE (1993): In vitro aging of a heat/pressure-cured composite. Dent Mater $\underline{9}(3), 214-216$

Eakle WS, Staninec M, Lacy AM (1992): Effect of bonded amalgam on the fracture resistance of teeth. J Prosthet Dent $\underline{68}(2), 257-260$

Eichner K (1963): Messung der Kräfte bei Kauvorgängen. Dtsch Zahnärztl Z. 18 (17), 915-24

Eliades T, Bourauel C (2005): Intraoral aging of orthodontic materials: the picture we miss and its clinical relevance. Am J Orthod Dentofacial Orthop 127(4), 403-412

Eliades G, Eliades T, Vavuranakis M: General aspects of biomaterials' surface alterations following exposure to biological fluids; in: Dental materials in vivo: aging and related phenomena; hrsg. v. Eliades G, Eliades T, Brantley WA, Watts DC; Quintessence, Chicago 2003, 3-23.

Faltin RM, Arana-Chavez VE, Faltin K, Sander FG, Wichelhaus A (1998): Root resorptions in upper first premolars after application of continuous intrusive forces. Intra-individual study. J Orofac Orthop 599(4), 208-219

Faltin RM, de Almeida MAA, Kessner CA, Faltin K (2003): Efficiency, three-dimensional planning and prediction of the orthodontic treatment with the Invisalign System: case report. R Clin Ortodon Dental Press 2, 61-71

Fuck LM, Drescher D (2006): Force systems in the initial phase of orthodontic treatment -- a comparison of different leveling arch wires. J Orofac Orthop 67(1), 6-18

Gale MS, Darvell BW (1999): Thermal cycling procedures for laboratory testing of dental restorations. J Dent 27(2), 89-99 
Göz G: Kraft und Kraftdauer; in: Kieferorthopädie Band 2, 4. Auflage; hrsg. V. Diedrich P; Urban \& Fischer, München/Jena 2000, 36-38

Göz G, Rakosi T (1989): Die apikale Wurzelresorption unter kieferorthopädischer Behandlung. J Orofac Orthop $\underline{50}(3), 196-206$

Harry MR, Sims MR (1982): Root resorption in bicuspid intrusion. A scanning electron microscope study. Angle Orthod 52(3), 235-258

Hinz R (1991): Das Elasto-KFO-System - eine Weiterentwicklung des Positioners. Prakt Kieferorthop $\underline{5}, 179-188$

Joffe L (2003): Invisalign: early experiences. J Orthod $\underline{30(4), ~ 348-352 ~}$

Kanca J $3^{\text {rd }}$ (1989): Microleakage of five dentin bonding systems. Dent Mater $\underline{5}(6), 415-416$

Kesling HD (1945): The philosophy of the tooth positioning appliance, Am J Orthod $\underline{31}$, 297304

Kincaid RM (1951): The frequency of deglutition in man: its relationship to overbite. Angle Orthod 21(1):34-43.

Kohorst P: Experimentelle In-vitro-Untersuchung zur Belastbarkeit viergliedriger Seitenzahnbrücken aus Zirkoniumdioxid. Med. Diss. Hannover 2007

Kravitz ND, Kusnoto B, Agran B, Viana G (2008): Influence of attachments and interproximal reduction on the accuracy of canine rotation with invisalign. Angle Orthod $\underline{78(4), 682-687}$

Krishnan V, Davidovitch Z (2006): Cellular, molecular, and tissue-level reactions to orthodontic force. Am J Orthod Dentofacial Orthop 129(4), 469.e1-32

Kwon JS, Lee JK, Lim BS, Lim YK (2008): Force delivery properties of thermoplastic orthodontic materials. Am J Orthod Dentofacial Orthop 133(2), 228-234 
Lagravère MO, Flores-Mir C (2005): The treatment effects of Invisalign orthodontic aligners: a systematic review. J Am Dent Assoc 136(12), 1724-1729

Lear CS, Flanagan JB Jr, Moorrees CF (1965): The Frequency of Deglutition in man. Arch Oral Biol $\underline{10}, 83-100$

Lehmann KM, Hellwig E: Einführung in die restaurative Zahnheilkunde, 8. Auflage; Urban\&Schwarzenberg, München 1998

Lim Y, Quick A, Swain M, Herbison P (2008): Temperature Effects on the Forces, Moments and Moment to Force Ratio of Nickel-Titanium and TMA Symmetrical T-loops Angle Orthod $\underline{78}(6), 1035-1042$

Linge BO, Linge L (1983): Apical root resorption in upper anterior teeth. Eur J Orthod $\underline{5}(3)$, $173-183$

Linge L, Linge BO (1991): Patient characteristics and treatment variables associated with apical root resorption during orthodontic treatment. Am J Orthod Dentofacial Orthop $\underline{99}(1)$, $35-43$

Masella RS, Meister M (2006): Current concepts in the biology of orthodontic tooth movement. Am J Orthod Dentofacial Orthop 129(4), 458-468

McNamara JA, Kramer KL, Juenker JP (1985): Invisible retainers. J Clin Orthod 19(8), 570578

Meier B, Wiemer KB, Miethke RR (2003): Invisalign--patient profiling. Analysis of a prospective survey. J Orofac Orthop $\underline{64(5), 352-358}$

Melkos AB (2005): Advances in digital technology and orthodontics: a reference to the Invisalign method. Med Sci Monit 11(5), 39-42 
Melsen B, Burstone CJ: The transpalatal arch and the lower lingual arch. Their use as active and passive appliance; in: Melsen B, Burstone Ch, Introduction to biomechanics, Syllabus University of Aarhus 1990

Mirabella AD, Artun J (1995): Risk factors for apical root resorption of maxillary anterior teeth in adult orthodontic patients. Am J Orthod Dentofac Orthop 108(1), 48-55

Mixson JM, Eick JD, Moore DL, Tira DE (1992): Effect of two dentin bonding agents on microleakage in two different cavity designs. J Prosthet Dent 67(4), 441-445

Murell EF, Yen EH, Johnson RB (1996): Vascular changes in the periodontal ligament after removal of orthodontic forces. Am J Orthod Dentofacial Orthop 110(3), 280-286

Nakamura Y, Noda K, Shimoda S, Oikawa T, Arai C, Nomura Y, Kawasaki K (2008): Timelapse observation of rat periodontal ligament during function and tooth movement, using microcomputed tomography. Eur J Orthod 30(3), 320-326

Nedwed V, Miethke RR (2005): Motivation, acceptance and problems of Invisalign ${ }^{\circledR}$ patients. J Orofac Orthop $\underline{66}(2), 162-173$

Nishigawa K, Bando E, Nakano M (2001): Quantitative study of bite force during sleep associated bruxism. J Oral Rehabil 28 (5), 485-491

O'Brien JA 3rd, Retief DH, Bradley EL, Denys FR (1988): Shear bond strength of a new dentin bonding restorative system. Dent Mater $\underline{4}(4), 179-183$

Owen AH (2001): Accelerated Invisalign treatment. J Clin Orthod. 35(6), 381-385

Palmer DS, Barco MT, Billy EJ (1992): Temperature extremes produced orally by hot and cold liquids. J Prosthet Dent $\underline{67}(3), 325-327$

Pandis N, Eliades T, Partowi S, Bourauel C (2008 a):Forces exerted by conventional and selfligating brackets during simulated first- and second-order corrections. Am J Orthod Dentofacial Orthop 133(5), 738-742 
Pandis N, Eliades T, Partowi S, Bourauel C (2008 b): Moments Generated during Simulated Rotational Correction with Self-Ligating and Conventional Brackets. Angle Orthod $\underline{78(6)}$, $1030-1034$

Peutzfeldt A, Asmussen E (1989): Accuracy of alginate and elastomeric impression materials. Scand J Dent Res 97(4), 375-379

Plant CG, Jones DW, Darvell BW (1974): The heat evolved and temperatures attained during setting of restorative materials. Br Dent J $\underline{137}(6), 233-238$

Ponitz RJ (1971): Invisible retainers. Am J Orthod 59(3), 266-271

Proffit WR: The biological basis of orthodontic therapy; in: Contemporary Orthodontics. 3. Auflage; hrsg. v. Proffit WR, Fields HW; Mosby Year Book Inc, St Louis 1999, 296-325

Proffit WR, Fields HW: The first stage of comprehensive treatment: alignment and levelling; in: Contemporary Orthodontics, 3. Auflage; hrsg. v. Proffit WR, Fields HW; Mosby Year Book Inc, St Louis 1999, 527-529

Proffit WR Fields HW Nixon WL (1983): Occlusal Forces in Normal- and Long-face Adults. J Dent Res $\underline{62}(5), 566-571$

Reid JS, Saunders WP, Chen YY (1991): The effect of bonding agent and fissure sealant on microleakage of composite resin restorations. Quintessence Int. 1991 22(4), 295-298

Ren Y, Maltha JC, Kuijpers-Jagtman AM (2003): Optimum force magnitude for orthodontic tooth movement: a systematic literature review.Angle Orthod $\underline{73}(1), 86-92$

Rinchuse DJ, Rinchuse DJ (1997): Active tooth movement with Essix based appliances. J Clin Orthod 31(2), 109-112

Roberts WE, Goodwin WC Jr, Heiner SR (1981): Cellular response to orthodontic force. Dent Clin North Am $\underline{25}, 3-17$ 
Rost D, Schwarze CW, Hilgers RD (1995): Die Kraftabgabe von Positionern bei unterschiedlicher Schneidezahnprotrusion. Eine In-vitro-Untersuchung. Fortschr Kieferorthop $\underline{56}(2), 104-109$

Sander C, Sander FM, Sander Fg (2006): The Derotation of Premolars and Canines with NiTi Elements. J Orofac Orthop $\underline{67}(2), 117-126$

Sawyer HF, Sandrik JL, Neiman R (1976): Accuracy of casts produced from alginate and hydrocolloid impression materials. J Am Dent Assoc 93(4), 806-808

Schopf P: Curriculum Kieferorthopädie Band 2, 3. Auflage; Quintessenz Verlags-GmbH, Berlin 2000

Schroeder HE: Entwicklung und Struktur des Zahnhalteapparats; in: Orale Strukturbiologie, 5. Auflage. Georg Thieme Verlag; Stuttgart 2000, 187-292

Schuster S, Eliades G, Zinelis S, Eliades T, Bradley TG (2004): Structural conformation and leaching from in vitro aged and retrieved Invisalign appliances. Am J Orthod Dentofacial Orthop $\underline{126}(6), 725-728$

Sheridan JJ, Ledoux W, McMinn R (1993): Essix Retainers: fabrication and supervision for permanent retention. J Clin Orthod 27 (1), 37-45

Sheridan JJ, LeDoux W, McMinn R (1994): Essix appliance: minor tooth movement with divots and windows. J Clin Orthod 28, 659-663

Sheridan JJ, Hillard K, Armbruster P. Essix Appliance Technology: Applications, Fabrication and Rationale. GAC International, Bohemia NY 2003

Smith RJ, Burstone CJ (1984): Mechanics of tooth movement. Am J Orthod 85(4), 294-307

Straub WJ (1961): Malfunction of the tongue: Part II. The abnormal swallowing habit: Its causes, effects, and results in relation to orthodontic treatment and speech therapy. Am J Orthod $\underline{47}(8), 596-617$ 
Swift EJ Jr, Denehy GE, Beck MD (1993): Use of phosphoric acid etchants with Scotchbond Multi-Purpose. Am J Dent $\underline{6}(2), 88-90$

Synge JL (1933): The theory of an incompressible periodontal membrane. The international Journal of Orthodontia and Dentistry for Children 19(6), 567-573

Turpin DL (2005): Clinical trials needed to answer questions about Invisalign. Am J Orthod Dentofacial Orthop $\underline{127}(2), 157-158$

Vlaskalic V, Boyd RL (2002): Clinical evolution of the Invisalign appliance. J Calif Dent Assoc $\underline{30}(10), 769-776$

Vlaskalic V, Boyd R, Hordt C, Miethke RR (2001): Die kieferorthopädische Behandlung mit dem Invisalign-System. Kieferorthopädie Sonderheft Invisalign, 17-24

von Böhl M, Kuijpers-Jagtman AM (2009): Hyalinization during orthodontic tooth movement: a systematic review on tissue reactions. Eur J Orthod $\underline{31}$, 30-36

Walker MP, Ries D, Kula K, Ellis M, Fricke B (2007): Mechanical properties and surface characterization of beta titanium and stainless steel orthodontic wire following topical fluoride treatment. Angle Orthod 77(2), 342-348

Wang T, Zhou G, Tan X, Dong Y (2007): Evaluation of force degradation characteristics of orthodontic latex elastics in vitro and in vivo. Angle Orthod. $77(4), 688-693$

Warunek SP, Sorensen SE, Cunat JJ, Green LJ (1989): Physical and mechanical properties of elastomers in orthodontic positioners. Am J Orthod Dentofacial Orthop 95(5), 388-400

Weiland F (2003): Apikale Wurzelresorption als Folge unterschiedlicher kieferorthopädischer Krafteinwirkung. Inf Orthod Kieferorthop 35, 199-203

Wichelhaus A, Sander C, Sander FG (2004): Development and biomechanical investigation of a new compound palatal arch. J Orofac Orthop $\underline{65}(2), 104-122$ 
Witt E, Timper E (1974):Experimentelle Untersuchungen über Schluckdauer und Schluckhäufigkeit bei Kindern und Erwachsenen mit verschiedenen Anomalien. J Orofac Orthop $\underline{35}(4), 306-322$

Wong BH (2002): Invisalign A to Z. Am J Orthod Dentofacial Orthop 121(5), 540-541

Yokoya K, Sasaki T, Shibasaki Y (1997): Distributional changes of osteoclasts and preosteoclastic cells in periodontal tissues during experimental tooth movement as revealed by quantitative immunhistochemistry of $\mathrm{H}(+)$-ATPase. J Dent Res $\underline{76}, 580-587$ 


\section{Danksagung}

Mein ganz besonderer Dank gilt Herrn PD Dr. med. dent. Wolfram Hahn, Oberarzt der Abteilung Kieferorthopädie der Universitätsmedizin Göttingen, für die stetige Motivation und die hilfreichen Anregungen bei der Planung, Gestaltung und Durchführung dieser Arbeit.

Mein herzlicher Dank gilt Herrn Professor Dr. Dietmar Kubein-Meesenburg, Direktor der Abteilung Kieferorthopädie, der durch seine uneingeschränkte Unterstützung und Förderung diese Arbeit erst ermöglicht hat.

Außerdem möchte ich allen Mitarbeitern der Abteilung Kieferorthopädie sowie den Mitgliedern der Biomechanischen Arbeitsgruppe für ihre Unterstützung und die zahlreichen Anregungen und fachlichen Ratschläge danken. Besonderer Dank gilt dabei Prof. Dr. Hans Nägerl und Frau Dr. Julia Fialka-Fricke.

Weiterhin bedanke ich mich bei Dr. Klaus Jung für seine Unterstützung bei der statistischen Auswertung der vorliegenden Ergebnisse.

Großer Dank gilt ferner Herrn Sven Köhler, Herrn Jens Köhler und Herrn Reinhold Wegener für ihren unermüdlichen Einsatz und die große Hilfe bei den zahn- und labortechnischen Arbeitsschritten.

Auch möchte ich mich bei Herrn Dr. rer. Nat. Henning Dathe für die hervorragende Hilfe bei der Erarbeitung der in dieser Studie angewandten Methodik bedanken.

Nicht zuletzt möchte ich meinen Eltern, meiner Lebensgefährtin Ina Schmonsees und Benjamin Klein für die Hilfe und Unterstützung bei der Korrektur dieser Arbeit danken. 


\section{Lebenslauf}

Am 15. September 1980 wurde ich als erstes Kind von Johannes Josef Engelke und seiner Ehefrau Judith Engelke, geb. Engelhardt, in Göttingen geboren. Ich bin deutscher Staatsangehöriger, ledig und gehöre der katholischen Konfession an.

1987 erfolgte meine Einschulung in die Grundschule Zellerfeld. Im Anschluss besuchte ich von 1991 bis 1993 die Orientierungsstufe Clausthal-Zellerfeld. 1993 wechselte ich dann auf das Gymnasium Robert-Koch-Schule in Clausthal-Zellerfeld. Die Allgemeine Hochschulreife erlangte ich 2000 .

Von 2000 bis 2001 war ich als Auszubildender im Zahntechnischen Labor Dentalteam Wermke in Osterode beschäftigt.

Zum Sommersemester 2001 nahm ich das Studium der Zahnheilkunde an der Georg-AugustUniversität Göttingen auf. Im Februar 2002 legte ich die Naturwissenschaftliche Vorprüfung ab. Die Zahnärztliche Vorprüfung absolvierte ich im September 2003 und die Zahnärztliche Prüfung in Juni 2006. Die Approbation wurde mir im Juni 2006 erteilt.

Von Juli 2006 bis September 2007 war ich als Assistenzzahnarzt in der Gemeinschaftspraxis Dr. J.J. Engelke und M. Abel in Clausthal-Zellerfeld angestellt. Von Oktober 2007 bis Dezember 2008 war ich als Assistenzzahnarzt und im Verlauf als angestellter Zahnarzt in der Gemeinschaftspraxis H. J. Kurth und C. Jähn beschäftigt. Seit Februar 2009 arbeite ich als Weiterbildungsassistent für Oralchirurgie in der Praxis Dr. Dr. Weisser in Ingolstadt.

Im Mai 2007 begann ich in der kieferorthopädischen Abteilung der Universitätsmedizin Göttingen mit den Versuchen zur vorliegenden Dissertation. Die Ergebnisse der Dissertation wurden zum Teil bereits international publiziert: Hahn W, Engelke B, Jung K, Dathe H, Fialka-Fricke J, Kubein-Meesenburg D, Sadat-Khonsari R (2010): Initial Forces and Moments Delivered by Removable Thermoplastic Appliances during Rotation of an Upper Central Incisor. Angle Orthod 80(2), 239-246. 